\title{
Sister Rod Destructive Examinations (FY20)
}

Spent Fuel and Waste Disposition

\author{
Prepared for \\ US Department of Energy \\ Spent Fuel and Waste Science \\ and Technology \\ Oak Ridge National Laboratory \\ Rose Montgomery \\ and \\ Bruce Bevard
}

November 30, 2020

M2SF-21OR010201032

ORNL/SPR-2020/1798

Approved for public release

Distribution is unlimited 
This report was prepared as an account of work sponsored by an agency of the United States Government. Neither the United States Government nor any agency thereof, nor any of their employees, makes any warranty, express or implied, or assumes any legal liability or responsibility for the accuracy, completeness, or usefulness of any information, apparatus, product, or process disclosed, or represents that its use would not infringe privately owned rights. Reference herein to any specific commercial product, process, or service by trade name, trademark, manufacturer, or otherwise, does not necessarily constitute or imply its endorsement, recommendation, or favoring by the United States Government or any agency thereof. The views and opinions of authors expressed herein do not necessarily state or reflect those of the United States Government or any agency thereof. 


\section{SUMMARY}

This report documents work performed under the Spent Fuel and Waste Disposition's Spent Fuel and Waste Science and Technology program for the US Department of Energy (DOE) Office of Nuclear Energy (NE). This work was performed to fulfill Level 2 Milestone M2SF-21OR010201032, "ORNL High Burnup Confirmatory Demo Sibling Rod Testing Results," within work package SF-21OR01020103 and is an update to the work reported in M2SF-19ORO010201026 and M2SF-19OR010201028.

As a part of DOE NE High Burnup Spent Fuel Data Project, Oak Ridge National Laboratory (ORNL) is performing destructive examinations (DEs) of high burnup (HBU) ( $>45 \mathrm{GWd} / \mathrm{MTU}$ ) spent nuclear fuel (SNF) rods from the North Anna Nuclear Power Station operated by Dominion Energy. The SNF rods, called sister rods or sibling rods, are all HBU and include four different kinds of fuel rod cladding: standard Zircaloy-4 (Zirc-4), low-tin (LT) Zirc-4, ZIRLO, and M5. The DEs are being conducted to obtain a baseline of the HBU rod's condition before dry storage and are focused on understanding overall SNF rod strength and durability. Composite fuel and defueled cladding will be tested to derive material properties. Although the data generated can be used for multiple purposes, one primary goal for obtaining the post-irradiation examination data and the associated measured mechanical properties is to support SNF dry storage licensing and relicensing activities by (1) addressing identified knowledge gaps and (2) enhancing the technical basis for post-storage transportation, handling, and subsequent disposition.

This report documents the status of the ORNL Phase 1 DEs of eight sister rods and outlines the DE tasks performed and the data collected to date, as guided by the sister rod test plans. The DEs are performed using a phased approach, and the Phase 1 DEs being performed at ORNL include:

- full-length rod heat treatments (FHT) of three selected sister rods to examine the effects of temperatures reached during dry storage preparation;

- rod internal pressure and void volume measurements of the three FHT rods and three corresponding baseline rods, as well as two additional rods selected for depressurization/gas transmission tests and fatigue lifetime tests;

- fission gas sampling and analysis;

- depressurization and gas transmission tests;

- rough segmentation of the selected rods for mechanical tests and rod characterization;

- fuel sampling and burnup analysis;

- metallography (MET);

- cladding total hydrogen measurements; and

- mechanical testing, including fatigue lifetime (e.g., Cyclic Integrated Reversible-Bending Fatigue Tester [CIRFT]), four-point bend (4PB), axial tension, microhardness, ring compression, and burst tests.

Table S-1 summarizes the DE status. The mechanical testing will be performed using fueled segments and is expected to complement previous and current mechanical test results using defueled cladding segments. 
Table S-1. DE status.

\begin{tabular}{|c|c|c|c|}
\hline \multicolumn{2}{|c|}{ Planned DE } & \multirow{2}{*}{$\begin{array}{l}\text { Status } \\
\text { Complete }\end{array}$} & \multirow[b]{2}{*}{$\begin{array}{l}\text { Comments } \\
\text { Three fuel rods were heat treated: one Zirc-4-clad (F35P17), one } \\
\text { ZIRLO-clad (3F9N05), and one M5-clad (30AE14) rod. The target heat- } \\
\text { up rates, soak temperatures and times, and cooldown rates were } \\
\text { successfully achieved, except for the spent fuel rod heat treatment oven } \\
\text { Zone } 1 \text { for rod 30AE14 (the upper } \sim 550 \mathrm{~mm} \text { ), which reached } \\
\text { temperatures as high as } 485^{\circ} \mathrm{C} \text { for approximately } 1.75 \mathrm{~h} \text { during the } \\
\text { thermal soak. 30AE14's Zone } 1 \text { average temperature during the soak } \\
\text { period was } 452^{\circ} \mathrm{C} \text {. At the higher average temperature imposed, the } \\
\text { pressure was } \sim 7.6 \mathrm{MPa} \text {, about } 8 \% \text { higher than planned. The maximum } \\
\text { pressure during the soak was estimated as } 8.0 \mathrm{MPa} \text { at the } 485^{\circ} \mathrm{C} \text { peak } \\
\text { temperature for } \sim 1.75 \mathrm{~h} \text {. The rod's temperature was corrected before } \\
\text { cooldown, and cooldown was as expected. }\end{array}$} \\
\hline FHT & $\begin{array}{l}\text { Heat treat whole } \\
\text { rods to } 400^{\circ} \mathrm{C}, \\
\text { cool at } \leq 5^{\circ} \mathrm{C} / \mathrm{hr} \\
\text { one ZIRLO, one } \\
\text { M5, and one } \\
\text { Zirc-4 rod }\end{array}$ & & \\
\hline RS & $\begin{array}{l}\text { Segment seven } \\
\text { rods }\end{array}$ & Complete & $\begin{array}{l}\text { Initial test segments were rough cut from seven Phase } 1 \text { sister rods and } \\
\text { placed into individual storage capsules. They are not stored in an inert } \\
\text { gas atmosphere. The segments are further sectioned in preparation for } \\
\text { testing, as needed. }\end{array}$ \\
\hline $\mathrm{DEF}$ & $\begin{array}{l}\text { Defuel segments } \\
\text { for Argonne } \\
\text { National } \\
\text { Laboratory } \\
\text { (ANL) }\end{array}$ & Complete & Twelve segments slated for testing at ANL were defueled and shipped. \\
\hline AERO & $\begin{array}{l}\text { Collect aerosol } \\
\text { particles released } \\
\text { during selected } \\
\text { tests }\end{array}$ & In progress & $\begin{array}{l}\text { An aerosol collection system with fixturing and sampling devices was } \\
\text { designed to characterize and quantify the respirable fraction of } \mathrm{UO}_{2} \\
\text { particles released during rod fracture. The fixture is used in conjunction } \\
\text { with } 4 \mathrm{~PB} \text { tests. The aerosol collection system is currently being tested } \\
\text { and verified out-of-cell. }\end{array}$ \\
\hline \multirow[t]{2}{*}{ DE.01 } & $\begin{array}{l}\text { Measure internal } \\
\text { pressure of five } \\
\text { baseline and three } \\
\text { heat-treated rods }\end{array}$ & Complete & $\begin{array}{l}\text { The rod internal pressure and the void volume available inside the rod } \\
\text { were measured for eight sister rods at room temperature, and all } \\
\text { pressures are within the publicly available database envelope. There is a } \\
\text { clear correlation between the post-irradiated rod internal pressure and } \\
\text { the as-designed fill pressure. The fission gas partial pressure trends well } \\
\text { with the rod average burnup. The pressure and void volumes measured } \\
\text { are consistent for rods from the same fuel vendor. The product of the } \\
\text { partial pressure of the fission gas and the void volume, } P_{f} V \text {, is consistent } \\
\text { from lab to lab for sister rods from the same assembly, except for the } \\
\text { two rods from assembly F35. A comparison of } P_{f} V \text { indicates that the } \\
\text { ZIRLO-clad rods might have experienced some change in pressure, void } \\
\text { volume, or both due to the heat treatment applied, but the M5-clad rods } \\
\text { do not exhibit the same effects. Comparisons with predictions from fuel } \\
\text { rod performance codes FAST and BISON indicate a tendency for FAST } \\
\text { to underpredict pressure and BISON to overpredict pressure. }\end{array}$ \\
\hline & $\begin{array}{l}\text { Measure rod void } \\
\text { volume of five } \\
\text { baseline and three } \\
\text { heat-treated rods }\end{array}$ & Complete & $\begin{array}{l}\text { Eight rods were measured. All measured volumes are on the lower side } \\
\text { of the publicly available database envelope but are consistent with other } \\
\text { rods of their design type. By comparing the measured volumes of the } \\
\text { baseline and heat-treated ZIRLO-clad rods, as well as the } P_{f} V \text { for all } \\
\text { ZIRLO-clad sister rods, it appears that the heat treatment resulted in an } \\
\text { increase in void volume. The heat-treated M5-clad rod is within }\end{array}$ \\
\hline
\end{tabular}




\begin{tabular}{|c|c|c|c|}
\hline \multicolumn{2}{|c|}{ Planned DE } & \multirow[t]{2}{*}{ Status } & \multirow[b]{2}{*}{$\begin{array}{l}\text { Comments } \\
\text { measurement uncertainty of the baseline rod, and the heat-treatment did } \\
\text { not appear to affect the void volume. No conclusions could be made } \\
\text { about the effects of the heat-treatment on the Zirc-4-clad rod based on a } \\
\text { comparison with the LT Zirc-4 baseline rod or the Pacific Northwest } \\
\text { National Laboratory Zirc-4-clad rod. Comparisons with predictions from } \\
\text { fuel rod performance codes FAST and BISON indicate a tendency for } \\
\text { FAST to overpredict void volume and BISON to underpredict void } \\
\text { volume. }\end{array}$} \\
\hline & & & \\
\hline & $\begin{array}{l}\text { Measure the } \\
\text { transmissibility } \\
\text { of gas along the } \\
\text { pellet stack }\end{array}$ & Complete & $\begin{array}{l}\text { Pellet stack gas transmissibility at room temperature was measured by } \\
\text { using depressurization tests on eight rods and transmission tests on three } \\
\text { rods. In all cases, gas was transmissible through the pellet stack at room } \\
\text { temperature, requiring between } 30 \text { min and } 24 \mathrm{~h} \text { to reach equilibrium } \\
\text { conditions, depending upon the pressure differential applied. The data } \\
\text { correlates well using the Muskat-Poiseuille porous media method. }\end{array}$ \\
\hline & & & $\begin{array}{l}\text { The permeability of the pellet stack varied over less than one order of } \\
\text { magnitude for this set of rods and could indicate some common feature } \\
\text { about HBU fuel. Graphs of the data with burnup, lifetime maximum } \\
\text { HDCI, and operating lifetime average assembly middle-of-cycle } \\
\text { predicted fuel temperature indicate that the derived permeability is } \\
\text { correlated to fuel operating temperature and maximum HDCI but is not } \\
\text { correlated to the rod average burnup. The permeability does appear to be } \\
\text { closely related to the rod's manufacturer, and the pellet manufacturing } \\
\text { process might be important in determining the permeability of the pellet } \\
\text { stack. }\end{array}$ \\
\hline & & & $\begin{array}{l}\text { Although the flow regimes associated with the pellet stack transmissibility } \\
\text { did not change significantly for the heat-treated fuel rods, it appears that } \\
\text { the heat treatments might have induced a shift to higher evaluated } \\
\text { permeability. The role of the cladding in the resulting permeability shift } \\
\text { is unclear. }\end{array}$ \\
\hline & $\begin{array}{l}\text { Collect fission } \\
\text { gas samples and } \\
\text { analyze }\end{array}$ & Complete & $\begin{array}{l}\text { Fission gas samples were collected and analyzed. Results are consistent } \\
\text { with publicly available database. Code-predicted fission gas production } \\
\text { is not available; therefore, the fission gas release ratio is not available. } \\
\text { ORNL and Pacific Northwest National Laboratory (PNNL) fission gas } \\
\text { analyses are consistent with one another, and the data are as expected } \\
\text { when differences in fission gas partial pressure are considered. }\end{array}$ \\
\hline & & & $\begin{array}{l}\text { Fueled and defueled specimens are being prepared for MET views. The } \\
\text { Phase } 1 \text { priority } 1 \text { specimens were cut and specimen } \\
\text { preparation/polishing is in progress. }\end{array}$ \\
\hline DE.02 & $\begin{array}{l}\text { Perform optical } \\
\text { microscopy } \\
(\mathrm{MET})\end{array}$ & In progress & $\begin{array}{l}\text { Cladding/pellet views and measurements are available for all Phase } 1 \\
\text { rods. Specific features including waterside oxide thickness, remaining } \\
\text { cladding wall thickness, pelletside oxide thickness, HBU rim, and } \\
\text { cladding inner and outer diameter were measured. Where applicable, } \\
\text { comparisons with nondestructive examinations were provided. Section } \\
\text { views were inspected for hydride orientation and radial hydrides are } \\
\text { visible in the heat-treated M5-clad specimen and the ZIRLO-clad heat- } \\
\text { treated specimen. There is a high hydride density in the heat-treated } \\
\text { Zirc-4 specimen. The few radial hydrides are short. The baseline } \\
\text { ZIRLO-clad specimen includes short radial hydrides. The other baseline }\end{array}$ \\
\hline
\end{tabular}




\begin{tabular}{|c|c|c|c|}
\hline \multicolumn{2}{|c|}{ Planned DE } & \multirow[t]{2}{*}{ Status } & \multirow[b]{2}{*}{$\begin{array}{l}\text { Comments } \\
\text { specimens did not have radial hydrides. An axial MET was created at a } \\
\text { pellet-pellet gap. Axial and radial METs do not show a change in the } \\
\text { hydride precipitation density through the gap. A section of the cladding } \\
\text { will be analyzed for total hydrogen content to determine whether the } \\
\text { total cladding hydrogen content varies between the pelleted region and } \\
\text { the pellet-pellet gap. } \\
\text { Other rod elevations are slated for MET views and the work will } \\
\text { continue. }\end{array}$} \\
\hline & & & \\
\hline \multirow{2}{*}{ DE.03 } & $\begin{array}{l}\text { Perform cladding } \\
\text { total hydrogen } \\
\text { measurements of } \\
\text { selected samples }\end{array}$ & $\begin{array}{l}\text { Equipment } \\
\text { verification } \\
\text { and } \\
\text { calibration }\end{array}$ & $\begin{array}{l}\text { Specimens were defueled and the equipment was set up. Out of cell } \\
\text { verification testing of the oxygen nitrogen hydrogen analyzer is } \\
\text { underway and cladding measurements are expected to follow in early } \\
\text { FY21. }\end{array}$ \\
\hline & $\begin{array}{l}\text { Analyze fuel } \\
\text { burnup to } \\
\text { confirm predicted } \\
\text { and extrapolated } \\
\text { values }\end{array}$ & In progress & $\begin{array}{l}\text { Eleven specimens were sent to the ORNL Radiochemical Engineering } \\
\text { Development Center for burnup analysis }(\mathrm{Nd}, \mathrm{U}, \mathrm{Pu} \text { only). Three are } \\
\text { complete. Additionally, other sponsors are funding isotopic analyses of } \\
\text { additional sister rod specimens ( } \sim 51 \text { isotopes measured). }\end{array}$ \\
\hline DE.07 & $\begin{array}{l}\text { Conduct four- } \\
\text { point bend ( } 4 \mathrm{~PB}) \\
\text { tests }\end{array}$ & In progress & $\begin{array}{l}\text { All Phase } 1 \text { tests, except for those planned for aerosol collection, are } \\
\text { complete. Tests were conducted at both room temperature (RT) and at } \\
200^{\circ} \mathrm{C} \text {. Data evaluation is in progress. Stress, strain, } 0.2 \% \text { offset yield } \\
\text { strength, flexural modulus, and flexural strength were calculated for the } \\
\text { tests completed. Generally, the heat-treated M5 and ZIRLO-clad } \\
\text { specimens have higher ductility than the baseline specimens, but it is } \\
\text { difficult to come to any firm conclusions about whether the heat } \\
\text { treatments affected specimen performance with the limited data available. } \\
\text { Additional evaluations of the data will be completed in FY } 21 \text {. } \\
\text { The mass loss from the specimen resulting from fracture was measured } \\
\text { during the } 4 \text { PB tests. There was not a trend of pellet mass loss related to } \\
\text { test temperature, although the RT fractures seemed more energetic than } \\
\text { the } 200^{\circ} \mathrm{C} \text { fracture. With each pellet weighing approximately } 5.1-7.0 \mathrm{~g} \text {, } \\
\text { the maximum mass released from the cladding represents about one- } \\
\text { quarter of a pellet, whereas the more typical } 0.4 \mathrm{~g} \text { mass released is less } \\
\text { than one-tenth of a full pellet. }\end{array}$ \\
\hline DE.08 & $\begin{array}{l}\text { Conduct axial } \\
\text { tensile tests }\end{array}$ & In progress & Specimen preparation in progress. \\
\hline DE.09 & $\begin{array}{l}\text { Test for } \\
\text { American Society } \\
\text { for Testing and } \\
\text { Materials } \\
\text { (ASTM) } \\
\text { microhardness }\end{array}$ & Not started & Equipment is available. \\
\hline DE.10 & $\begin{array}{l}\text { Conduct fueled } \\
\text { ring compression } \\
\text { tests (RCT) }\end{array}$ & Complete & $\begin{array}{l}\text { Complete. There is no appreciable difference in the maximum load- } \\
\text { bearing capability of the segments from RT to } 200^{\circ} \mathrm{C} \text {. Cladding type } \\
\text { also does not greatly influence the load-bearing capability, and there } \\
\text { does not appear to be a difference related to the heat-treatment applied to } \\
\text { some of the rods. The main observed variant is the orientation of the }\end{array}$ \\
\hline
\end{tabular}




\begin{tabular}{|c|c|c|c|}
\hline \multicolumn{2}{|c|}{ Planned DE } & \multirow[t]{2}{*}{ Status } & \multirow{2}{*}{$\begin{array}{l}\text { Comments } \\
\text { major cracks in the pellet because these appear to nucleate fracture of } \\
\text { the adjacent cladding and determine the pellet fracture plane. Observed } \\
\text { transverse bearing load of the specimen is } 16.4 \mathrm{kN}\left(3,690 \mathrm{lb}_{\mathrm{f}}\right) \text { on } \\
\text { average with a minimum load-bearing capability of } 12.3 \mathrm{kN}\left(2,766 \mathrm{lb}_{\mathrm{f}}\right) \\
\text { for the tested segments. The load-bearing capability of the fueled } \\
\text { specimen is about eight times higher than that of a defueled cladding } \\
\text { specimen. }\end{array}$} \\
\hline & & & \\
\hline DE.14 & $\begin{array}{l}\text { Perform burst } \\
\text { tests }\end{array}$ & Not started & $\begin{array}{l}\text { Equipment must be evaluated and modified for testing at the proposed } \\
\text { pressure and temperature. }\end{array}$ \\
\hline
\end{tabular}


This page is intentionally blank. 


\section{ACKNOWLEDGMENTS}

Many thanks to our US Department of Energy Office of Nuclear Energy sponsor, Ned Larson, along with the Spent Fuel and Waste Science and Technology storage and transportation program leadership for their continued support. The sister rod project would not have been possible without the vision and support of the Electric Power Research Institute, Westinghouse, Framatome, and Dominion Energy.

This work would not have been possible without the support and expertise provided by the leadership and staff members of the ORNL's Irradiated Fuel Examination Laboratory.

Many thanks are due Elizabeth Kirby for making this report clearer and more readable through her edits. 
This page is intentionally blank. 


\section{CONTENTS}

SUMMARY

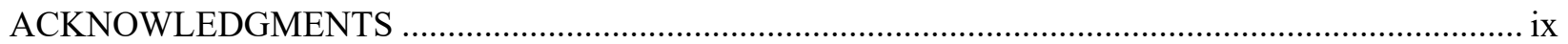

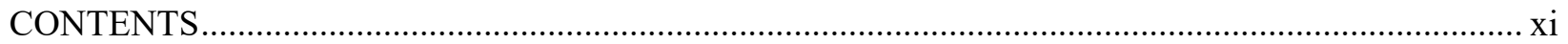

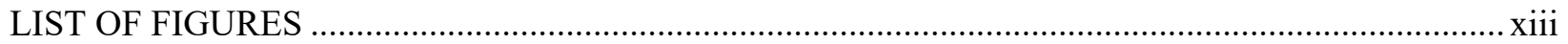

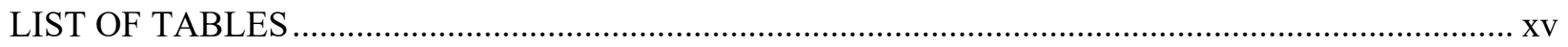

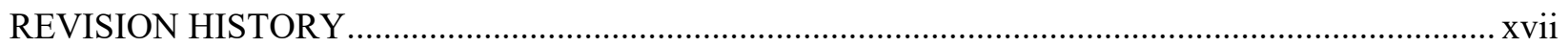

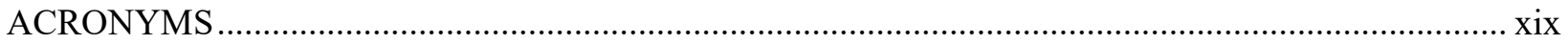

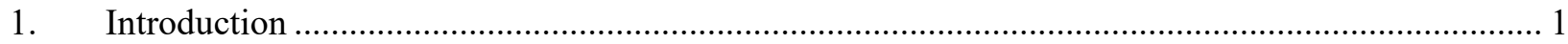

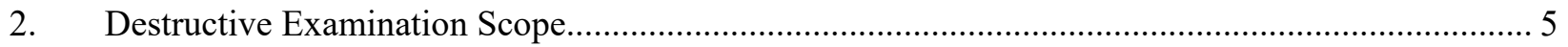

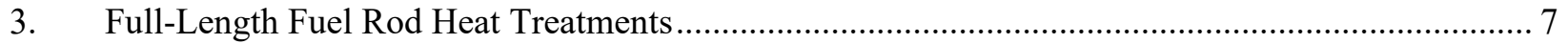

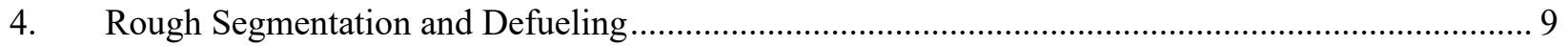

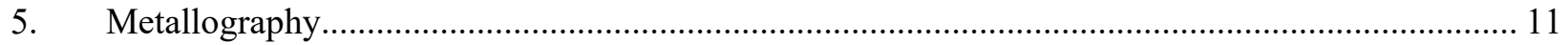

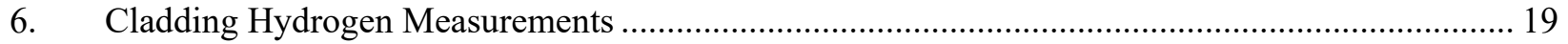

7. Rod Internal Pressure Measurement and Rod Void Volume Measurement ................................... 21

7.1 Effect of FHT on Rod Internal Pressure and Void Volume ................................................... 24

7.2 Comparisons with Code Predictions …............................................................................... 24

8. Pellet Stack Gas Depressurization and Transmission Testing .................................................... 27

9. Fission Gas Sample Isotopic Composition and Calculated Fission Gas Release ........................... 31

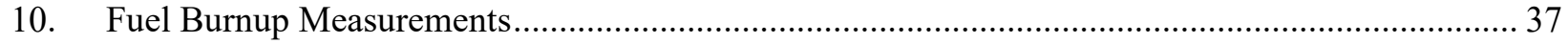

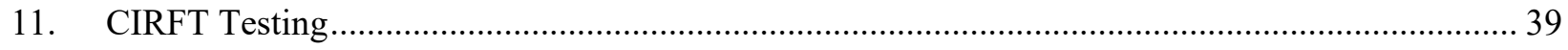

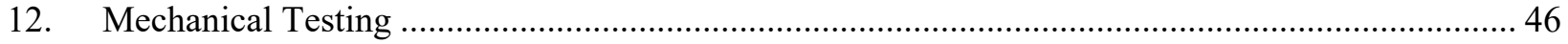

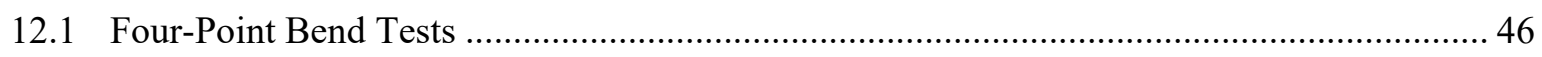

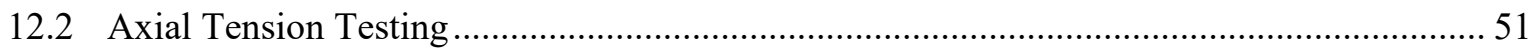

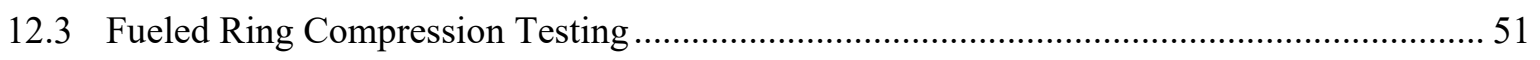

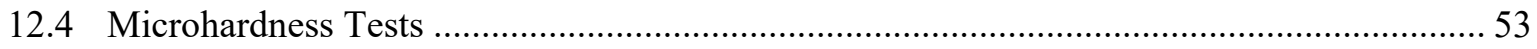

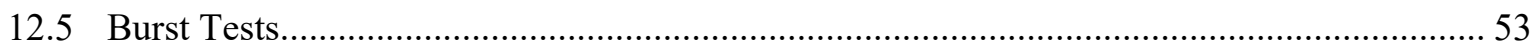

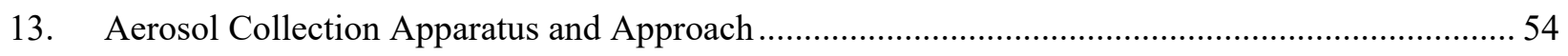

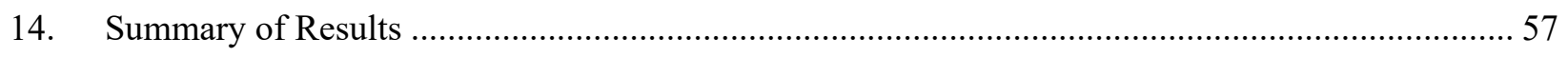

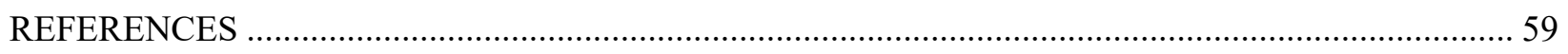

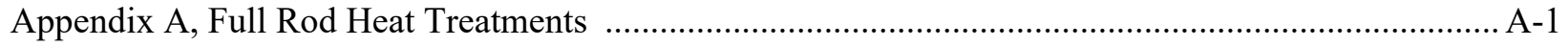

Appendix B, Segmentation, Defueling, MET, Total Cladding Hydrogen ............................................ B-1

Appendix C, Rod Internal Pressure, Void Volume and Gas Transmission Tests .................................. C-1

Appendix D, Fission Gas Analysis, Fuel Rod Burnup and Isotopics ................................................ D-1

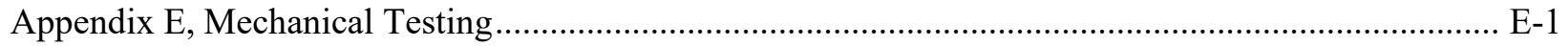

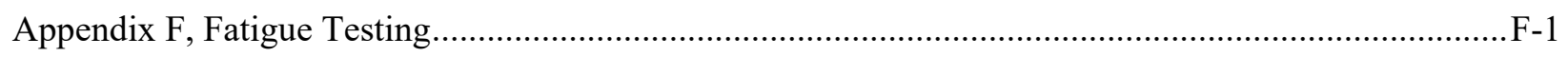


This page is intentionally blank. 


\section{LIST OF FIGURES}

Figure 1. Metallographic measurements vs. estimated local burnup available for the Phase 1 rods: (a) remaining average cladding thickness, (b) average waterside oxide thickness, and (c) average pelletside oxide thickness.

Figure 2. Metallographic measurements vs. estimated local burnup available for the Phase 1 rods: (a) average cladding OD, (b) average cladding ID, and (c) average pellet HBU rim thickness.

Figure 3. Selected METs illustrating primary hydride content and orientations for baseline and FHT sister rods

Figure 4. 3D8E14 at 1,403 mm elevation; pellet-pellet (a) gap measurements, (b) cropped axial section view and cross-sectional view locations, (c) cross-sectional view in the gap, and (d) cross-sectional view of the pellet above the gap

Figure 5. 3D8E14 centered at 1,403 mm elevation; cladding hydride distribution (a) above the gap in the pellet body, (b) in the gap, (c) below the gap in the pellet body. 18

Figure 6. Sister rod measured rod internal Pressure at $25^{\circ} \mathrm{C}$.

Figure 7. Results of gas transmission tests on two sister rods (three different pressures on each rod).

Figure 8. Results of the depressurization tests on eight sister rods (three rods were heat treated)............29

Figure 9. The measured krypton content of the rod fission gas for ZIRLO-clad sister rods.

Figure 10. Measured krypton content of the rod fission gas as a function of the independently measured fission gas partial pressure.

Figure 11. Results of sister rod CIRFT tests plotted with previous data, applied moment vs. cycles to failure.

Figure 12. Comparison of CIRFT stress amplitude vs. cycles to failure with other fatigue limits. 43

Figure 13. CIRFT-measured flexural rigidity of the heat-treated and baseline specimens. 44

Figure 14. Typical appearance of post-fatigue test specimens. 45

Figure 15. Stress vs. strain plot for RT data. 48

Figure 16. Stress vs. strain plot for $200^{\circ} \mathrm{C}$ data. 49

Figure 17. (a) Posttest debris was captured by a catch tray located below the specimen with (b) the typical RT debris field composed of small particles. 50

Figure 18. Typical post-RCT appearance. .51

Figure 19. Typical test specimen. .51

Figure 20. RCT fracture path along major pellet crack. 52

Figure 21. Illustration of the load frame aerosol collection enclosure with one sampling card shown.

Figure 22. Sampling card with multistage cascade impactor and dedicated pump (a) set up for verification testing and (b) fit up on the load frame in the hot cell. 
This page is intentionally left blank. 


\section{LIST OF TABLES}

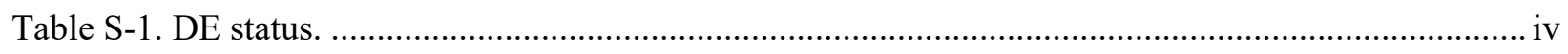

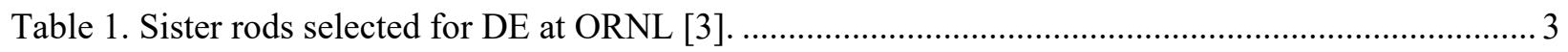

Table 2. Summary of metallographic section measurements obtained to date........................................ 13

Table 3. Results of rod internal pressure and void volume measurements at $25^{\circ} \mathrm{C}$............................... 22

Table 4. Summary of measured and predicted rod internal pressure and void volume. ............................26

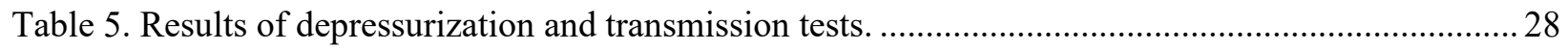

Table 6. Sister rod gas sample measured elemental composition, mole $0^{*}$................................................ 32

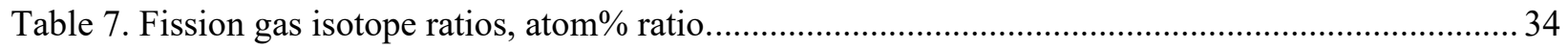

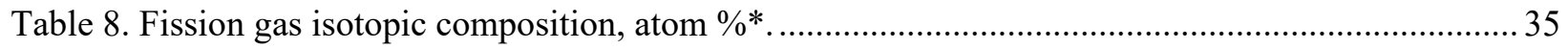

Table 9. Measured xenon-to-krypton ratio for the sister rods................................................................ 36

Table 10. Chemical isotopic analysis (burnup only) of sister rod specimens.......................................... 37

Table 11. Results arranged by paired specimens (baseline vs. FHT) for static/dynamic and dynamic

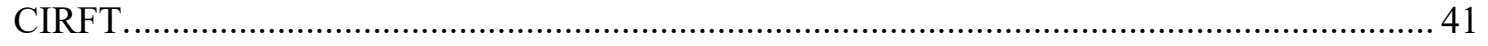

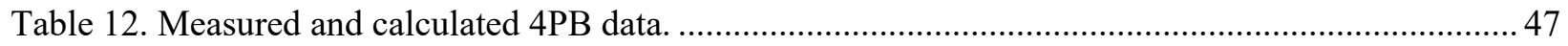

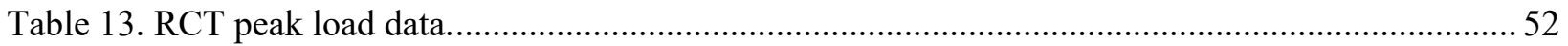


This page is intentionally left blank. 


\section{REVISION HISTORY}

\begin{tabular}{|c|l|}
\hline \multicolumn{1}{|c|}{ Date } & \multicolumn{1}{c|}{ Changes } \\
\hline $3 / 29 / 2019$ & Initial release. \\
\hline $9 / 27 / 2019$ & $\begin{array}{l}\text { Revised to include additional data and incorporate comments from the } \\
\text { previously released report. }\end{array}$ \\
\hline $10 / 29 / 2020$ & $\begin{array}{l}\text { Revised format of report to include detailed information in appendices } \\
\text { and included additional data obtained in FY20. Issued for project } \\
\text { review and comment. }\end{array}$ \\
\hline $11 / 30 / 2020$ & $\begin{array}{l}\text { Comments from review of the 10/29/2020 draft were incorporated, the } \\
\text { document numbering was revised to reflect its M2 status and the date } \\
\text { was changed. }\end{array}$ \\
\hline
\end{tabular}


This page is intentionally left blank. 


\section{ACRONYMS}

AERO

CIRFT

DE

DEF

DOE

FGR

FHT

FY

GTRF

HBU

HDCI

ID

IFBA

IFEL

LT

MET

NE

NDE

OD

ORNL

PCI

PNNL

PV

PWR

RCT

RT

RS

SNF

SRSS

TEM aerosol collection capability

cyclic integrated reversible-bending fatigue tester

destructive examination

defueling

US Department of Energy

fission gas release

full-length fuel rod heat treatment

fiscal year

grid-to-rod fretting

high burnup

high duty core index

inner diameter

Integral Fuel Burnable Absorber

Irradiated Fuels Examination Laboratory

low tin

metallography

Office of Nuclear Energy

nondestructive examination

outer diameter

Oak Ridge National Laboratory

pellet-cladding interaction

Pacific Northwest National Laboratory

the product of the rod internal pressure and void volume

pressurized water reactor

ring compression test

room temperature

rough segmentation

spent nuclear fuel

square-root-sum-square

transmission electron microscope 
This page is intentionally left blank. 


\section{SPENT FUEL AND WASTE SCIENCE AND TECHNOLOGY SISTER ROD DESTRUCTIVE EXAMINATIONS}

\section{Introduction}

As a part of the US Department of Energy (DOE) Office of Nuclear Energy (NE) High Burnup Spent Fuel Data Project, Oak Ridge National Laboratory (ORNL) is performing destructive examinations (DEs) of high burnup (HBU) (>45 GWd/MTU) spent nuclear fuel (SNF) rods from the North Anna Nuclear Power Station operated by Dominion Energy. The goals of the High Burnup Spent Fuel Data Project are to "provide confirmatory data for model validation and potential improvement, provide input to future SNF dry storage cask design, support license renewals and new licenses for Independent Spent Fuel Storage Installations, and support transportation licensing for high burnup SNF" [1]. The SNF rods, called sister rods or sibling rods, are all HBU and include four different kinds of fuel rod cladding: standard Zircaloy-4 (Zirc-4), low-tin (LT) Zircaloy-4 (LT Zirc-4), ZIRLO, and M5 [2, 3]. The sister rods have similar characteristics to SNF that was placed in dry storage in a modified TN-32B cask because they were extracted from fuel assemblies of the same design and with similar operating histories (symmetric partners) or from the actual fuel assemblies that are included in the TN-32B cask. ${ }^{1}$ Details about the sister rods, their operation in the North Anna Nuclear Power Station, and the HBU spent fuel data project are provided in References 1 through 4.

The 25 sister rods were subjected to nondestructive examinations (NDEs) at ORNL's Irradiated Fuels Examination Laboratory (IFEL), as described in Montgomery et al. [4]. The NDEs included visual and dimensional inspections, gamma scanning, eddy current, and rod surface temperature measurements. Following the NDEs, 10 of the 25 sister rods were shipped from ORNL to Pacific Northwest National Laboratory for defueled cladding mechanical tests. Several segments from ORNL's sister rods were defueled and shipped to Argonne National Laboratory (ANL).

DEs are being conducted to obtain a baseline of the HBU rod's condition before dry storage and to investigate specific conditions of dry storage through small-scale and separate effects tests. The ORNL testing performed is focused on understanding overall SNF rod strength and durability and tested composite fuel and empty cladding to derive material properties. Although the data generated can be used for multiple purposes, one primary goal for obtaining the post-irradiation examination data and the associated measured properties is to support SNF dry storage licensing and relicensing activities by (1) addressing identified knowledge gaps and (2) enhancing the technical basis for post-storage transportation, handling, and consolidation activities.

The 15 rods available at ORNL for DE are described in Table 1. The planned DEs include full-length rod heat treatments simulating the peak dry storage cladding temperature, rod internal pressure and void volume measurements, fission gas analysis and release ratios, fuel burnup, gas transmission testing, metallography (MET), cladding total hydrogen measurements, four-point bend (4PB) and axial tension tests, microhardness tests, ring compression tests (RCTs), and burst tests. The mechanical testing will be performed using fueled segments and is expected to complement previous and current mechanical test

\footnotetext{
${ }^{1}$ Except for the Zirc-4 rods taken from assembly F35 and the LT Zirc-4 rods taken from assembly 3A1. These rods are not exact sister rods to any rods in the dry storage cask but were the closest available. Furthermore, assembly F35 was operated as a test assembly and was irradiated for four cycles of operation to high burnup.
} 
results for defueled cladding segments. The DE scope necessarily includes preparatory tasks - such as rod segmenting, defueling, and heat treatments - and those activities are discussed within this report.

To summarize the main results with brevity while maintaining a complete record of the tests, the details and supporting information for the tests are provided in the appendices.

Throughout this document, the following terms are used:

- Rod: the full-length sister rod, unpunctured or punctured, but not segmented, with the exception that a rod used for gas transmission testing (lower end cap removed only) can continue to be called a rod.

- Segment: a length of cladding with pellets cut from the parent rod to be further modified for use in examinations.

- Specimen: a segment modified for use in a DE.

- Sample: a small portion of material taken from a segment or specimen for local property testing.

The DEs are performed using a phased approach, as described by Saltzstein [2]. This report documents the status of the ORNL Phase 1 DEs, outlines the DE tasks performed, and documents the data collected to date, as guided by the sister rod test plans $[2,3]$. Testing is performed and documented per the requirements of the ORNL sister rod test plan [3], which includes applicable consensus standards (e.g., American Society for Testing and Materials), regulatory requirements (e.g., DOE orders), and adherence to the laboratory and Fuel Cycle Technologies quality assurance plans. In compliance with the ORNL sister rod test plan, measuring and test equipment necessary to conduct the examinations are controlled and calibrated at the facilities that perform the work in accordance with approved laboratory procedures.

Unless otherwise specified, examinations were completed at ambient temperature at standard pressure in air, including those using heat-treated specimens. Throughout the remainder of this document, the sister rods will be described using the format XXXYYY, where $X X X$ represents the fuel assembly ID, and $Y Y Y$ represents the rod lattice position within the assembly. Individual sister rod segments are described using the format XXXYYY-RRRR-TTTT, where $X X X Y Y Y$ is the sister rod ID as previously described, $R R R R$ is the lowest original rod elevation of specimen, and TTTT is the upper original rod elevation of the segment. If segments longer than $50 \mathrm{~mm}$ are subdivided to provide additional test specimens, then the ID is further adjusted to reflect the rod elevations originally occupied by the specimen. This nomenclature is intended to provide traceability to the elevation on the sister rod where each specimen originated.

This report is organized with the primary findings provided in the main body of the document and the more detailed calculations, evaluations, and explanations provided in an appendix to the document for each area of DE. Each appendix is meant to be a standalone document that provides all results, including those provided in the main body of the document, and therefore there is some duplicated information between the two. 
Table 1. Sister rods selected for DE at ORNL [3].

\begin{tabular}{|c|c|c|c|c|c|c|c|}
\hline \multirow[b]{2}{*}{$\begin{array}{c}\text { Clad } \\
\text { material }\end{array}$} & \multirow[b]{2}{*}{ Sister rod } & \multirow[b]{2}{*}{$\begin{array}{c}\text { Rod average } \\
\text { burnup } \\
(\mathrm{GWd} / \mathrm{MTU})\end{array}$} & \multirow[b]{2}{*}{$\begin{array}{c}\text { Assembly } \\
\text { average burnup } \\
\text { (GWd/MTU) }\end{array}$} & \multirow[b]{2}{*}{ Assembly operation } & \multirow[b]{2}{*}{ Key characteristics } & \multicolumn{2}{|c|}{$\begin{array}{c}\text { Cask-stored } \\
\text { sister(s) }\end{array}$} \\
\hline & & & & & & $\begin{array}{l}\text { Assembly } \\
\text { identifier }\end{array}$ & \begin{tabular}{|c|} 
Cask \\
rod \\
lattice \\
location
\end{tabular} \\
\hline M5 & 30AG09 & 53 & \multirow{4}{*}{52.0} & \multirow{4}{*}{$\begin{array}{l}30 \mathrm{~A} \text { was operated hot-hot-cold. Its last } \\
\text { cycle was uprated } \sim 1.6 \% \text { about } 3 \\
\text { months before the end of the cycle, } \\
\text { making it the cycle with the highest } \\
\text { power density of those represented. } \\
\text { This assembly had the highest pellet } \\
\text { enrichment. The assembly design } \\
\text { included mid-span mixing grids, which } \\
\text { should have lowered the rod operating } \\
\text { temperature in the hot spans. All the } \\
\text { M5 rods are expected to have relatively } \\
\text { low rod internal pressure and cladding } \\
\text { hydrogen content. }\end{array}$} & $\begin{array}{l}\text { Sister rod to assembly rod in assembly 57A lance } \\
\text { position with close proximity to the peak (hottest) } \\
\text { cask rod position (I-7). The rod was operated in a } \\
\text { guide tube adjacent location. Of the sister rods, } \\
\text { predicted to have the highest decay heat. }\end{array}$ & $57 \mathrm{~A}$ & I07 \\
\hline M5 & $30 \mathrm{AK} 9^{a}$ & 54 & & & $\begin{array}{l}\text { The corresponding cask rod is next to a lance } \\
\text { position with close proximity to the peak (hottest) } \\
\text { rod position (I-7) in the cask }\end{array}$ & $57 \mathrm{~A}$ & I07 \\
\hline M5 & $30 \mathrm{AD} 05^{a}$ & 54 & & & \multirow{2}{*}{$\begin{array}{l}\text { D-5 and E-14 were operated in a guide tube } \\
\text { adjacent location with (E-14) and without (D-5) } \\
\text { burnable poisons. Because the poisons influence } \\
\text { power output during irradiation, the rods are } \\
\text { expected to have different characteristics, even } \\
\text { though they have similar burnups. }\end{array}$} & $57 \mathrm{~A}$ & E14 \\
\hline M5 & $30 \mathrm{AE} 14^{b}$ & 54 & & & & $57 \mathrm{~A}$ & D05 \\
\hline M5 & $5 \mathrm{~K} 7 \mathrm{O} 14$ & 53 & 53.3 & $\begin{array}{l}5 \mathrm{~K} 7 \text { was operated hot-hot-cold and had } \\
\text { the highest pellet enrichment of the } \\
\text { assembly batches represented. The } \\
\text { assembly design included mid-span } \\
\text { mixing grids, which should have } \\
\text { lowered the rod operating temperature } \\
\text { in the hot spans. }\end{array}$ & $\begin{array}{l}\text { Approximately average assembly burnup; the rod } \\
\text { was operated in a guide tube diagonal location. } \\
\text { All M5 rods are expected to have relatively low } \\
\text { rod internal pressure and cladding hydrogen } \\
\text { content. }\end{array}$ & $\begin{array}{l}5 \mathrm{~K} 6 \\
3 \mathrm{~K} 7 \\
5 \mathrm{~K} 1\end{array}$ & $\mathrm{C} 04$ \\
\hline ZIRLO & 6U3I07 & 54 & \multirow{3}{*}{52.7} & \multirow{3}{*}{$\begin{array}{l}6 \mathrm{U} 3 \text { was operated hot-cold-cold. The } \\
6 \mathrm{U} 3 \text { sister rods are expected to have } \\
\text { relatively high rod internal pressure } \\
\text { and cladding hydrogen contents. }\end{array}$} & $\begin{array}{l}\text { This rod is a sister to three different fuel } \\
\text { assemblies in the central, middle, and outer } \\
\text { regions of the Research Project Cask basket. The } \\
\text { rod was operated in a guide tube adjacent } \\
\text { location. }\end{array}$ & $\begin{array}{l}3 \mathrm{U} 4 \\
3 \mathrm{U} 9 \\
3 \mathrm{U} 6\end{array}$ & $\begin{array}{l}\text { I07 } \\
\text { I1 } 1 \\
\text { I11 }\end{array}$ \\
\hline ZIRLO & 6U3M09 & 55 & & & This rod's cask sister is next to a lance position & $\begin{array}{l}3 \mathrm{U} 4 \\
3 \mathrm{U} 9 \\
3 \mathrm{U} 6 \\
\end{array}$ & E09 \\
\hline ZIRLO & $6 \mathrm{U} 3 \mathrm{~K} 09^{a}$ & 55 & & & This rod's cask sister is next to a lance position & $\begin{array}{l}3 \mathrm{U} 4 \\
3 \mathrm{U} 9 \\
3 \mathrm{U} 6\end{array}$ & K09 \\
\hline
\end{tabular}


Table 1. Sister rods selected for DE at ORNL [3].

\begin{tabular}{|c|c|c|c|c|c|c|c|}
\hline \multirow[b]{2}{*}{$\begin{array}{c}\text { Clad } \\
\text { material }\end{array}$} & \multirow[b]{2}{*}{ Sister rod } & \multirow[b]{2}{*}{$\begin{array}{c}\text { Rod average } \\
\text { burnup } \\
(\mathbf{G W d} / \mathrm{MTU})\end{array}$} & \multirow[b]{2}{*}{$\begin{array}{c}\text { Assembly } \\
\text { average burnup } \\
\text { (GWd/MTU) }\end{array}$} & \multirow[b]{2}{*}{ Assembly operation } & \multirow[b]{2}{*}{ Key characteristics } & \multicolumn{2}{|c|}{$\begin{array}{l}\text { Cask-stored } \\
\text { sister(s) }\end{array}$} \\
\hline & & & & & & $\begin{array}{l}\text { Assembly } \\
\text { identifier }\end{array}$ & $\begin{array}{c}\text { Cask } \\
\text { rod } \\
\text { lattice } \\
\text { location }\end{array}$ \\
\hline ZIRLO & $3 \mathrm{~F} 9 \mathrm{~N} 05^{* *}$ & 54 & & $\begin{array}{l}\text { 3F9 was operated hot-hot-cold. Both } \\
\text { sister rods appear to have experienced } \\
\text { grid-to-rod fretting (GTRF) in-reactor; }\end{array}$ & $\begin{array}{l}\text { Rod is a good match for several cask rods with a } \\
\text { relatively HBU. }\end{array}$ & $\begin{array}{l}\mathrm{F} 1 \\
3 \mathrm{~F} 6 \\
6 \mathrm{~F} 2\end{array}$ & $\begin{array}{l}\text { N05 } \\
\text { N05 } \\
\text { N05 }\end{array}$ \\
\hline ZIRLO & 3F9D07 & 52 & 52.3 & $\begin{array}{l}\text { marks were observed at grid locations } \\
\text { along the entire axial length. The } 3 \mathrm{~F} 9 \\
\text { rods are expected to have moderately } \\
\text { high rod internal pressure and cladding } \\
\text { hydrogen content. }\end{array}$ & $\begin{array}{l}\text { Rod with an approximate average assembly } \\
\text { burnup }\end{array}$ & $\begin{array}{l}4 \mathrm{~F} 1 \\
3 \mathrm{~F} 6 \\
6 \mathrm{~F} 2\end{array}$ & D07 \\
\hline ZIRLO & $3 \mathrm{D} 8 \mathrm{E} 14^{*}$ & 59 & 550 & $\begin{array}{l}\text { 3D8 was operated hot-cold-cold. The } \\
\text { 3D8 rods are expected to have }\end{array}$ & $\begin{array}{l}\text { Rod with approximately the highest burnup in } \\
\text { assembly and with the highest sister rod burnup. }\end{array}$ & $\begin{array}{l}\text { 5D9 } \\
\text { 5D5 }\end{array}$ & $\begin{array}{l}\text { N13 } \\
\text { M04 }\end{array}$ \\
\hline ZIRLO & 3D8B02 & 50 & 55.0 & $\begin{array}{l}\text { moderate rod internal pressure and high } \\
\text { cladding hydrogen content. }\end{array}$ & $\begin{array}{l}\text { Rod with nearly the lowest burnup in assembly } \\
\text { (selected based on pulling restriction). }\end{array}$ & $\begin{array}{l}\text { 5D9 } \\
\text { 5D55 }\end{array}$ & $\begin{array}{l}\text { B16 } \\
\text { P16 }\end{array}$ \\
\hline LT Zirc-4 & $3 \mathrm{~A} 1 \mathrm{~B} 16$ & 48 & & $3 \mathrm{~A} 1$ was burned hot and reached HBUs & $\begin{array}{l}\text { Rod with the lowest burnup in assembly; close to } \\
\text { assembly periphery }\end{array}$ & $\mathrm{OA} 4^{* * *}$ & B16 \\
\hline LT Zirc-4 & $3 \mathrm{~A} 1 \mathrm{~F} 05^{*}$ & 51 & 50.0 & $\begin{array}{l}\text { comparable with the other sister rods in } \\
\text { only two cycles. }\end{array}$ & $\begin{array}{l}\text { Rod with the highest burnup in assembly; } \\
\text { reasonably close to center of assembly. Areas of } \\
\text { CRUD observed. }\end{array}$ & OA4 ${ }^{* * *}$ & F05 \\
\hline Zirc-4 & $\mathrm{F} 35 \mathrm{P} 17^{* *}$ & 60 & 57.9 & $\begin{array}{l}\text { Four cycles of operation. F35 operated } \\
\text { its fourth cycle in D-bank with control } \\
\text { rods partially inserted. Operated before } \\
\text { North Anna's power uprates so lower } \\
\text { power density. Lowest enrichment. At } \\
\text { time of exams, predicted to have the } \\
\text { lowest decay heat. }\end{array}$ & $\begin{array}{l}\text { Rod located on the assembly periphery. Spalled } \\
\text { oxide was observed. This rod is expected to have } \\
\text { a high rod internal pressure combined with a } \\
\text { relatively large cladding hydrogen content. }\end{array}$ & $\begin{array}{l}\text { None } \\
(\mathrm{F} 40)^{* * * *}\end{array}$ & N/A \\
\hline
\end{tabular}

* Phase 1 baseline rod.

** $\quad$ Phase 1 full length heat-treated (FHT) rod.

*** The LT Zirc-4 rods taken from assembly $3 \mathrm{~A} 1$ are not exact sister rods to $0 \mathrm{~A} 4$ but were the closest available.

**** The Zirc-4 rods are not exact sister rods to F40 but were the closest available. Additionally, assembly F35 was operated as a test assembly and was irradiated for four cycles of operation to HBU. 


\section{Destructive Examination Scope}

The Phase 1 DE tasks $[2,3]$ are as follows.

FHT Full-length fuel rod heat treatments (FHT) of three sister rods: one ZIRLO, one M5, and one LT Zirc-4.

RS Rough segmenting of the rods for allocation of segments to DE. Segments are stored in aluminum capsules, in air, until the time of the test.

DEF Defueling of selected segments. Some segments are defueled as preparation for claddingonly DE; other segments are defueled to gather samples for fuel isotopic and burnup measurements.

AERO Capture of aerosolized particles released from the segments in which fracture occurs during testing (e.g., 4PB); fixtures and sampling methods are developed to support this effort.

DE.01 Rod internal pressure measurement, rod void volume measurement, collection of fission gas specimens, gas transmission testing, fuel isotopics, and burnup measurements.

DE.02 MET.

DE.03 Cladding total hydrogen measurements.

DE.05 Cyclic integrated reversible-bending fatigue tester (CIRFT) in static, dynamic, and cumulative test modes.

DE.07 4PB tests.

DE.08 Axial tension testing.

DE.09 Microhardness tests.

DE.10 RCTs.

DE.14 Burst tests.

DE.04, DE.06, DE.11, DE.12, and DE.13 were deferred to later phases of the test program [2].

Each section of this document summarizes and describes the status and results of the DEs. More detailed information is provided in the appendices. 
This page is intentionally left blank. 


\section{Full-Length Fuel Rod Heat Treatments}

In preparation for dry storage, the fuel assemblies and canister cavity must be drained and dried. Typically, the most challenging thermal condition experienced by the fuel during dry storage occurs during the drying sequence or just after drying during canister transfer to the storage pad. To better understand the effects of the drying and transfer sequence, three full-length sister rods were subjected to a simulated dry storage peak cladding temperature before DE. A comparison of the FHT rod DE with the baseline rod DE will quantify any impacts related to increased fuel rod temperature before dry storage $[1,2,3]$.

The rods were heated slowly $\left(10^{\circ} \mathrm{C} / \mathrm{h}\right.$ ), then held at $400^{\circ} \mathrm{C}$ (all axial elevations) for $8 \mathrm{~h}$, and then slowly cooled $\left(3.7^{\circ} \mathrm{C} / \mathrm{h}\right)$ to ambient temperature. One Zirc-4-clad (F35P17), one ZIRLO-clad (3F9N05), and one M5-clad (30AE14) rod were heat treated. During heat treatment of the M5-clad rod, the oven controller malfunctioned during the $8 \mathrm{~h}$ soak, and the rod plenum end of the oven was at $485^{\circ} \mathrm{C}$ for $\sim 1.75 \mathrm{~h}$. It is unlikely that the higher temperature affected the behavior of the cladding hydrides because: (1) the M5clad rod is expected to have very low hydrogen content and (2) the temperature was corrected before the cooldown sequence. The short time at the increased temperature could have resulted in additional annealing of irradiation defects; however, past data [5] indicate that a much longer time at temperature is required. Based on this information, it is unlikely that the short increase in soak temperature will influence the DE results; however, the difference in the heat-treatment conditions will be considered with the results of the $\mathrm{DE}$ as it becomes available.

Additional information related to the heat treatments applied is provided in Appendix A. 
This page is intentionally left blank. 


\section{Rough Segmentation and Defueling}

Seven Phase 1 rods were rough segmented (RS):

- 30AD05 (M5 clad, baseline),

- 30AE14 (M5 clad, FHT),

- 3D8E14 (ZIRLO clad, baseline),

- 3F9N05 (ZIRLO clad, FHT),

- F35P17 (Zirc-4 clad, FHT),

- 3A1F05 (LT Zirc-4 clad, baseline), and

- 6U3K09 (ZIRLO clad, baseline).

Many segments will be sub-sectioned and/or defueled in the process of specimen preparation for DE. For example, all DE.03 specimens are sub-sectioned from DE.03 segments and then defueled (DEF) before testing. In some cases, the removed fuel is the target of the test (e.g., DE.01 includes burnup measurements).

Appendix B provides details of the RS and DEF processes. 
This page is intentionally left blank. 


\section{Metallography}

Metallographic mounts (DE.02) are specified at several elevations of each Phase 1 sister rod to provide supplementary information - such as hydride distribution, oxide thickness, cladding wall thickness, and pellet HBU rim thickness - for correlation with other test data. MET images are available for all seven Phase 1 sister rods, but not all planned elevation views are available. Appendix B provides a list of the planned METs, the status, and a compilation of images and measurements for the completed elevations.

A summary of the available measurement data taken using the MET views is provided by rod and elevation in Table 2. The minimum remaining cladding wall thickness of those measured is $495 \mu \mathrm{m}$ for $3 \mathrm{~A} 1 \mathrm{~F} 05$, and the thickest waterside oxide thickness was $128 \mu \mathrm{m}$ for the same rod, which also had very extensive oxide spalling. The maximum pellet HBU rim thickness measured is $115 \mu \mathrm{m}$ for F35P17, consistent with its usage as a lead test rod over four cycles of operation and as the highest burnup sister rod in ORNL's collection. Figure 1 plots the average cladding wall thickness, waterside oxide thickness, and pelletside oxide thickness for each MET measured as a function of the local estimated rod burnup. Figure 2 plots the average cladding outer diameter (OD), cladding inner diameter (ID), and pellet HBU rim thickness measured as a function of the local estimated rod burnup. Most parameters do exhibit a trend with burnup; those that appear significant, even within the low range of burnup variability within the sister rod collection, are pelletside average oxide thickness, cladding average ID (which is also the pellet OD), and the pellet HBU rim thickness. When rod OD is sub-grouped by cladding alloy, there might be trends, but there are not enough data points to present a correlation. There does not appear to be an effect related to the FHT for the parameters measured. Generally, the NDE-provided measurements (taken pre-FHT) are consistent with the MET measurements. The MET measurements reported here are considered to be the most accurate.

One primary application of the METs is visualizing the cladding hydrides and determining whether the applied heat treatments changed the hydride orientation.

- M5-clad rods

- The hydrides in the baseline M5-clad rod (30AD05) are homogeneously distributed through the thickness of the cladding and are oriented circumferentially.

- For the FHT M5-clad rod (30AE14), many radial hydrides are visible, particularly at the ID of the cladding. They preferentially precipitated at locations in which a pellet crack exists at the cladding ID.

- ZIRLO-clad rods

- The precipitated hydrides in the baseline ZIRLO-clad rods are primarily located at the OD and ID of the cladding and are oriented circumferentially. For 3D8E14, there are many short hydrides in the central region of the wall that form a cross pattern, and there are several relatively long radial hydrides located at the cladding ID.

- For the FHT ZIRLO-clad rod, the circumferential hydrides are more regularly distributed through the wall section, perhaps indicating the migration of hydrogen during FHT, and several radial hydrides are visible at the ID and near the OD of the cladding.

- Zirc-4-clad and LT Zirc-4-clad rods

- Baseline rod 3A1F05 is heavily spalled, and there is a high density of circumferential hydrides near the waterside surface of the cladding. There is a lower density of circumferential hydrides through the remainder of the wall section. A few short radial hydrides are visible near the cladding ID. 
- The FHT Zirc-4-clad rod contains numerous circumferential hydrides that are visible throughout the thickness of the cladding. The few visible radial hydrides are very short.

Figure 3 provides selected MET images that illustrate the hydride content and orientation for the baseline and FHT sister rods. Additional views and descriptions are provided in Appendix B.

The NDE identified several pellet-pellet gaps among the sister rods. One gap, which was measured at $3 \mathrm{~mm}$ long and located at an elevation of 1,403 $\mathrm{mm}$ on baseline rod 3D8E14, was sectioned axially to allow for additional examination of the pellet and cladding. MET measurements revealed that the gap is actually less than $1 \mathrm{~mm}$ and was overestimated by the gamma scan likely due to the chamfers and dishes in the pellets. The axial view, shown in Figure 4 (also provided in Appendix B), allows axial and radial pellet cracks that occurred during reactor operation to be inspected. The pellet HBU rim is easily discernable and is enhanced at the pellet chamfer locations. The lower pellet has a small chip that relocated within the dish region, and at least one chamfer has loose chips. The axial section was then sectioned radially to view the hydride distribution through the cladding wall. Figure 5 (also provided in Appendix B) provides examples of the hydride distribution in the cladding in the gap and below the gap in the pellet body. There is not a visual difference in the hydride distribution in the gap compared with the cladding in the pellet body below the gap. Total cladding hydrogen measurements will be performed to better quantify any additional hydrogen (in solution or precipitated) in the pellet-pellet gap region. Additional detail is provided on the axial gap METs in Appendix B. 
Table 2. Summary of metallographic section measurements obtained to date.

\begin{tabular}{|c|c|c|c|c|c|c|c|c|c|c|c|c|c|c|c|c|c|c|c|c|c|c|c|}
\hline & 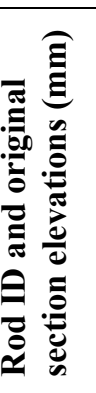 & & 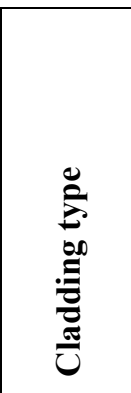 & 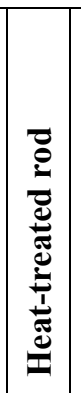 & 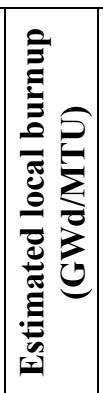 & 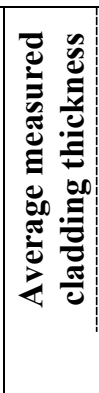 & 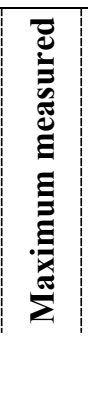 & 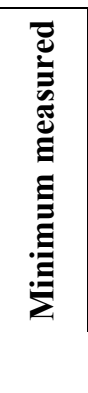 & 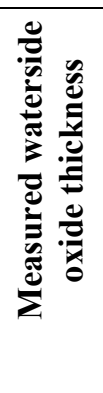 & 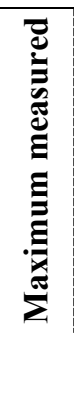 & 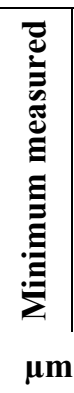 & 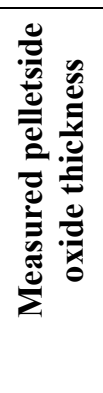 & 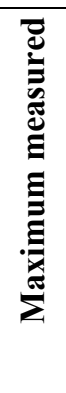 & 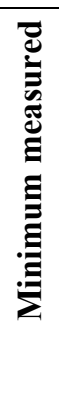 & 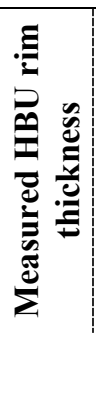 & 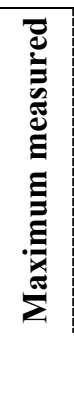 & 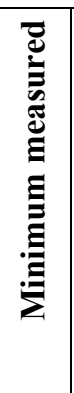 & 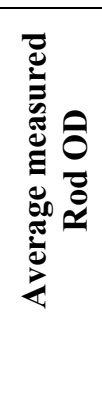 & 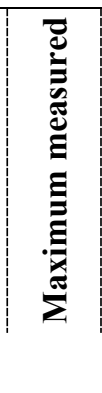 & 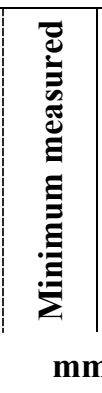 & 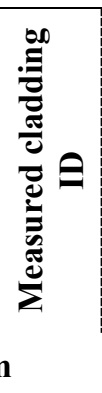 & 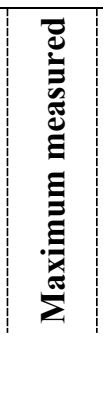 & 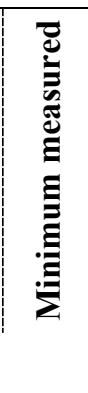 \\
\hline 30AD05 & 3240 & 3259 & M5 & No & 55 & 541 & 546 & 535 & 12 & 13 & 11 & 11 & 14 & 7 & 57 & 70 & 43 & 9.389 & 9.416 & 9.374 & 8.279 & 8.288 & 8.273 \\
\hline 30AE14 & 2675 & 2694 & M5 & Yes & 61 & 560 & 575 & 541 & 9 & 10 & 8 & 13 & 18 & 10 & & & & 9.389 & 9.416 & 9.374 & 8.279 & 8.288 & 8.273 \\
\hline 30AE14 & 3399 & 3418 & M5 & Yes & 50 & 562 & 585 & 545 & 12 & 15 & 10 & 10 & 16 & 8 & 61 & 82 & 42 & 9.419 & 9.449 & 9.398 & 8.310 & 8.338 & 8.283 \\
\hline 3D8E14 & 2655 & 2674 & ZIRLO & No & 64 & 549 & 564 & 531 & 34 & 41 & 31 & 15 & 18 & 12 & 70 & 108 & 52 & 9.466 & 9.495 & 9.424 & 8.330 & 8.344 & 8.306 \\
\hline $6 \mathrm{U} 3 \mathrm{~K} 09$ & 2616 & 2635 & ZIRLO & No & 58 & 560 & 571 & 549 & 21 & 22 & 19 & 9 & 12 & 6 & 59 & 107 & 36 & 9.440 & 9.455 & 9.425 & 8.276 & 8.302 & 8.249 \\
\hline 3F9N05 & 2863 & 2882 & ZIRLO & Yes & 58 & 554 & 563 & 547 & 30 & 38 & 24 & 12 & 16 & 8 & & & & 9.450 & 9.450 & 9.449 & 8.277 & 8.277 & 8.275 \\
\hline 3F9N05 & 3331 & 3350 & ZIRLO & Yes & 51 & 554 & 559 & 544 & 39 & 60 & 27 & 9 & 12 & 6 & 35 & 51 & 27 & 9.480 & 9.496 & 9.464 & 8.271 & 8.271 & 8.270 \\
\hline 3A1F05 & 1260 & 1279 & $\begin{array}{c}\text { LT } \\
\text { Zirc-4 }\end{array}$ & No & 56 & 560 & 565 & 555 & 15 & 18 & 14 & 10 & 12 & 7 & 54 & 74 & 43 & 9.436 & 9.436 & 9.436 & 8.299 & 8.299 & 8.299 \\
\hline 3A1F05 & 2735 & 2754 & $\begin{array}{c}\text { LT } \\
\text { Zirc-4 } \\
\end{array}$ & No & 54 & 546 & 630 & 495 & 90 & 128 & 43 & 12 & 16 & 9 & 72 & 90 & 62 & 9.485 & 9.548 & 9.421 & 8.290 & 8.300 & 8.280 \\
\hline F35P17 & 2735 & 2754 & Zirc-4 & Yes & 66 & 524 & 591 & 510 & 81 & 86 & 73 & 15 & 27 & 10 & 101 & 115 & 94 & 9.438 & 9.517 & 9.385 & 8.319 & 8.366 & 8.274 \\
\hline
\end{tabular}

Shaded cells indicate that measurement is unavailable.

Some METs were imaged but not measured, and they are not included in this table. 

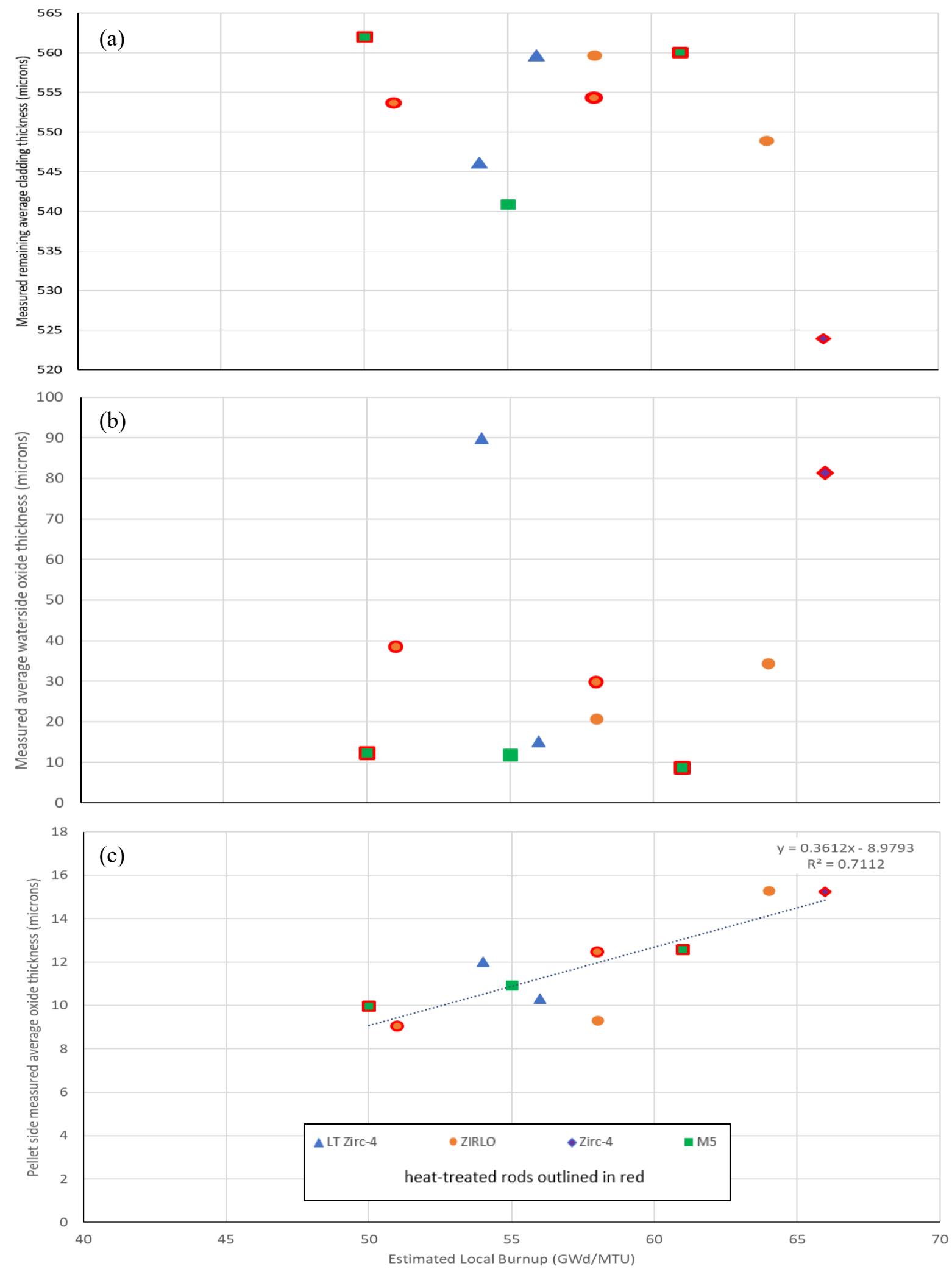

Figure 1. Metallographic measurements vs. estimated local burnup available for the Phase 1 rods: (a) remaining average cladding thickness, (b) average waterside oxide thickness, and (c) average pelletside oxide thickness. 


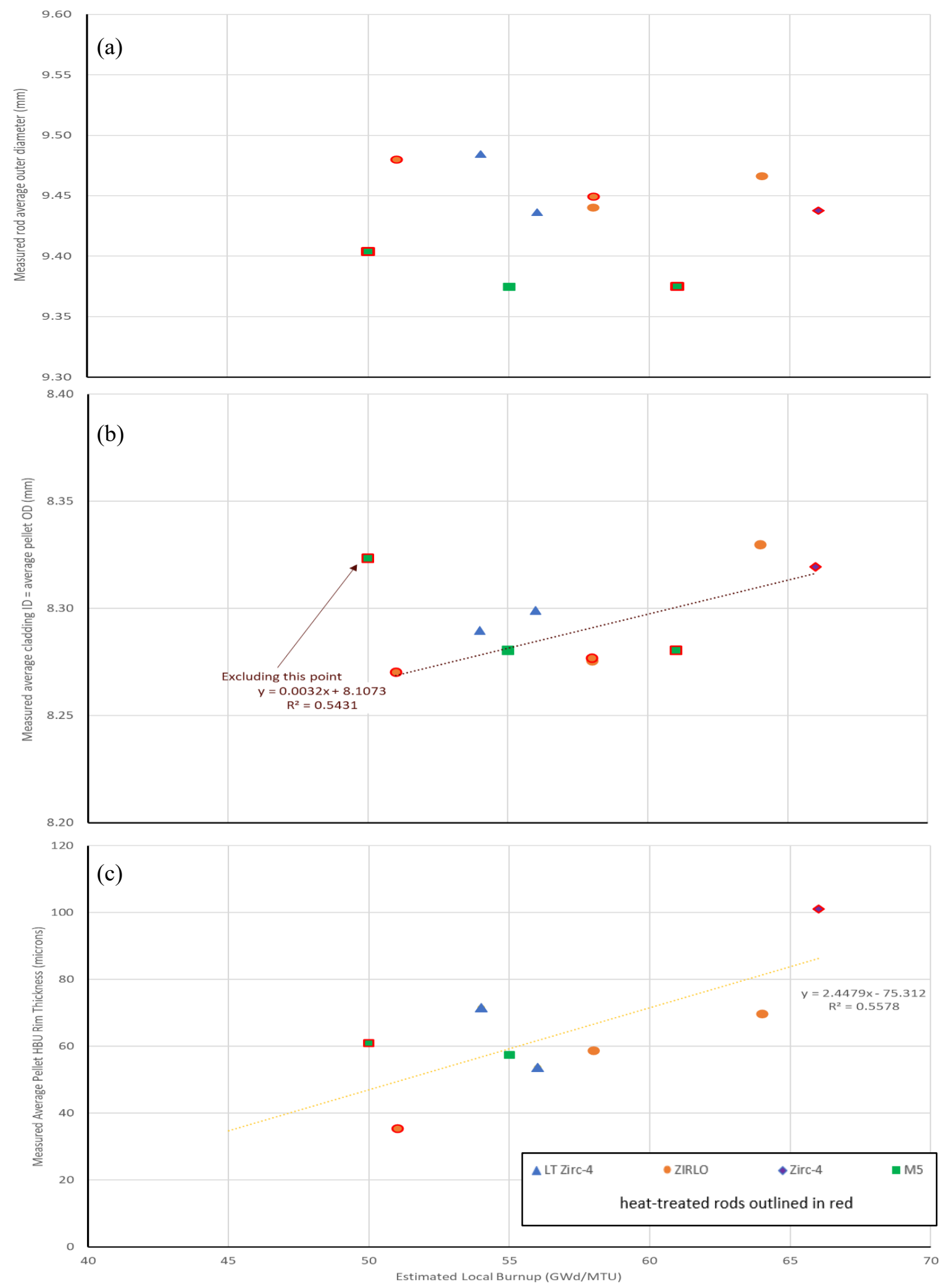

Figure 2. Metallographic measurements vs. estimated local burnup available for the Phase 1 rods: (a) average cladding $O D$, (b) average cladding $I D$, and (c) average pellet $\mathrm{HBU}$ rim thickness. 


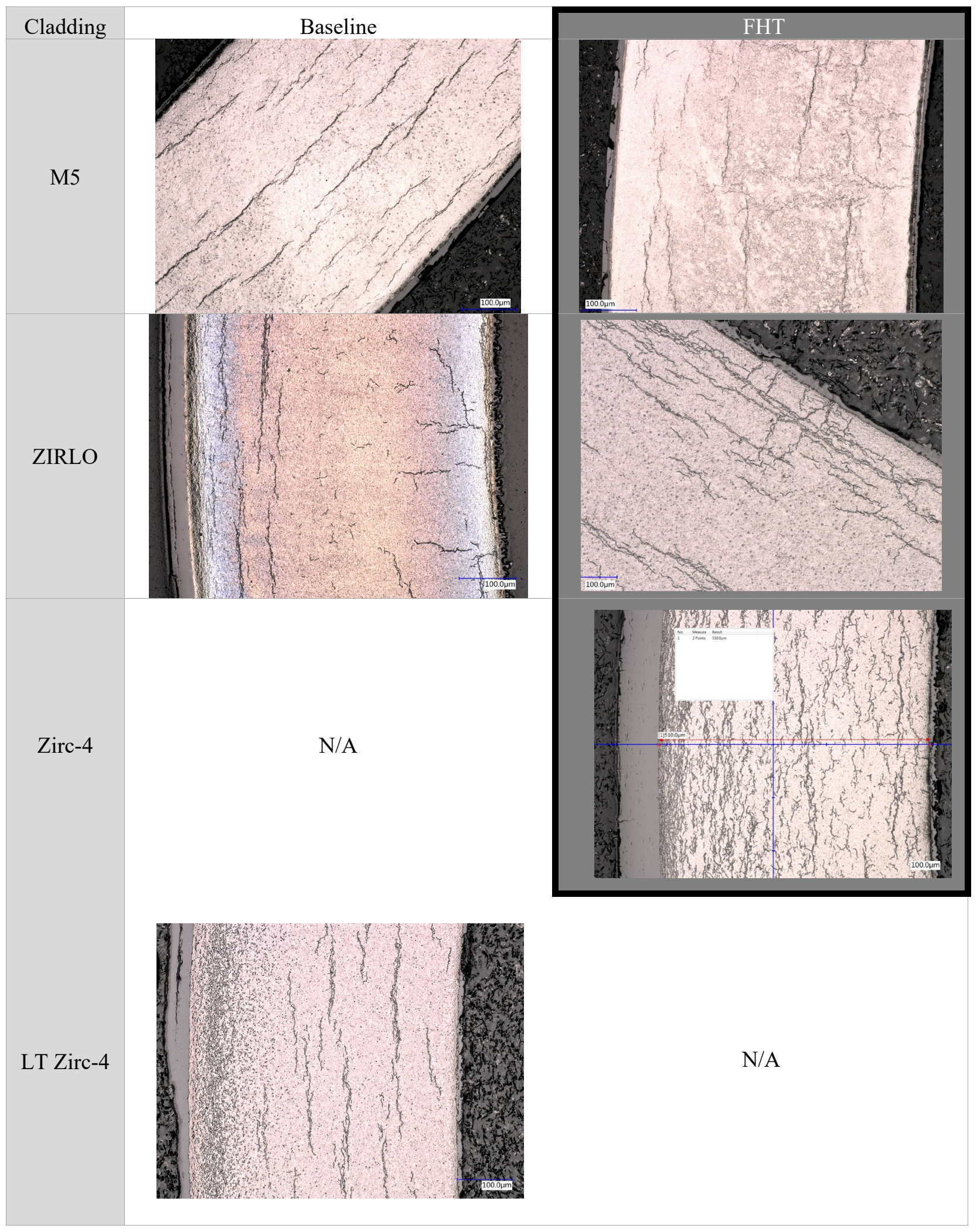

Figure 3. Selected METs illustrating primary hydride content and orientations for baseline and FHT sister rods. 




Figure 4. 3D8E14 at 1,403 mm elevation; pellet-pellet (a) gap measurements, (b) cropped axial section view and cross-sectional view locations, (c) cross-sectional view in the gap, and (d) crosssectional view of the pellet above the gap . 


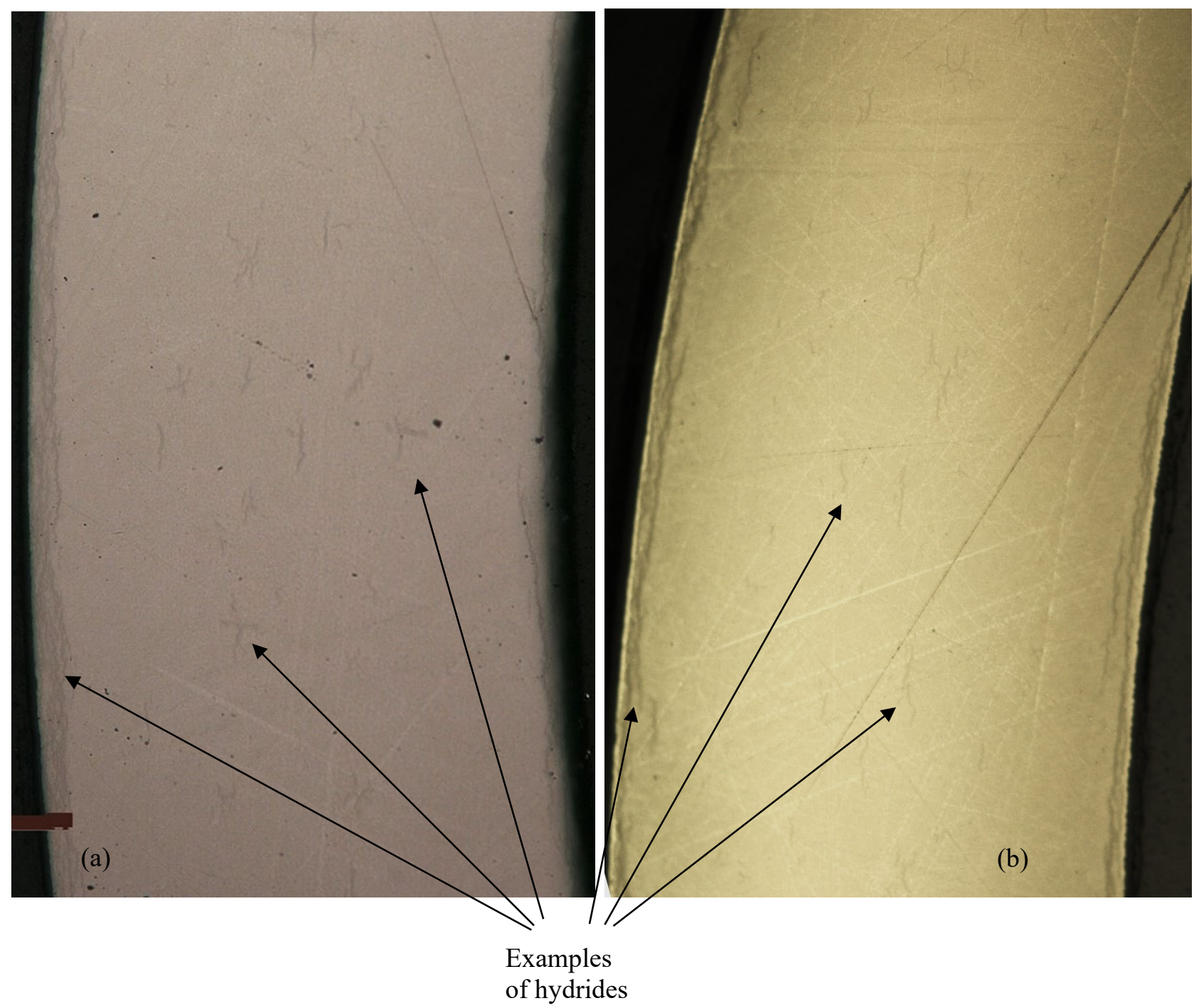

Figure 5. 3D8E14 centered at 1,403 mm elevation; cladding hydride distribution (a) in the gap and (b) below the gap in the pellet body. 


\section{Cladding Hydrogen Measurements}

The specimens for total cladding hydrogen analysis (DE.03) are being cut, defueled, and sectioned azimuthally into four quadrants to obtain a minimum sample size of $0.1 \mathrm{~g}$. The oxygen-nitrogen-hydrogen analyzer is being calibrated, and total cladding hydrogen measurements will begin in FY21. 
This page is intentionally left blank. 


\section{Rod Internal Pressure Measurement and Rod Void Volume Measurement}

Commercial nuclear fuel rods are pre-pressurized with helium before irradiation. The magnitude of prepressurization varies with fuel design; at manufacture, the sister rods were pre-pressurized between 1.7 and 2.5 $\mathrm{MPa}$, depending on their design. Each fuel rod includes a spring in a plenum at the top of the rod to provide a small compression load on the fuel pellet stack inside the rod, mainly to ensure that gaps between pellets do not occur. During irradiation and subsequent storage, the rod internal pressure increases due to the production of fission gases (e.g., xenon, krypton) and volumetric changes, resulting from swelling and irradiation growth. At manufacture, the rod includes spaces that are unoccupied by the fuel stack and spring, termed the void volume. The void volume changes during operation as the cladding creeps and grows due to irradiation and as cracks and porosity are formed within the pellets. For purposes of this discussion, the void volume is defined as including the volume in the plenum of the rod that is not occupied by the spring, the gap between the pellet OD and the cladding ID, the volume of any pellet chamfers and dishes, and the volume of pellet cracks and open porosity at the specified temperature. Because rod internal pressure and void volume are important parameters in determining rod performance throughout its lifetime, both were measured for each of the sister rods.

The gas pressure and void volume of a fuel rod was measured by puncturing the plenum region of the rod and using the ideal gas law in conjunction with known pressures and volumes, as described in Appendix C. The plenum end of the fuel rod is sealed into an evacuated housing of known volume (the "tare" volume). After puncture, the pressure in the housing was measured. Then, the gas was expanded into another chamber of known volume, and the new pressure was measured. This double expansion method allowed the rod's internal pressure and free internal volume to be determined. Once measurements were completed, the housing and now-accessible free rod volume were evacuated and backfilled with a known volume and pressure of gas, and the final gas pressure was measured. This process allowed a second two-step measurement of the rod's void volume and a second calculation for the rod's internal pressure. Appendix C discusses the design of the puncture system, system testing, experimental uncertainties, data analysis techniques, and many other important considerations in the highly sensitive measurement system used in the ORNL IFEL hot cell. The Phase 1 rod measurements, detailed data analysis, and comparisons with historical data are also provided in Appendix C.

The results of the rod internal pressure and void volume measurements for the eight sister rods punctured to date are summarized in Table 3 along with the $2 \sigma$ uncertainty. The rod puncture left a very small hole in the plenum region of the rod, estimated to be less than $0.5 \mathrm{~mm}$ in diameter. The sister rod internal pressure is within the envelope of the available previous data [6] and is consistent with measurements of the 10 sister rods measured at Pacific Northwest National Laboratory (PNNL) [7]. Likewise, the sister rod measured void volumes are within the extents of past measurements [6] and are consistent with the sister rod measurements completed by PNNL [7]. The measured sister rod internal pressures are lower than four available data points for Westinghouse $17 \times 17$ rods that were fabricated with an Integral Fuel Burnable Absorber (IFBA) coating ${ }^{2}$ on the fuel pellets [8]. None of the sister rods had IFBA coatings, but otherwise the IFBA rods are very similar to the sister rods. The FHT Zirc-4-clad sister rod, F35P17, was expected to

\footnotetext{
${ }^{2}$ The coating is typically a thin layer of zirconium diboride on the OD of the pellets that is used for reactor reactivity control during reactor operation.
} 
be atypical because it was operated to HBU for four cycles as a lead test rod, but the measured results are well within the bounds of the previous data. The results are plotted with other available data in Figure 6.

Table 3. Results of rod internal pressure and void volume measurements at $25^{\circ} \mathrm{C}$.

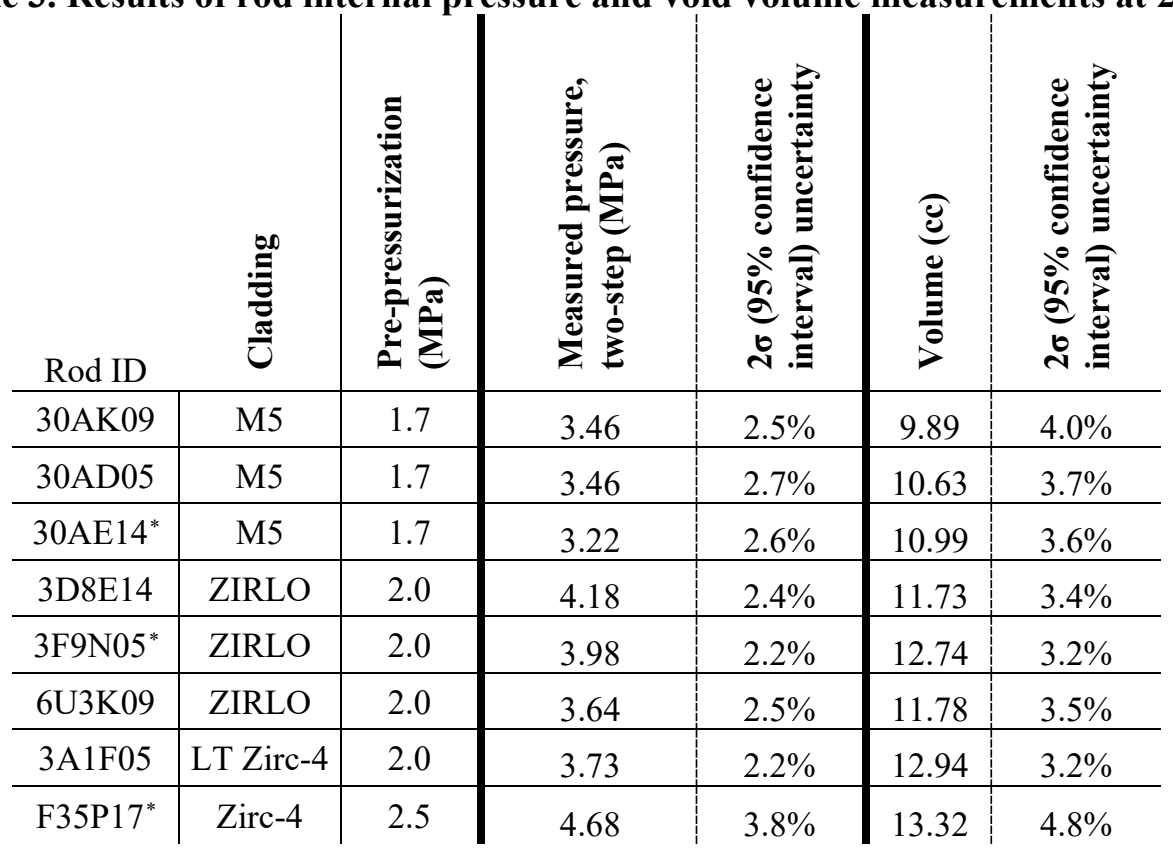

* The rod was heat-treated, as described in Section 3.

The calculated partial pressure of the fission gas (i.e., the measured rod internal pressure minus the rod design pre-pressurization as adjusted for the change in void volume) with rod average burnup yields similar information, indicating a strong uptick in void volume fission gas pressure between 50 and $60 \mathrm{GWd} / \mathrm{MTU}$. The rod internal pressure and rod void volume are specific to each vendor design/cladding type. For example, the Framatome-designed rods are consistent with each other and the Westinghouse ZIRLO rods are consistent with each other, and there is a strong correlation between the end-of-life and beginning-oflife pressures $\left(\mathrm{R}^{2}>0.6\right)$. Other parameters - such as the rod average burnup, assembly duty, average fuel temperature, and maximum fuel temperature - are not as strongly correlated $\left(0.4<\mathrm{R}^{2}<0.6\right)$. This is likely due to the lack of a variety within the sister rods with respect to those parameters. The range of burnup within the group of rods is small, the dataset is small, and - considering measurement uncertainties and inaccuracies in available rod design and operational data-correlations with these parameters are not conclusive. When considering only the fission gas partial pressure, the design and operational data are correlated at about the same quality $\left(\mathrm{R}^{2} \approx 0.4\right)$. More operating data for rods at other conditions are required to further correlate the measured pressure and volume data within the context of power operation.

As a further comparison point, the product of the fission gas partial pressure and volume $\left(P_{f} V\right)$ was examined because it tends to neutralize any lab-specific biases in the available data. The $P_{f} V$ is relatively consistent for all Phase 1 sister rods, except for a single data point: the Zirc-4-clad rod that was punctured in the pellet stack, F35K13 [7]. The sister rod data are consistent with the historical database, including a change in slope occurring between 50 and $60 \mathrm{GWd} / \mathrm{MTU}$. 


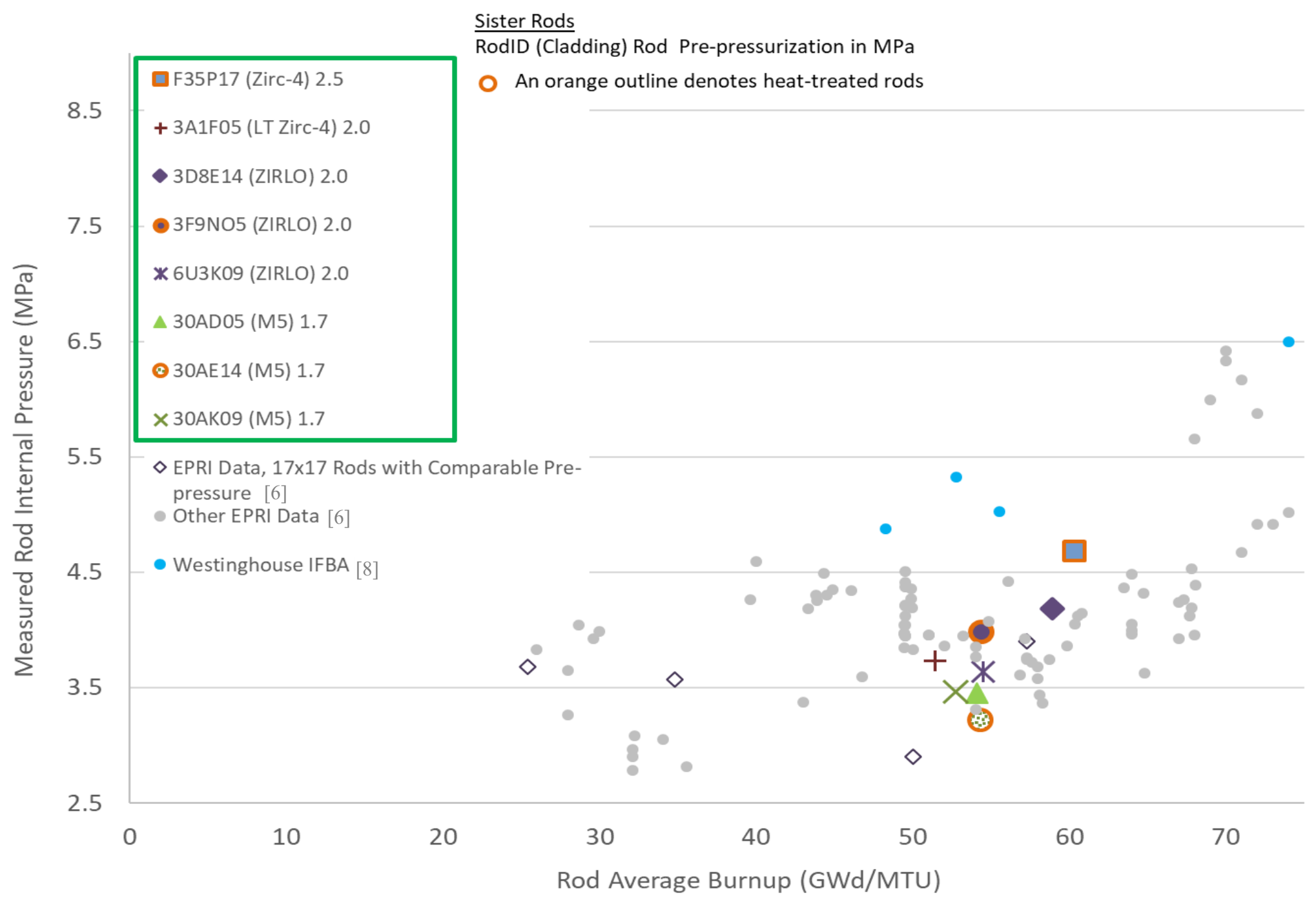

Figure 6. Sister rod measured rod internal Pressure at $25^{\circ} \mathrm{C}$. 


\subsection{Effect of FHT on Rod Internal Pressure and Void Volume}

Comparisons of the measured rod internal pressure and void volume can provide some information about the effects, if any, of the heat treatments performed on three of the sister rods. For the ZIRLO-clad rods, the FHT rod has a higher void volume and a higher internal pressure than the corresponding baseline. Evaluating the measured pressure and void volume data independently of other data reported herein and considering the measurement uncertainty and expected variation in rod internal pressure and void volume related to operational differences, the difference between the baseline and FHT rod measurement results are unlikely to be statistically different.

However, based on comparisons of the $P_{f} V$ for all ZIRLO Phase 1 rods, there is evidence that the FHT 3F9N05 sister rod is different from the baseline rods, and there could have been an effect on either void volume or fission gas partial pressure related to the FHT.

When the same information is evaluated for the Phase 1 M5-clad sister rods, no effects related to FHT are evident. The M5 FHT rod had a higher void volume and lower pressure than the M5 baseline rods, but they are nearly within measurement uncertainty of each other.

To determine whether the heat treatment of the Zirc-4-clad rod made a difference in the rod internal pressure and void volume, it is preferable to compare the results with the baseline Zirc-4 rod measured by PNNL. The void volume measured by PNNL on the baseline Zirc- 4 rod is $\sim 0.7 \mathrm{cc}$ lower than that measured by ORNL on the FHT rod, which is almost within the ORNL $2 \sigma$ volume measurement uncertainty of $0.5 \mathrm{cc}$. The rod internal pressure measured by PNNL for the baseline Zirc-4 rod is $\sim 12 \%$ higher than that measured by ORNL for the FHT rod. PNNL's measurements of that rod were obtained from the bottom of the fuel rod in the pellet stack. Other than the PNNL Zirc-4-clad rod, the closest comparable baseline sister rod is a LT Zirc-4-clad rod. The void volumes of the FHT Zirc-4 rod and the baseline LT Zirc-4 rod are within measurement uncertainty of each other, but the FHT Zirc-4 rod pressure is significantly higher than the baseline LT Zirc-4 rod. The pre-pressure of the Zirc-4 rod was $0.5 \mathrm{MPa}$ higher than the LT Zirc-4, but this does not account for the almost $1 \mathrm{MPa}$ difference observed in the rods' end-of-life rod internal pressures. Although the Zirc-4 and LT Zirc-4 rods are very similar, differences in the rods' mechanical designs could result in different end-of-life pressures and void volumes. Also, as mentioned previously, the Zirc-4 rod was a lead test rod operated to HBU over four cycles, whereas the LT Zirc-4 rod was part of a typical batch fuel assembly operated over two cycles. Given these differences and based only on a comparison of the rod internal pressure and void volume data, it is unclear whether there was an effect related to the heat treatments on the Zirc-4-clad rod.

\subsection{Comparisons with Code Predictions}

As listed in Table 4, blind predictions of the sister rod internal pressure and void volume were made by Geelhood [9] using the FAST code and by Stimpson [10] using BISON. The two codes represent two different approaches in fuel rod modeling with FAST providing models that are highly calibrated to a large body of empirical data and BISON operating through a more general first principles approach. This section compares the two predictions with the measured data.

BISON generally overpredicted pressure, whereas FAST underpredicted it. FAST pressure predictions for the ZIRLO-clad $6 \mathrm{U} 3$ rods were within $\pm 5 \%$ of measured pressure, but other ZIRLO-clad rods from assembly $3 \mathrm{~F} 9$ and $3 \mathrm{D} 8$ were within $-25 \%$ of measured pressure. FAST underpredicted all the M5-clad rods with differences between -13 and $-28 \%$. The LT Zirc-4 rod pressure was also underpredicted (-18\%), and FAST underpredicted the Zirc-4 rods (-15 and -25\%). The average difference between the FAST pressure prediction and the measured value is $-14 \%$. Although the FAST code appeared to produce more accurate pressure predictions for ZIRLO-clad sister rods, the BISON predictions did not appear to have a trend 
related to the cladding alloy. The BISON pressure prediction difference from measured ranged from +10 to $+81 \%$ with an average difference of $+40 \%$. Five BISON rod simulations did not converge [10].

BISON underpredicted rod void volume, whereas FAST overpredicted it most of the time. As with pressure, the FAST void volume predictions for ZIRLO-clad rods from assembly $6 \mathrm{U} 3$ were more accurate than the predictions for other sister rods with the average difference ranging from 0 to $+14 \%$. Other than the trend noted for the $6 \mathrm{U} 3$ rods, there did not appear to be a cladding alloy-related trend within the FAST void volume predictions. The average difference from measured void volume for the FAST predictions was $+20 \%$. The BISON void volume prediction average difference from measured was $-37 \%$. The BISON void volume trends appeared relatively insensitive, producing nearly the same void volume for all rods.

The product of the rod internal pressure and void volume (PV) provides an additional metric to compare the measured rod data with the code predictions. When considering PV, the FAST prediction difference from measured ranged from -14 to $+18 \%$ with an average difference of $2 \%$. For the BISON predictions, the difference from $P_{m} V_{m}$ ranged from $+16 \%$ to $-26 \%$ with an average difference of $-11 \%$.

When fission gas release is available for the sister rod measurements, it would be useful to compare it with the predicted fission gas release. Other operating data could be reviewed in a similar fashion to determine whether the improved modeling of a single parameter or a group of parameters can increase the accuracy of the internal pressure and void volume predictions.

Finally, to provide an additional viewpoint on whether the heat treatments applied to three of the sister rods resulted in a change of the rod internal pressure or void volume, the predictions were compared with ORNL's measurements. The variations from rod to rod that were measured are consistent with variations predicted by FAST. An additional FAST calculation was completed to simulate the applied sister rod heat treatments, and there was no change to the predicted fission gas release resulting from the short time at $400^{\circ} \mathrm{C}$. There does not appear to be a consistent pattern when comparing the BISON results with the measured results, and two of the BISON simulations for the rods graphed did not converge.

Additional discussion and graphs comparing the predicted vs. measured results are provided in Appendix C. 
Table 4. Summary of measured and predicted rod internal pressure and void volume.

\begin{tabular}{|c|c|c|c|c|c|c|c|c|}
\hline Rod ID & $\begin{array}{c}\text { Cladding } \\
\text { type }\end{array}$ & $\begin{array}{c}\text { Average } \\
\text { rod } \\
\text { burnup }\end{array}$ & $\begin{array}{c}\text { Measured } \\
\text { rod } \\
\text { internal } \\
\text { pressure } \\
\text { (MPa) }\end{array}$ & $\begin{array}{l}\text { Measured } \\
\text { void } \\
\text { volume } \\
\text { (cc) }\end{array}$ & $\begin{array}{c}\text { FAST } \\
\text { predicted } \\
{[9] \text { rod }} \\
\text { internal } \\
\text { pressure } \\
(\mathrm{MPa}) \\
\end{array}$ & $\begin{array}{c}\text { Fast } \\
\text { predicted } \\
\text { [9] void } \\
\text { volume } \\
\text { (cc) }\end{array}$ & $\begin{array}{c}\text { BISON } \\
\text { predicted } \\
{[10] \text { rod }} \\
\text { internal } \\
\text { pressure } \\
(\mathrm{MPa}) \\
\end{array}$ & $\begin{array}{l}\text { BISON } \\
\text { predicted } \\
{[10] \text { void }} \\
\text { volume } \\
\text { (cc) }\end{array}$ \\
\hline 30AD05 & M5 & 54 & 3.46 & 10.63 & 2.82 & 13.48 & 4.96 & 7.42 \\
\hline 30AE14 & M5 & 54 & 3.22 & 10.99 & 2.82 & 13.50 & 5.06 & 7.44 \\
\hline 30AK09 & M5 & 53 & 3.46 & 9.89 & 2.82 & 13.26 & 4.50 & 7.34 \\
\hline $\begin{array}{c}\text { 30AP02 } \\
{[7]}\end{array}$ & M5 & 49 & 3.36 & 10.8 & 2.80 & 12.85 & 3.69 & 7.40 \\
\hline $\begin{array}{c}5 \mathrm{~K} 7 \mathrm{C} 05 \\
{[7]}\end{array}$ & M5 & 57 & 3.97 & 9.7 & 3.11 & 14.61 & $\begin{array}{l}\text { No result } \\
\text { reported }\end{array}$ & $\begin{array}{l}\text { No result } \\
\text { reported }\end{array}$ \\
\hline $\begin{array}{c}\text { 5K7K09 } \\
{[7]}\end{array}$ & M5 & 54 & 3.79 & 10.5 & 2.72 & 13.96 & 5.82 & 7.55 \\
\hline $\begin{array}{c}\text { 5K7P02 } \\
{[7]}\end{array}$ & M5 & 51 & 3.35 & 11.2 & 2.73 & 13.43 & 4.53 & 7.39 \\
\hline 3D8E14 & ZIRLO & 59 & 4.18 & 11.73 & 3.19 & 15.28 & 7.56 & 7.51 \\
\hline 3F9N05 & ZIRLO & 54 & 3.98 & 12.74 & 3.46 & 14.76 & $\begin{array}{l}\text { No result } \\
\text { reported }\end{array}$ & $\begin{array}{l}\text { No result } \\
\text { reported }\end{array}$ \\
\hline $\begin{array}{c}\text { 3F9P02 } \\
{[7]}\end{array}$ & ZIRLO & 49 & 3.44 & 12.8 & 3.28 & 13.45 & 5.36 & 7.15 \\
\hline 6U3K09 & ZIRLO & 55 & 3.64 & 11.78 & 3.47 & 13.41 & 4.56 & 7.10 \\
\hline $\begin{array}{c}\text { 6U3L08 } \\
\text { [7] }\end{array}$ & ZIRLO & 55 & 3.56 & 12.4 & 3.48 & 13.44 & 4.62 & 7.02 \\
\hline $\begin{array}{c}\text { 6U3M03 } \\
{[7]}\end{array}$ & ZIRLO & 57 & 3.72 & 11.9 & 3.53 & 13.57 & 4.95 & 6.97 \\
\hline $\begin{array}{c}6 \mathrm{U} 3 \mathrm{O} 05 \\
{[7]}\end{array}$ & ZIRLO & 58 & 3.70 & 12.7 & 3.55 & 13.61 & 5.07 & 6.96 \\
\hline $\begin{array}{c}\text { 6U3P16 } \\
\text { [7] }\end{array}$ & ZIRLO & 50 & 3.28 & 13.1 & 3.37 & 13.16 & 4.29 & 7.40 \\
\hline 3A1F05 & $\begin{array}{c}\text { LT Zirc- } \\
4\end{array}$ & 51 & 3.73 & 12.94 & 3.04 & 16.77 & $\begin{array}{l}\text { No result } \\
\text { reported }\end{array}$ & $\begin{array}{l}\text { No result } \\
\text { reported }\end{array}$ \\
\hline $\begin{array}{c}\text { F35K13 } \\
{[7]}\end{array}$ & Zirc-4 & 59 & 5.26 & 12.6 & 3.97 & 14.42 & $\begin{array}{c}\text { No result } \\
\text { reported }\end{array}$ & $\begin{array}{l}\text { No result } \\
\text { reported }\end{array}$ \\
\hline F35P17 & Zirc-4 & 60 & 4.68 & 13.32 & 3.99 & 14.55 & $\begin{array}{c}\text { No result } \\
\text { reported }\end{array}$ & $\begin{array}{c}\text { No result } \\
\text { reported }\end{array}$ \\
\hline
\end{tabular}




\section{Pellet Stack Gas Depressurization and Transmission Testing}

The typical design of pressurized water reactor (PWR) fuel rods includes a small gap between the pellet OD and the cladding ID and a plenum volume at the top of the fuel rod that provides void volume for the helium gas used to pre-pressurize the rods. In addition to the gap and plenum void volumes, the sister rods' pellets include chamfers and dishes, and those void volumes provide a relatively large reservoir throughout the pellet stack for pre-pressurization gas. At beginning-of-life, these relatively large void volumes provide an open pathway for gas transmission up to the onset of pellet-cladding interaction (PCI). By the end of the first cycle, cladding creep-down and pellet swelling tend to close the gap between the pellet OD and the cladding ID, and after PCI, gas transmission is restricted because the gap is no longer open. The amount of PCI varies axially. Local fission gas production and its release to the rod void volume are variable along the axial length of the rod because power, fluence, and fuel temperature vary radially and axially within the fuel rod.

However, as the rod is operated in the reactor, additional circulation paths through the pellet stack are developed, depending on local operating conditions. The process is somewhat stochastic and is related to thermal cycling of the fuel, crack development in the pellet due to thermal stresses, and crack self-healing. Once the fuel is discharged, the flow path becomes essentially fixed.

To characterize the ability for helium and fission gases to move through the pellet stack, gas transmission tests were performed. Appendix C discusses the general setup of ORNL's gas transmission and depressurization tests, provides a more detailed discussion of the measurement procedures, derives the methods used to correlate the data, and presents the detailed results of the sister rod measurements.

The results of the testing are summarized in Table 5. For the gas transmission tests, two sister rods were tested at three different pressures, and the time vs. pressure recorded is shown in Figure 7. At the pressures used in the transmission tests, the time response of the system was $\sim 30 \mathrm{~min}$ for one rod and $\sim 3 \mathrm{~h}$ for the other. Both rods demonstrated a clear correlation of gas transmission time with the applied pressure. The time vs. pressure recorded for the depressurization tests is shown in Figure 8. Although some rods took longer than others to depressurize, none took longer than $\sim 24 \mathrm{~h}$ to reach atmospheric pressure, demonstrating good communication along the pellet stack at room temperature (RT). All tests verified the ability of the argon gas used in the test to move through the pellet stack at RT.

The permeability of the pellet stack varied over less than one order of magnitude for this set of rods, which is modest and could indicate some common feature about HBU fuel. The average permeability for the HBU $17 \times 17$ PWR fuel rods is $4.25 \mathrm{e}-14 \mathrm{~m}^{2}$ using the Muskat-Poiseuille model. These are about $20 \%$ of that measured by Rondinella [11] and correlated using Darcy's Law at $2 \mathrm{e}-13 \mathrm{~m}^{2}$. If the average low-pressure Darcy porosity measured for the sister rods $\left(1.6 \mathrm{e}-13 \mathrm{~m}^{2}\right)$ is compared with Rondinella's results and if the same level of precision is applied, then the data are comparable. 3A1F05 (LT Zirc-4) and F35P17 (heattreated Zirc-4) have the largest permeability values. The variance in the measurements is likely due to the wide variety of claddings, pellets designs, and operating histories. A higher permeability value means the gas moves more easily through the pellet stack. The permeability maintains a relatively constant value with pressure variation in the three rods on which the gas transmission test was repeated at varying starting pressures.

Evaluations of the data did not identify a close correlation of permeability with rod average burnup. The permeability is closely related to the rod manufacturer, indicating that the pellet manufacturing process and operating temperature determine the permeability of the pellet stack. Furthermore, the permeability data strongly indicate that an offset in the permeability could have resulted from the heat treatment. 
A natural extension of this work is to conduct the same tests at the fuel rod storage and transportation temperatures using a similar apparatus. Also, it would be prudent to measure gas transmissibility on rods that have been in dry storage for $\sim 10$ years to determine whether the flow paths have become restricted.

Table 5. Results of depressurization and transmission tests.

\begin{tabular}{|c|c|c|c|}
\hline \multirow[t]{2}{*}{ Rod } & \multirow{2}{*}{$\begin{array}{l}\text { Applied pressure } \\
\text { differential (MPa) }\end{array}$} & \multicolumn{2}{|c|}{$\begin{array}{l}\text { Muskat-Poiseuille permeability and } \\
\text { regression model coefficient of determination }\end{array}$} \\
\hline & & $\mathbf{K}\left(\mathbf{m}^{2}\right)$ & $\mathbf{R}^{2}$ \\
\hline \multirow{5}{*}{$3 \mathrm{~A} 1 \mathrm{~F} 05$} & 0.10 & $8.40 \mathrm{E}-14$ & 0.999 \\
\hline & 1.41 & 8.32E-14 & 0.999 \\
\hline & 2.17 & $8.32 \mathrm{E}-14$ & 1.000 \\
\hline & 2.89 & $8.23 \mathrm{E}-14$ & 1.000 \\
\hline & Average & $8.32 E-14$ & \\
\hline F35P17 & 0.10 & $9.96 \mathrm{E}-14$ & 0.999 \\
\hline 3F9N05 & 0.10 & 7.30E-14 & 0.999 \\
\hline 3D8E14 & 0.10 & $4.08 \mathrm{E}-14$ & 0.998 \\
\hline \multirow{4}{*}{ 6U3K09 } & 0.10 & $1.99 \mathrm{E}-14$ & 1.000 \\
\hline & 1.55 & $1.62 \mathrm{E}-14$ & 0.994 \\
\hline & 2.82 & $2.05 \mathrm{E}-14$ & 1.000 \\
\hline & Average & $1.89 E-14$ & \\
\hline \multirow{5}{*}{ 30AK09 } & 0.10 & $1.04 \mathrm{E}-14$ & 0.999 \\
\hline & 1.41 & $1.02 \mathrm{E}-14$ & 0.999 \\
\hline & 2.17 & $1.05 \mathrm{E}-14$ & 1.000 \\
\hline & 2.89 & $1.11 \mathrm{E}-14$ & 1.000 \\
\hline & Average & $1.06 E-14$ & \\
\hline $30 \mathrm{AD} 05$ & 0.10 & $1.15 \mathrm{E}-14$ & 1.000 \\
\hline $30 \mathrm{AE} 14$ & 0.10 & $2.40 \mathrm{E}-14$ & 1.000 \\
\hline$A$ & age of all & $4.25 E-14$ & \\
\hline
\end{tabular}




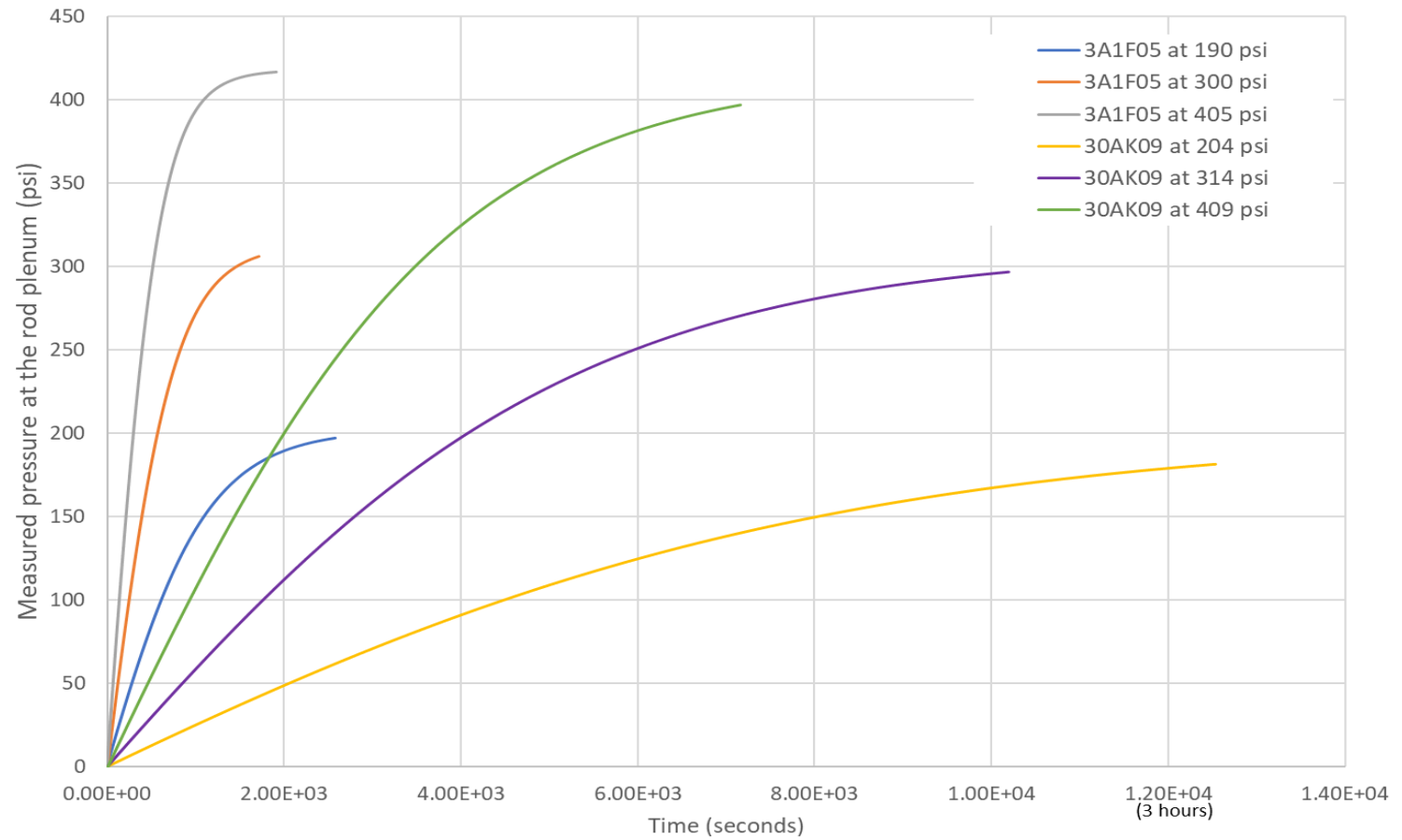

Figure 7. Results of gas transmission tests on two sister rods (three different pressures on each rod).

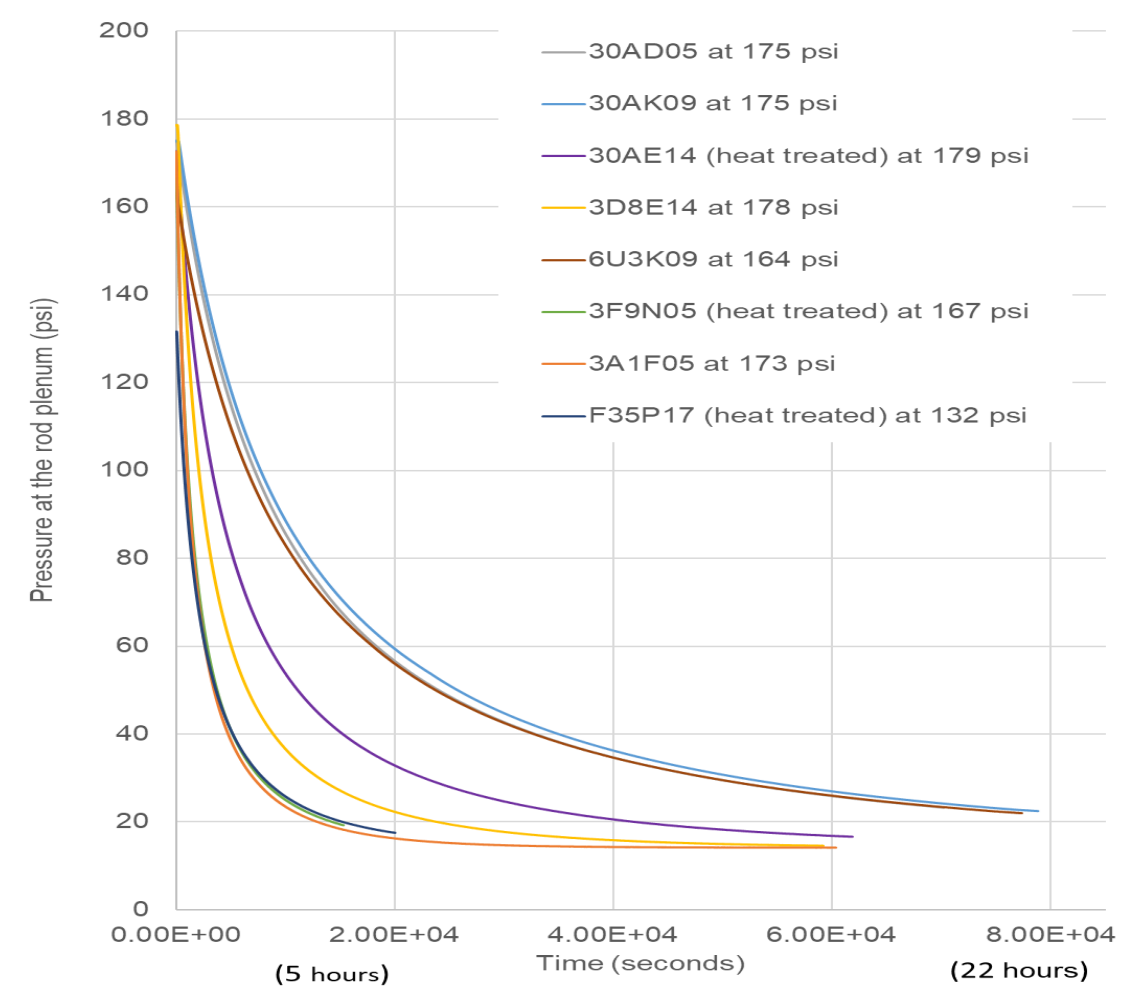

Figure 8. Results of the depressurization tests on eight sister rods (three rods were heat treated). 
This page is intentionally blank. 


\section{Fission Gas Sample Isotopic Composition and Calculated Fission Gas Release}

A fission gas sample was taken from each punctured sister rod. Gaseous fission products evolve in all $\mathrm{UO}_{2}$ nuclear fuel pellets at all axial elevations during reactor operation. They are located near the site of the fission, within the fuel grains, at a grain boundary, or at free surfaces on the pellet. The gaseous fission products form small bubbles within the pellet since the xenon and krypton gases produced are virtually insoluble in $\mathrm{UO}_{2}$. Although much of the fission gas remains trapped within the fuel pellet microstructure as porosity, some fraction of the fission gas is released to the interior void volume of the fuel rod and contributes to an increase in the fuel rod internal pressure.

According to the Electric Power Research Institute, less than 5\% of the fission gas produced in the pellet stack during normal operation is released to the rod void volume. The quantity of fission gas released from the pellet to the rod void volume during reactor operation has been the topic of much study because the gross rod pressure and localized rod pressure are important to rod performance during reactor transients, such as loss-of-coolant accidents and reactivity initiated accidents. The percentage of fission gas released is calculated as the moles of fission gas in the rod void volume divided by the total calculated fission gas produced during operation.

The eight sister rod fission gas samples were analyzed by the ORNL Nuclear Analytical Chemistry and Isotopic Laboratories group, and the details of the analysis are provided in Appendix D. Measured gas concentrations for the eight sister rod gas samples collected are provided in Table 6. Six of the sister rod samples were measured up to three times on nonconsecutive days, and the determined fission gas concentrations were averaged for those samples. The concentrations measured were determined by linear regression monitoring ${ }^{84} \mathrm{Kr}$ and ${ }^{132} \mathrm{Xe}$, which are naturally occurring isotopes present at 56.99 and 26.91 atom\%, respectively. The isotopic concentration in the sister rod samples was determined by measuring the current responses corresponding to the ${ }^{84} \mathrm{Kr}$ and ${ }^{132} \mathrm{Xe}$ isotopes and comparing those with the current response of the known concentration calibration standards. The total uncertainty values reported are the combined uncertainties of the duplicate measurements at a $95 \%$ level of confidence. The number of digits in the reported mole $\%$ and their uncertainties are provided for information and are not intended to convey a significant degree of reliability.

Based on inspection of Table 6, there is generally good agreement between the M5 rods and the LT Zirc-4 and Zirc-4 clad rods. However, per Table 6, one ZIRLO rod (6U3K09) appears to have about half the fission gas content (krypton and xenon) compared with two other ZIRLO rods that were measured at ORNL. When the PNNL sister rod data [7] are included in the dataset, as illustrated in Figure 9, 6U3K09 is clearly consistent with the remainder of the dataset, whereas the other two ORNL-measured ZIRLO rods are too high with the deviation not explained by measurement uncertainty. When all the data are plotted as a function of the independently measured fission gas partial pressure, the data are consistent, as shown in Figure 10, except for one Zirc-4 rod (F35K13), which is $\sim 1.4 \mathrm{MPa}$ above other sister rods. Based on Figure 10, the differences in the measured rod fission gas composition of the two ZIRLO-clad rods appear to be simply a consequence of higher fission gas release for those rods. Although not shown here, when xenon is graphed, the same trends are observed. Regardless of cladding alloy, all sister rods have a different operational duty. The source of higher fission gas release will be investigated once more detailed information on the measured rod burnup and predicted rod fission gas production are available.

The isotopic data reported in Table 7 and Table 8 include natural and fission product krypton and xenon isotopes. 
Table 6. Sister rod gas sample measured elemental composition, mole\%*.

\begin{tabular}{|c|c|c|c|c|c|c|c|c|c|c|c|c|}
\hline \multirow[b]{2}{*}{ Detected gas ${ }^{* *}$} & \multicolumn{12}{|c|}{ Sample ID } \\
\hline & \multicolumn{3}{|c|}{$\begin{array}{l}\text { 30AK09 (M5) } \\
\text { SR-Gr-02 }\end{array}$} & \multicolumn{3}{|c|}{$\begin{array}{l}\text { 30AD05 (M5) } \\
\text { SR-Gr-05 }\end{array}$} & \multicolumn{3}{|c|}{$\begin{array}{c}\text { 30AE14 (M5, heat } \\
\text { treated) } \\
\text { SR-Gr-06 }\end{array}$} & \multicolumn{3}{|c|}{$\begin{array}{l}\text { 3A1F05 (LT Zirc-4) } \\
\quad \text { SR-Gr-04 }\end{array}$} \\
\hline Krypton & 1.60 & & 0.15 & 1.41 & \pm & 0.19 & 1.45 & \pm & 0.22 & 1.97 & & \\
\hline Xenon & 15.31 & \pm & 1.33 & & \pm & & 14.11 & \pm & & 8.46 & \pm & \\
\hline Helium & .09 & \pm & 1.10 & & \pm & & 84.44 & \pm & 1.62 & 9.57 & \pm & \\
\hline & \multicolumn{12}{|c|}{ Sample ID } \\
\hline Detected gas ${ }^{* *}$ & \multicolumn{3}{|c|}{$\begin{array}{l}\text { 6U3K09 (ZIRLO) } \\
\text { SR-Gr-01 }\end{array}$} & \multicolumn{3}{|c|}{$\begin{array}{l}\text { 3D8E14 (ZIRLO) } \\
\text { SR-Gr-03 }\end{array}$} & \multicolumn{3}{|c|}{$\begin{array}{l}\text { 3F9N05 (ZIRLO, heat } \\
\text { treated) } \\
\text { SR-Gr-07 }\end{array}$} & \multicolumn{3}{|c|}{$\begin{array}{c}\text { F35P17 (Zirc-4, heat } \\
\text { treated) } \\
\text { SR-Gr-08 }\end{array}$} \\
\hline ryp & 1.11 & & 0.10 & 2.36 & & & 2.23 & \pm & 0.30 & 1.93 & \pm & \\
\hline & .45 & & 1. & & \pm & & 20.08 & \pm & & 19.8 & & \\
\hline Telium ${ }^{* * *}$ & 88.44 & \pm & 1.41 & 75.20 & \pm & 1.41 & 77.69 & \pm & 1.62 & 78.20 & \pm & 1.62 \\
\hline \multicolumn{13}{|c|}{$\begin{array}{l}\text { Reported uncertainties are the total combined uncertainties at the } 95 \% \text { level of confidence. Two decimal places are provided in } \\
\text { the reported values for information only and are not intended to imply a significant degree of reliability. The precision } \\
\text { contribution for samples } 01-06 \text { was the standard deviation of the values measured in August } 2018 \text { and September } 2018 \text {. Because } \\
\text { only a single dataset was measured for samples } 07 \text { and } 08 \text {, for conservatism, the precision contribution to the total uncertainty } \\
\text { for those data was taken as the worst-case scenario observed for samples } 01-06 \text {. }\end{array}$} \\
\hline \multicolumn{13}{|c|}{$\begin{array}{l}\text { ** Some residual air present in the sampling system were detected, and the resulting oxygen and nitrogen content was neglected } \\
\text { when determining the fission gas component percentages and FGR in the fuel rod (Table 9). }\end{array}$} \\
\hline
\end{tabular}

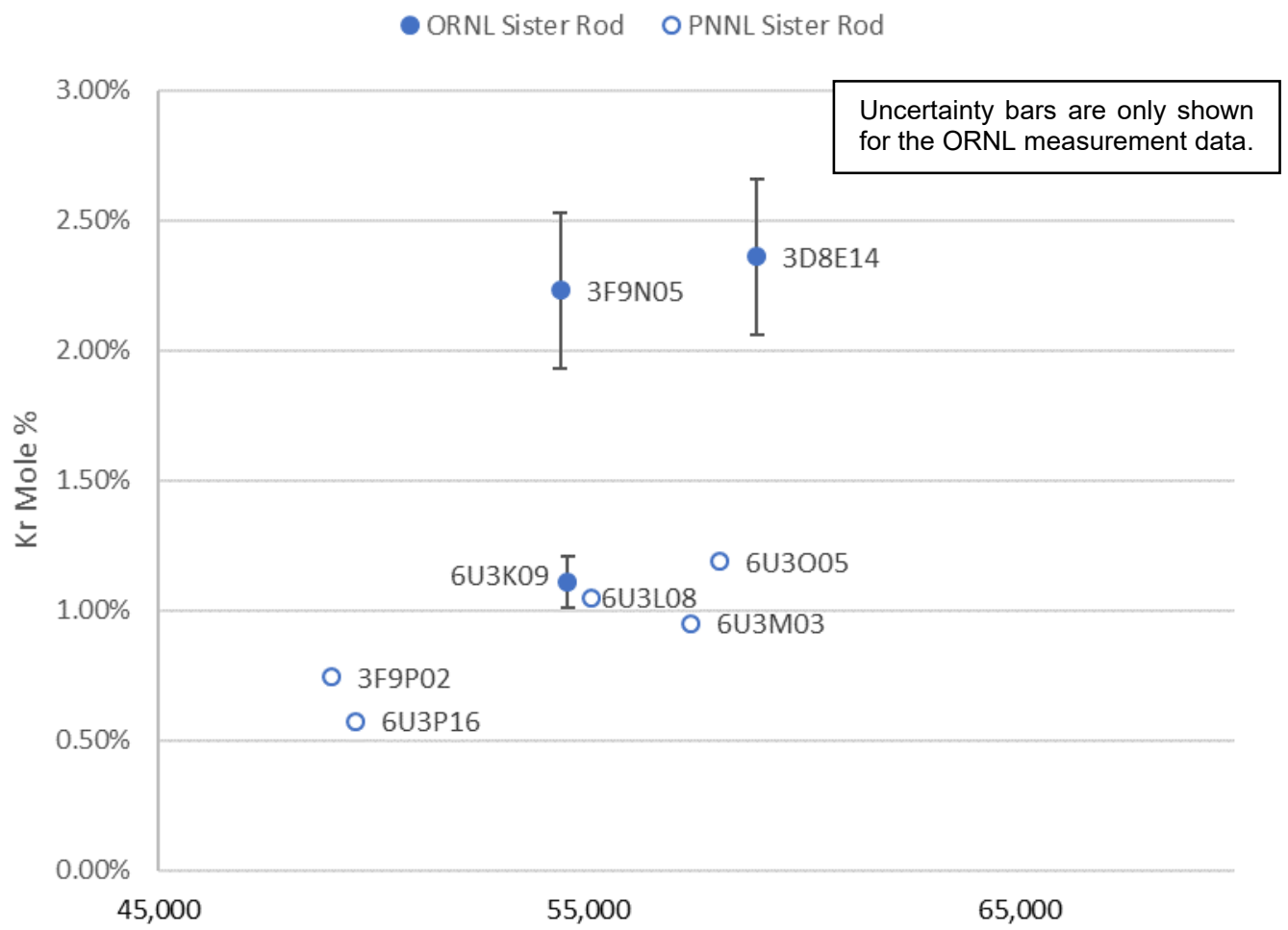

Average Rod Burnup

Figure 9. The measured krypton content of the rod fission gas for ZIRLO-clad sister rods. 


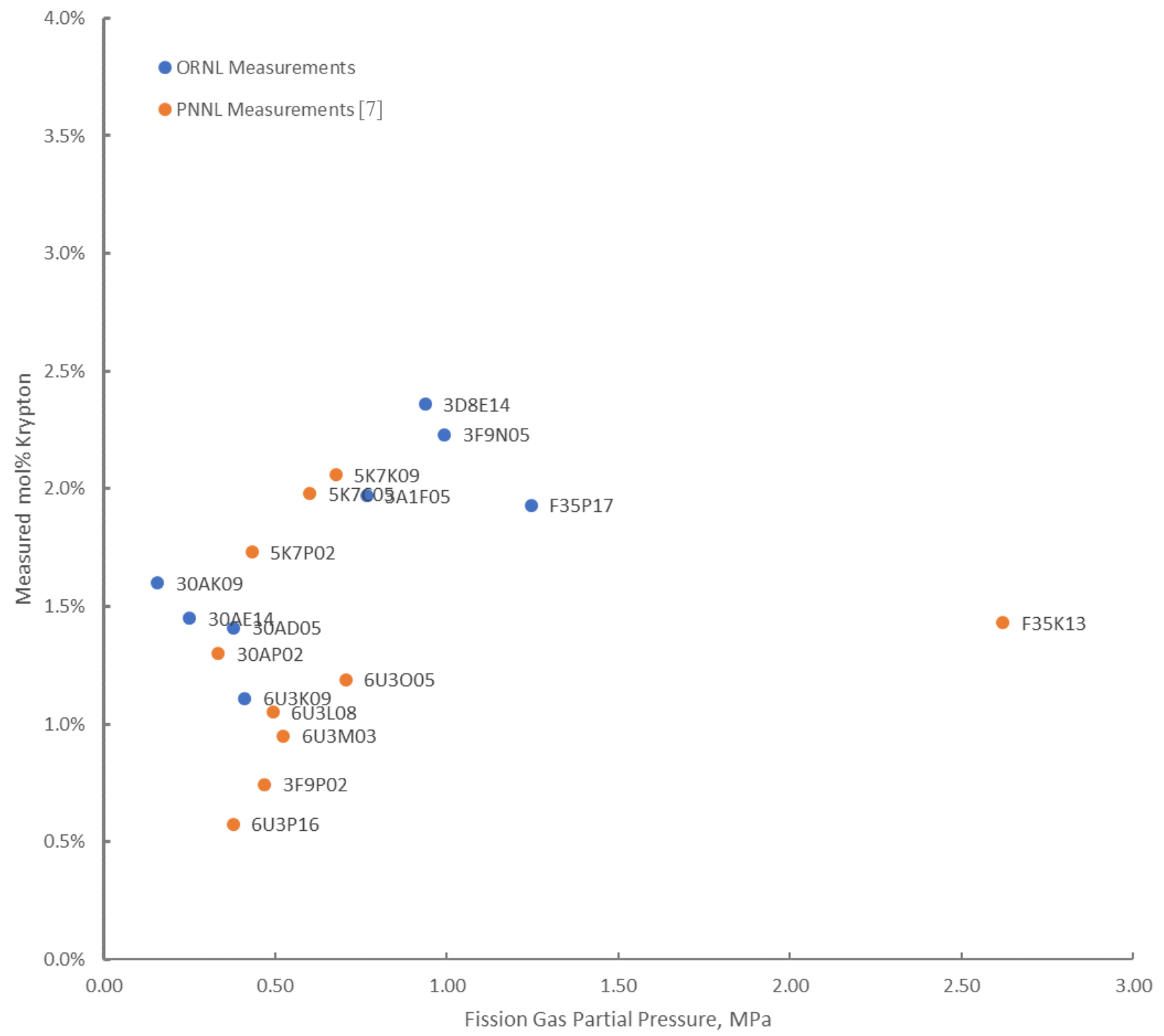

Figure 10. Measured krypton content of the rod fission gas as a function of the independently measured fission gas partial pressure. 
Table 7. Fission gas isotope ratios, atom\% ratio.

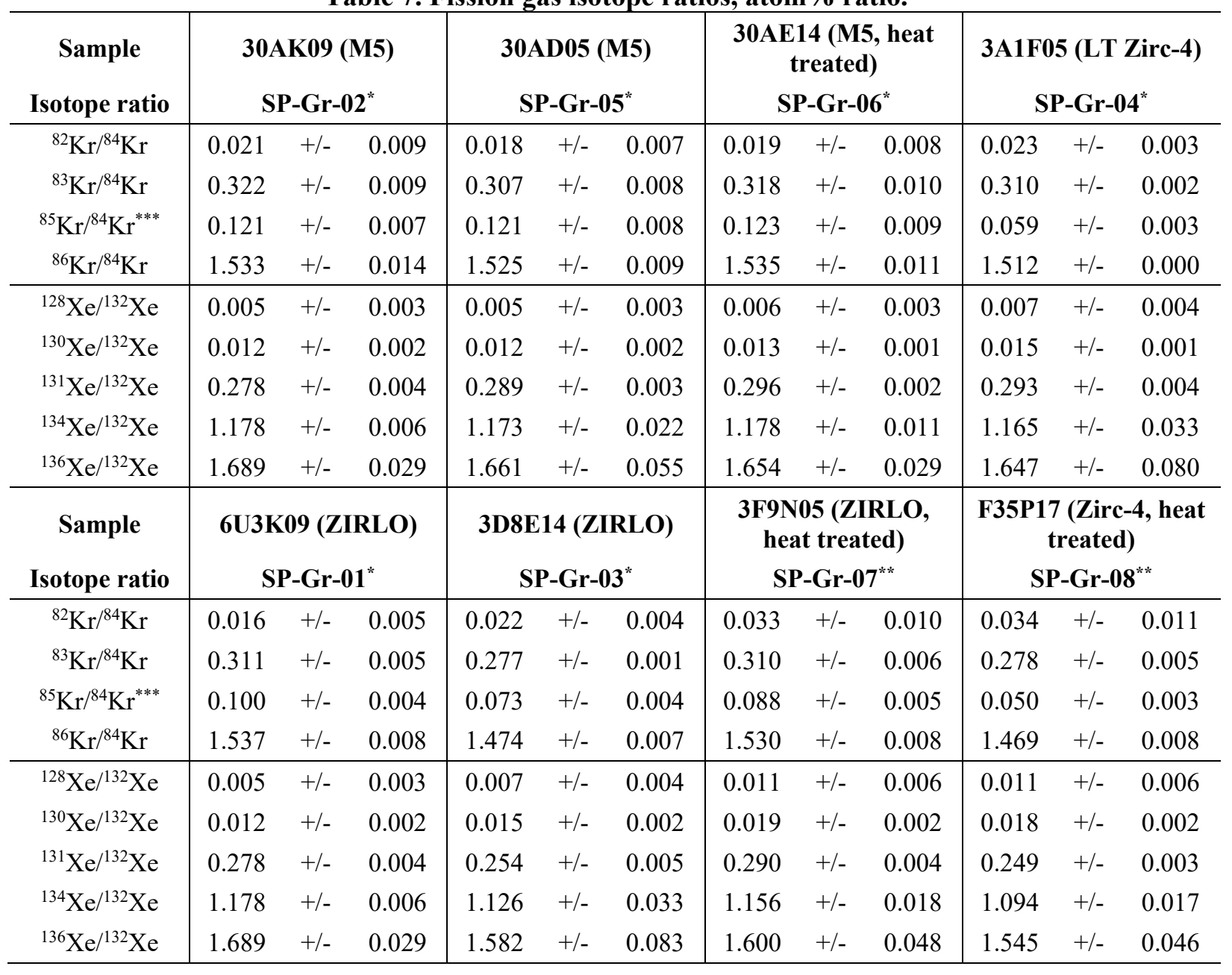

* Uncertainty for samples defined as a $1 \sigma$ external standard deviation of the replicate analyses (for 01,03 , and $04, n=2$; for 02 , 05 , and $06, n=4)$.

** For SP-Gr-07 and 08, only one replicate was performed; the assigned uncertainties are the averages of the other six samples.

${ }^{* * *} \quad{ }^{85} \mathrm{Kr}$ was decay-corrected to February 2019 in each case. 
Table 8. Fission gas isotopic composition, atom \%*.

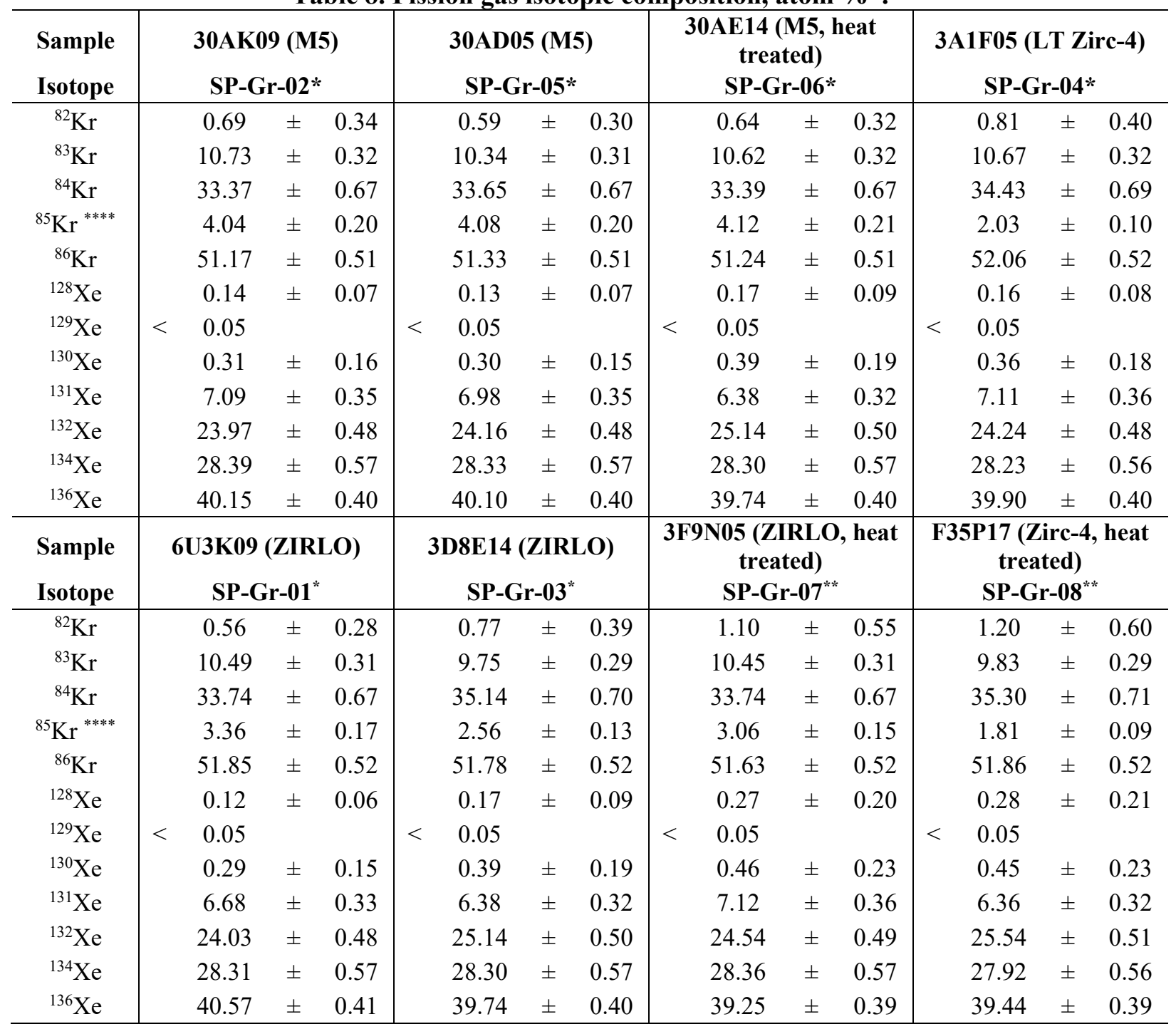

Reported numerical uncertainties are the $2 \sigma$ external standard deviation of all duplicate analyses. The last digit in the measurements and uncertainties is provided for information and is not intended to convey a significant degree of reliability. The accuracy of the analysis was confirmed using a NIST tracible standard, and a bias correction did not measurably alter the data within the uncertainty of the $2 \sigma$ standard deviation.

** SR-Gr-02, 05, and 06 also incorporate the uncertainty between two different modes of mass analysis, namely scanning electron microscopy, and Faraday.

*** For SR-Gr-07 and 08, only one replicate analyzed; for conservatism, the uncertainty attributed to those data was taken as the worst-case scenario observed for samples 01-06.

**** $\quad{ }^{85} \mathrm{Kr}$ was decay-corrected to February 2019 in each case. 
Table 9 provides the measured xenon-to-krypton ratio for the sister rod samples. The ratios are within the expected range. The xenon-to-krypton ratio was also evaluated to determine whether there was any additional xenon or krypton preferentially released as a result of the FHT performed on three of the sister rods. Based on the data available, if additional fission gas is released as result of the heat treatment, then it does not significantly affect the proportion of xenon to krypton released.

The predicted xenon-to-krypton ratio and the predicted fission gas production during operation are not yet available, so the calculated percentage of fission gas released from the pellets to the void volume of the rod (FGR) is not yet available. Once the predicted fission gas production is available, the FGR of the baseline and FHT rods will be compared to determine whether the heat treatment resulted in additional fission gas release to the rod void volume.

Table 9. Measured xenon-to-krypton ratio for the sister rods.

\begin{tabular}{ccc}
\hline Rod ID/condition & Cladding type & $\begin{array}{c}\text { Measured } \\
\text { xenon to krypton }\end{array}$ \\
\hline 30AK09/baseline & M5 & 9.6 \\
30AD05/baseline & M5 & 10.0 \\
30AE14/heat treated & M5 & 9.7 \\
6U3K09/baseline & ZIRLO & 9.4 \\
3D8E14/baseline & ZIRLO & 9.5 \\
3F9N05/heat treated & ZIRLO & 9.0 \\
3A1F05/baseline & LT Zirc-4 & 9.4 \\
F35P17/heat treated & Zirc-4 & 10.3 \\
\hline
\end{tabular}




\section{Fuel Burnup Measurements}

Three specimens were sent to the ORNL Radiochemical Engineering Development Center for chemical determination of burnup ( $\mathrm{Nd}, \mathrm{U}, \mathrm{Pu}$ only). Eight other specimens are being analyzed in more detail ( $\sim 51$ isotopes measured). The specimens cover the range of the Phase 1 sister rods that are being mechanically tested and will verify the code-predicted rod burnups and validity of the linear scaling of gamma scan profiles. Appendix D provides the details of the testing protocols.

To determine burnup, the sample results must be correlated to the initial uranium content, and this detailed modeling work is underway. Burnup measurement results are available for three samples and are provided in terms of $\mathrm{g} / \mathrm{gU}$ in Table 10.

Table 10. Chemical isotopic analysis (burnup only) of sister rod specimens.

\begin{tabular}{|c|c|c|c|c|c|c|}
\hline Project ID & \multicolumn{2}{|c|}{ 3D8E14-700-719 } & \multicolumn{2}{|c|}{ 3D8E14-3206-3225* } & \multicolumn{2}{|c|}{ 6U3K09-3506-3525 } \\
\hline $\begin{array}{l}\text { Specimen weight } \\
(\mathrm{g})\end{array}$ & \multicolumn{2}{|c|}{6.648} & \multicolumn{2}{|c|}{4.532} & \multicolumn{2}{|c|}{6.707} \\
\hline Units & g/gIHM & Uncertainty & $\mathbf{g} / \mathbf{g U}$ & Uncertainty & g/gIHM & Uncertainty \\
\hline $\begin{array}{l}\text { Nd (isotopics } \\
\text { over six runs) }\end{array}$ & $7.526 \mathrm{E}-03$ & 3.919E-05 & 7.724E-03 & $3.987 \mathrm{E}-05$ & $5.237 \mathrm{E}-03$ & $2.755 \mathrm{E}-05$ \\
\hline${ }^{124} \mathrm{Nd}$ wt $\%$ & $0.8687 \%$ & $0.0080 \%$ & $0.7634 \%$ & $0.0034 \%$ & $0.4903 \%$ & $0.0039 \%$ \\
\hline${ }^{143} \mathrm{Nd}$ wt $\%$ & $15.1330 \%$ & $0.0017 \%$ & $16.3629 \%$ & $0.0011 \%$ & $20.1298 \%$ & $0.0016 \%$ \\
\hline${ }^{144} \mathrm{Nd}$ wt $\%$ & $36.4023 \%$ & $0.0034 \%$ & $35.2676 \%$ & $0.0019 \%$ & $32.3057 \%$ & $0.0021 \%$ \\
\hline${ }^{145} \mathrm{Nd}$ wt $\%$ & $14.9920 \%$ & $0.0016 \%$ & $15.2970 \%$ & $0.0010 \%$ & $16.5945 \%$ & $0.0014 \%$ \\
\hline${ }^{146} \mathrm{Nd} w \mathrm{t} \%$ & $18.7087 \%$ & $0.0025 \%$ & $18.4323 \%$ & $0.0014 \%$ & $17.1489 \%$ & $0.0016 \%$ \\
\hline${ }^{148} \mathrm{Nd}$ wt $\%$ & $9.2956 \%$ & $0.0019 \%$ & $9.3012 \%$ & $0.0016 \%$ & $9.0248 \%$ & $0.0016 \%$ \\
\hline${ }^{150} \mathrm{Nd}$ wt $\%$ & $4.5996 \%$ & $0.0017 \%$ & $4.5756 \%$ & $0.0016 \%$ & $4.3059 \%$ & $0.0015 \%$ \\
\hline Units & g/gIHM & Uncertainty & g/gSoln & Uncertainty & g/gIHM & Uncertainty \\
\hline $\mathrm{U}$ & $9.150 \mathrm{E}-01$ & $3.235 \mathrm{E}-03$ & $3.424 \mathrm{E}-03$ & $0.342 \mathrm{E}-05$ & $9.418 \mathrm{E}-01$ & $1.561 \mathrm{E}-03$ \\
\hline${ }^{233} \mathrm{U}$ wt $\%$ & $0.0010 \%$ & NA & $0.0010 \%$ & NA & $0.0010 \%$ & NA \\
\hline${ }^{234} \mathrm{U}$ wt $\%$ & $0.0248 \%$ & $0.0002 \%$ & $0.0254 \%$ & $0.0002 \%$ & $0.0272 \%$ & $0.0003 \%$ \\
\hline${ }^{235} \mathrm{U}$ wt $\%$ & $0.4368 \%$ & $0.0005 \%$ & $0.5822 \%$ & $0.0007 \%$ & $1.3359 \%$ & $0.0016 \%$ \\
\hline${ }^{236} \mathrm{U}$ wt $\%$ & $0.6425 \%$ & $0.0066 \%$ & $0.6370 \%$ & $0.0066 \%$ & $0.5944 \%$ & $0.0061 \%$ \\
\hline${ }^{238} \mathrm{U}$ wt $\%$ & $98.8958 \%$ & $0.0066 \%$ & $98.7554 \%$ & $0.0066 \%$ & $98.0425 \%$ & $0.0063 \%$ \\
\hline Units & g/gU & Uncertainty & $\mathbf{g} / \mathbf{g U}$ & Uncertainty & $\mathbf{g} / \mathbf{g U}$ & Uncertainty \\
\hline $\begin{array}{l}\mathrm{Pu} \text { (isotopics } \\
\text { over six runs) }\end{array}$ & $1.119 \mathrm{E}-02$ & $1.976 \mathrm{E}-04$ & $1.276 \mathrm{E}-02$ & 4.890E-04 & $1.028 \mathrm{E}-02$ & $7.288 \mathrm{E}-05$ \\
\hline${ }^{238} \mathrm{Pu} \mathrm{wt} \%$ & $3.4261 \%$ & $0.0598 \%$ & $3.6434 \%$ & $0.2286 \%$ & $2.1232 \%$ & $0.0597 \%$ \\
\hline${ }^{239} \mathrm{Pu}$ wt $\%$ & $50.9118 \%$ & $0.1726 \%$ & $51.7021 \%$ & $0.9671 \%$ & $59.1770 \%$ & $0.4432 \%$ \\
\hline${ }^{240} \mathrm{Pu}$ wt $\%$ & $27.8080 \%$ & $0.1372 \%$ & $27.3843 \%$ & $0.8421 \%$ & $24.6114 \%$ & $0.4178 \%$ \\
\hline${ }^{241} \mathrm{Pu}$ wt $\%$ & $6.3293 \%$ & $0.1139 \%$ & $6.5196 \%$ & $0.2642 \%$ & $8.3739 \%$ & $0.1013 \%$ \\
\hline${ }^{242} \mathrm{Pu}$ wt $\%$ & $11.5248 \%$ & $0.1091 \%$ & $10.7505 \%$ & $0.3482 \%$ & $5.7145 \%$ & $0.0265 \%$ \\
\hline
\end{tabular}

* $\quad$ During the dissolution of sample 3D8E14-3206-3225, there was a loss of sample while filtering the final digested solution in the hot cell to remove undigested solids. At the time of loss, the solution was homogeneous; therefore, the ratio of ${ }^{148} \mathrm{Nd}$ burnup indicator to uranium and plutonium was not compromised. So, for this sample, burnup was calculated using total atom ratios in the final solution vs. the pellet as-is convention. Performing the calculation in this manner does not affect the results, and the final results are considered accurate. 
This page is intentionally blank. 


\section{CIRFT Testing}

SNF assemblies must be shipped to other sites for processing and disposal. During shipment, the fuel is typically oriented horizontally, and the fuel rods are subject to periodic alternating loads related to the movement of the vehicle that result in the alternating bending of the SNF fuel rods. The number of bending cycles is related to the length of the shipping route with longer routes producing more cycles. Since it is well-known that cyclic loads can produce failures even when the stress and strain imposed are below the yield point of the material, it is prudent to investigate the SNF fatigue behavior.

Wang et al. $[12,13]$ developed a method for SNF fatigue testing segments called the CIRFT. CIRFT (DE.05) has been used to test several sister rod specimens. Appendix F summarizes the test method, data collected during the test, and results of previous tests. Appendix F also provides a detailed documentation and discussion of the results of tests performed on sister rod specimens.

In Phase 1 of the sister rod test program, seven of ORNL's 15 sister rods were selected for paired testing: one baseline fuel rod and one FHT fuel rod of each cladding type-M5, ZIRLO, and Zirc-4/LT-Zirc-4)plus an extra ZIRLO-clad rod for additional data points since no ZIRLO-clad rods were tested in previous campaigns. The results from the FHT rods were compared with the results from the baseline rods to determine whether the fatigue lifetime is affected by dry storage thermal transients, and the results for the ZIRLO-clad rods are inspected to determine whether they are consistent with the results for rods clad with other alloys.

Twenty-five dynamic and six static CIRFT tests were performed using sister rod specimens, and one specimen slated for dynamic testing is yet to be tested. One data point that had erratic load cell data was thrown out. The results are tabulated in Table 11 with paired specimens shown together for easy comparison. Averages are provided for burnup, cycles to failure, strain, and flexural rigidity for comparison purposes. The results are consistent with previous data for the same size of fuel rods $(17 \times 17)$, as shown in Figure 11, although when trended with stress amplitude, as shown in Figure 12, the sister rod fatigue lifetimes appear to be on the lower side of other lifetime estimates, and some data are below the fatigue limit estimates $[14,15]$.

Flexural rigidity is measured during the dynamic test at the specific test conditions. The results of the average dynamic flexural rigidity measurements are provided in Table 10. Although there is a mild trend of CIRFT-measured flexural rigidity with burnup, when considered with previous CIRFT data, it appears rigidity could also be relatively constant with burnup. The flexural rigidity of the specimen changes over the duration of the CIRFT test; a rod subjected to many bending cycles is expected to have a lower flexural rigidity than an uncycled rod, especially at large applied moments.

For the M5-clad and ZIRLO-clad segments, the FHT rods generally have a shorter fatigue lifetime and lower flexural rigidity than the corresponding baseline specimens, as shown in Figure 13. There are at least three potential sources for a reduction in flexural rigidity with heat treatment: (1) a permanent increase in cladding OD and the pellet-cladding gap that resulted from the increased pressure at temperature during the heat treatment, (2) the annealing of irradiation defects resulting from the heat treatment, and (3) the reorientation of precipitated hydrides in the cladding during the heat treatment that make it more susceptible to cladding fracture. Since hydride reorientation was not observed for all FHT rods, the difference in flexural rigidity and fatigue lifetime is unlikely related to hydride reorientation. Also, the primary stresses during bending are in the axial direction, and failure is not expected to be significantly influenced by the direction of precipitated hydrides. However, some irradiation defect annealing could have occurred during the heat treatment, particularly on the M5-clad rod, as shown in Appendix A. This resulted in a lower overall rigidity of the FHT rod and a shorter fatigue lifetime at similar applied bending moments because a larger deflection of the specimen is imposed at lower flexural rigidity. A comparison between the LT Zirc-4-clad baseline and the Zirc-4-clad FHT specimen flexural rigidity is not valid due to the differences in operation of the reactor rods. 
One specimen with visible GTRF marks was tested with the marks aligned (as possible) with the point of the peak rod deflection (expected to be the highest cladding strain location), and the GTRF marks did not reduce the fatigue lifetime. The GTRF marks on this specimen are not considered representative or bounding; the specimen was selected based on availability only, and further tests should be completed to fully explore the effect.

The fractured CIRFT specimens were imaged, and all photos are provided in Appendix F. Typical views of the different fracture observations are provided in Figure 14. There is no visible difference in the fracture mode from baseline to FHT rods. The specimens with fatigue lifetimes lower than other data did not fracture in an anomalous manner. The F35P17 Zirc-4-clad rods seemed to fracture in a more brittle mode than the other specimens with deeper tearing of the cladding across the pellet body.

Equipment for performing the cumulative shock tests has been developed and was tested out-of-cell. The physical testing and finite element analysis performed, as discussed in Appendix F, indicate that delivering a shock to a CIRFT specimen mounted in a dogbone yields too high an impact load. If cumulative effects tests will be completed, then a different application fixture must be researched.

The simulation of flexural rigidity, pellet-pellet bonding, and pellet-clad bonding is underway to better understand test results and provide prediction capability. 
Table 11. Results arranged by paired specimens (baseline vs. FHT) for static/dynamic and dynamic CIRFT.

\begin{tabular}{|c|c|c|c|c|c|c|c|c|c|c|c|c|c|c|}
\hline \multicolumn{8}{|c|}{ Baseline rods } & \multicolumn{7}{|c|}{ FHT rods } \\
\hline \multicolumn{3}{|c|}{ Specimen ID } & $\begin{array}{c}\text { Cladding } \\
\text { type }\end{array}$ & $\begin{array}{c}\text { Estimated } \\
\text { specimen } \\
\text { average } \\
\text { burnup } \\
\text { (GWd/MTU) }\end{array}$ & $\begin{array}{c}\text { Cycles to } \\
\text { failure }\end{array}$ & $\begin{array}{c}\text { Flexural } \\
\text { rigidity } \\
\left(\mathrm{N}-\mathbf{m}^{2}\right)\end{array}$ & $\begin{array}{c}\text { Applied } \\
\text { strain } \\
\text { amplitude } \\
(\%)\end{array}$ & \multicolumn{2}{|c|}{ Specimen ID } & $\begin{array}{c}\text { Cladding } \\
\text { type }\end{array}$ & $\begin{array}{c}\text { Estimated } \\
\text { specimen } \\
\text { average } \\
\text { burnup } \\
\text { (GWd/MTU) } \\
\end{array}$ & $\begin{array}{l}\text { Cycles to } \\
\text { failure }\end{array}$ & $\begin{array}{c}\text { Flexural } \\
\text { rigidity } \\
\left(\mathrm{N}-\mathrm{m}^{2}\right)\end{array}$ & $\begin{array}{c}\text { Applied } \\
\text { strain } \\
\text { amplitude } \\
\text { (\%) }\end{array}$ \\
\hline $30 \mathrm{AD} 05$ & 0697 & $0850^{*}$ & \multirow[t]{4}{*}{ M5 } & 58 & 3,368 & $28.35^{* *}$ & $0.21^{* *}$ & 30AE14 0672 & $0825^{*}$ & \multirow[t]{4}{*}{ M5 } & 56 & 1,630 & 20.48 & 0.36 \\
\hline 30AD05 & 2050 & 2203 & & 59 & 133,000 & 28.73 & 0.08 & 30AE14 3156 & 3309 & & 56 & 113,000 & 23.23 & 0.10 \\
\hline $30 \mathrm{AD} 05$ & 2630 & 2783 & & 59 & 22,300 & 27.97 & 0.18 & \multirow[t]{2}{*}{$30 \mathrm{AE} 142850$} & \multirow[t]{2}{*}{3003} & & 60 & 9,800 & 23.63 & 0.22 \\
\hline Average & & & & 59 & 52,889 & 28.35 & 0.13 & & & & 57 & 41,477 & 22.45 & 0.23 \\
\hline $3 \mathrm{~A} 1 \mathrm{~F} 05$ & 1853 & $2006^{*}$ & \multirow[t]{5}{*}{ LT Zirc-4 } & 56 & 1,300 & 19.34 & 0.39 & F35P17 1855 & $2008^{*}$ & \multirow[t]{5}{*}{ Zirc-4 } & 53 & 525 & $28.74^{* *}$ & $0.16^{* *}$ \\
\hline 3A1F05 & 3367 & 3520 & & 44 & 214,000 & 29.74 & 0.06 & F35P17 2027 & 2180 & & 52 & $1,340,000$ & 26.83 & 0.07 \\
\hline 3A1F05 & 2025 & 2178 & & 56 & 48,200 & 23.18 & 0.18 & & & & & & & \\
\hline $3 \mathrm{~A} 1 \mathrm{~F} 05$ & 3214 & 3367 & & 48 & 3,450 & 21.56 & 0.19 & \multirow{2}{*}{\multicolumn{2}{|c|}{ F35P17 $31593312^{* * *}$}} & & 47 & 773 & 30.66 & 0.15 \\
\hline Average & & & & 51 & 66,738 & 23.46 & 0.21 & & & & 51 & 447,099 & 28.75 & 0.11 \\
\hline 3D8E14 & 0719 & $0872^{*}$ & \multirow[t]{10}{*}{ ZIRLO } & 64 & 9,589 & $30.89^{* *}$ & $0.11^{* *}$ & & & \multirow{10}{*}{ ZIRLO } & & & & \\
\hline 3D8E14 & 2412 & $2565^{* * * *}$ & & 64 & 191,000 & 31.31 & 0.08 & & & & & & & \\
\hline 3D8E14 & 2963 & 3116 & & 62 & 39,700 & 28.06 & 0.15 & & & & & & & \\
\hline 3D8E14 & 1178 & 1331 & & 63 & 212,000 & 30.94 & 0.08 & & & & & & & \\
\hline 6U3K09 & 2310 & 2463 & & 59 & 17,500 & 30.22 & 0.20 & 3F9N05 0719 & $0872^{*}$ & & 59 & 3,540 & 18.01 & 0.41 \\
\hline 6U3K09 & 2463 & 2616 & & 59 & 39,200 & 32.39 & 0.13 & 3F9N05 2329 & 2482 & & 59 & 189,000 & 22.55 & 0.10 \\
\hline 6U3K09 & 2635 & 2788 & & 58 & 110,000 & 37.10 & 0.08 & 3F9N05 2710 & 2863 & & 57 & 33,000 & 21.85 & 0.19 \\
\hline 6U3K09 & 3200 & 3353 & & 50 & 34,900 & 30.04 & 0.15 & & & & & & & \\
\hline 6U3K09 & 3353 & 3506 & & 46 & 14,100 & 27.03 & 0.21 & & & & & & & \\
\hline Average & & & & 60 & 50,400 & 32.44 & 0.14 & & & & 58 & 75,180 & 20.80 & 0.23 \\
\hline
\end{tabular}

* Dynamically tested following a static test.

** $\quad$ Estimated.

*** Erratic load cell data were recorded during the test. The applied moment was likely higher, and these data are considered unusable.

**** Specimen had a GTRF mark in the gauge section that was aligned (as possible) with the expected maximum strain location. 


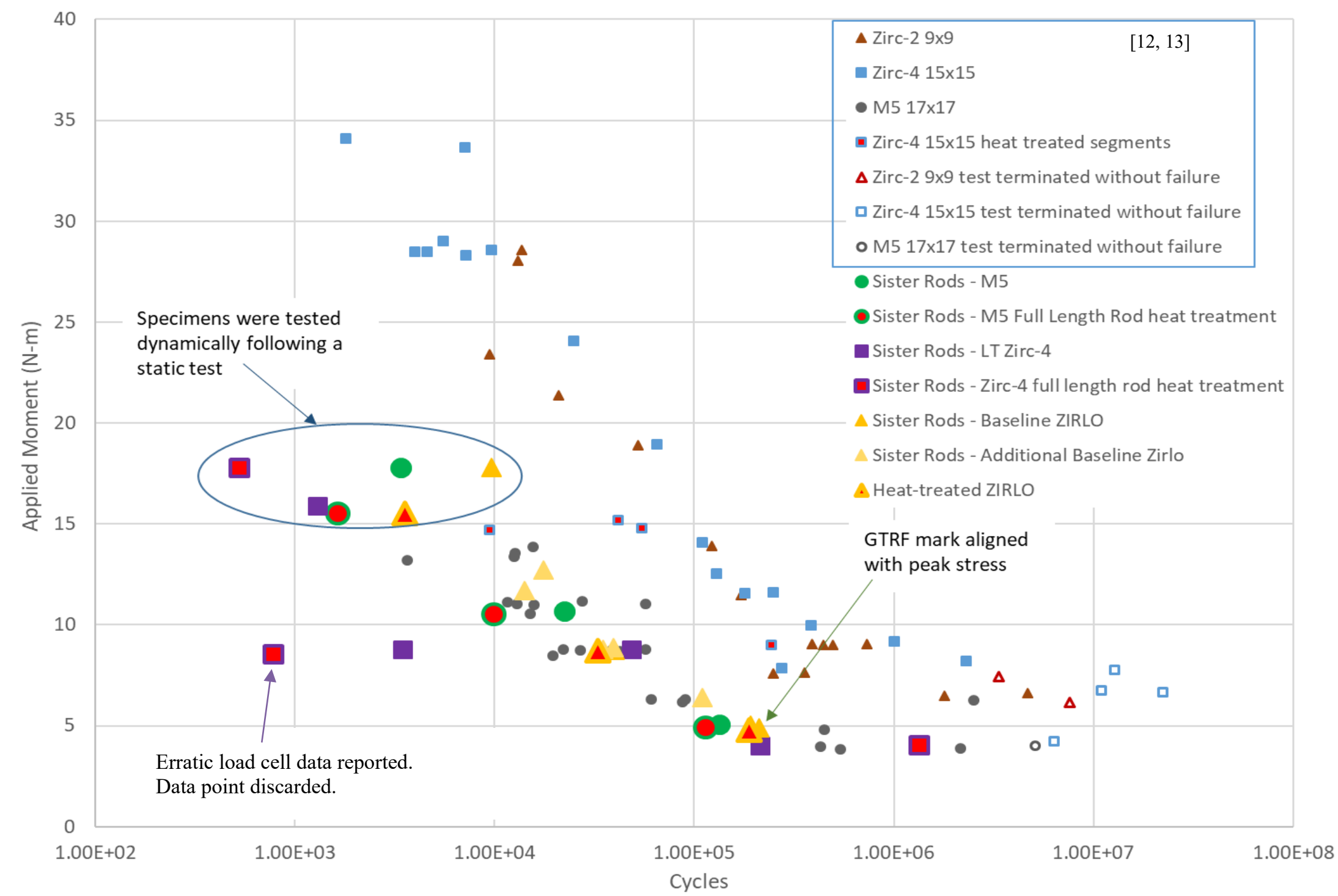

Figure 11. Results of sister rod CIRFT tests plotted with previous data, applied moment vs. cycles to failure. 
- CIRFT results (Wang et al. 2016)

- CIRFT results (terminated without failure) (Wang et al. 2016)

- CIRFT results for radially-oriented hydride specimens (Wang et al. 2016)

- Sister rods CIRF

Fatigue curve established using simulation (Geelhood and Beyer 2015) [15]

- - O'Donnell-Langer (1964) [14]

Measured stress amplitude during shaker/road tests (McConnell et al. 2014

- - Total shock cycles estimated for 2000-mi rail trip (McConnell et al. 2014) [16] Estimated range of vibration cycles for a 2,000-mile rail trip (McConnell et al. 2014)

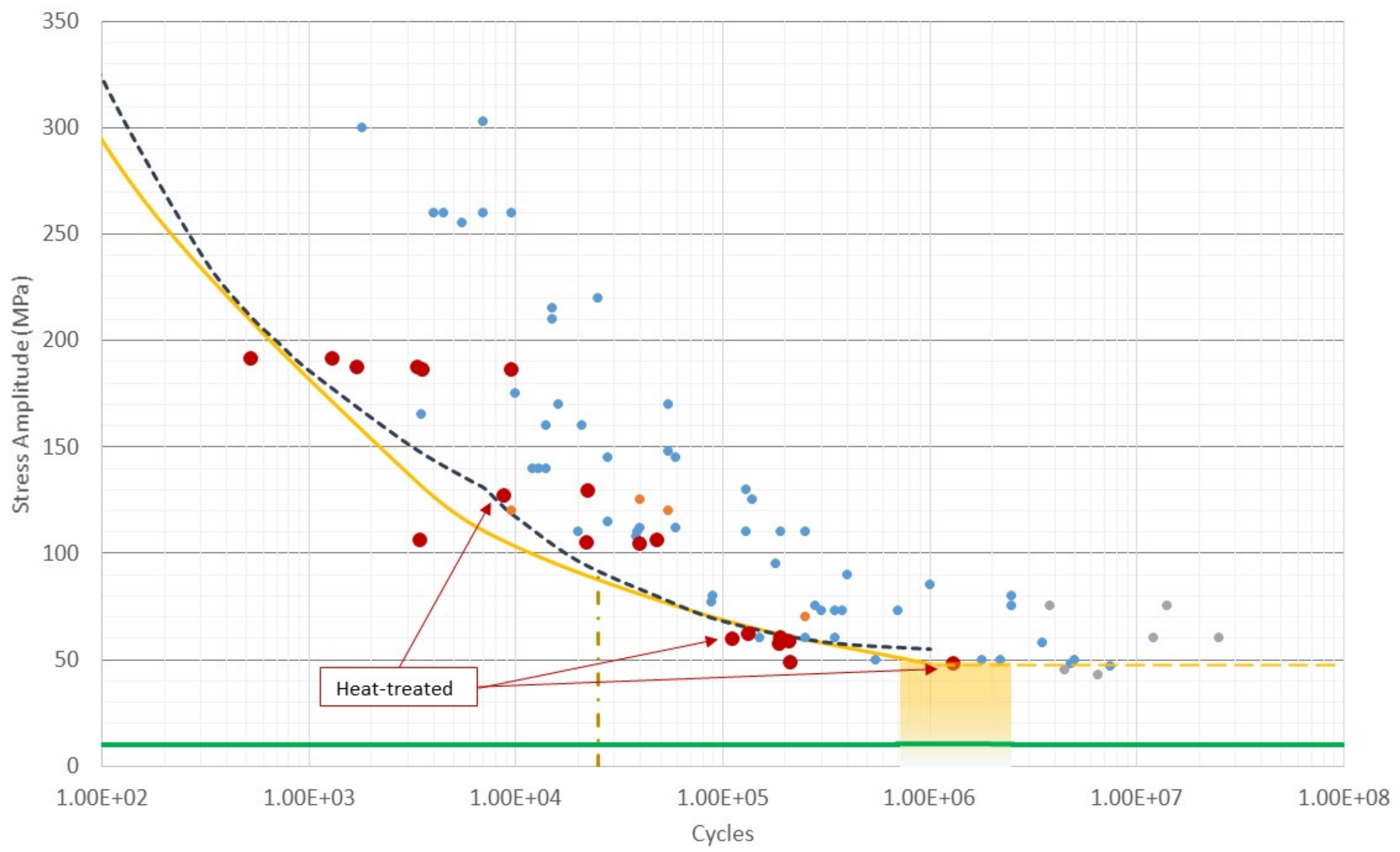

Figure 12. Comparison of CIRFT stress amplitude vs. cycles to failure with other fatigue limits. 


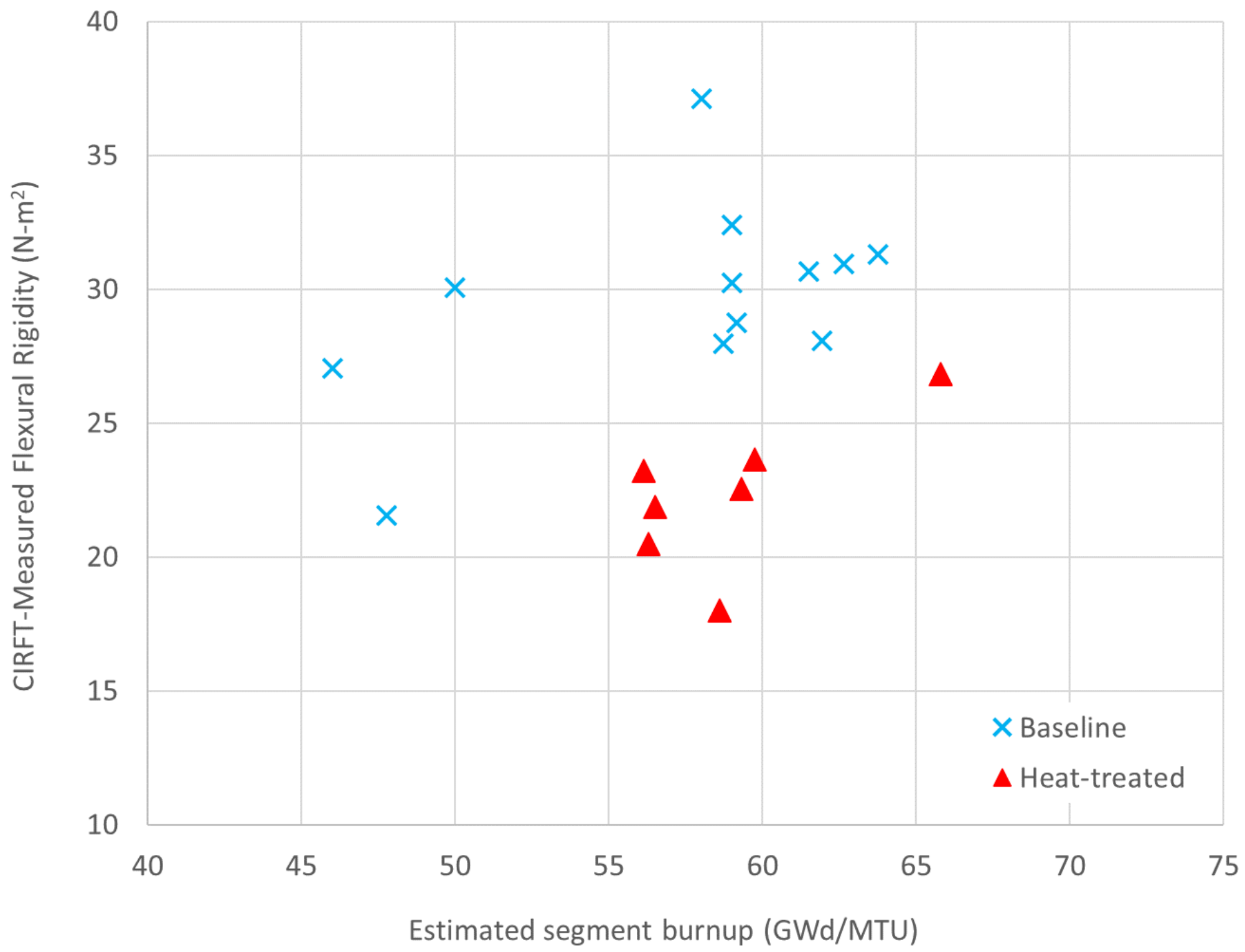

Figure 13. CIRFT-measured flexural rigidity of the heat-treated and baseline specimens. 
Typical view of a circumferential fracture at a pellet-pellet interface (3F9N05-2710-2863)

Typical view of a fracture through the pellet body with partial tearing of the cladding (30AE143156-3309)
Jagged fracture observed on the Zirc-4clad specimens (F35P17-1855-2008)
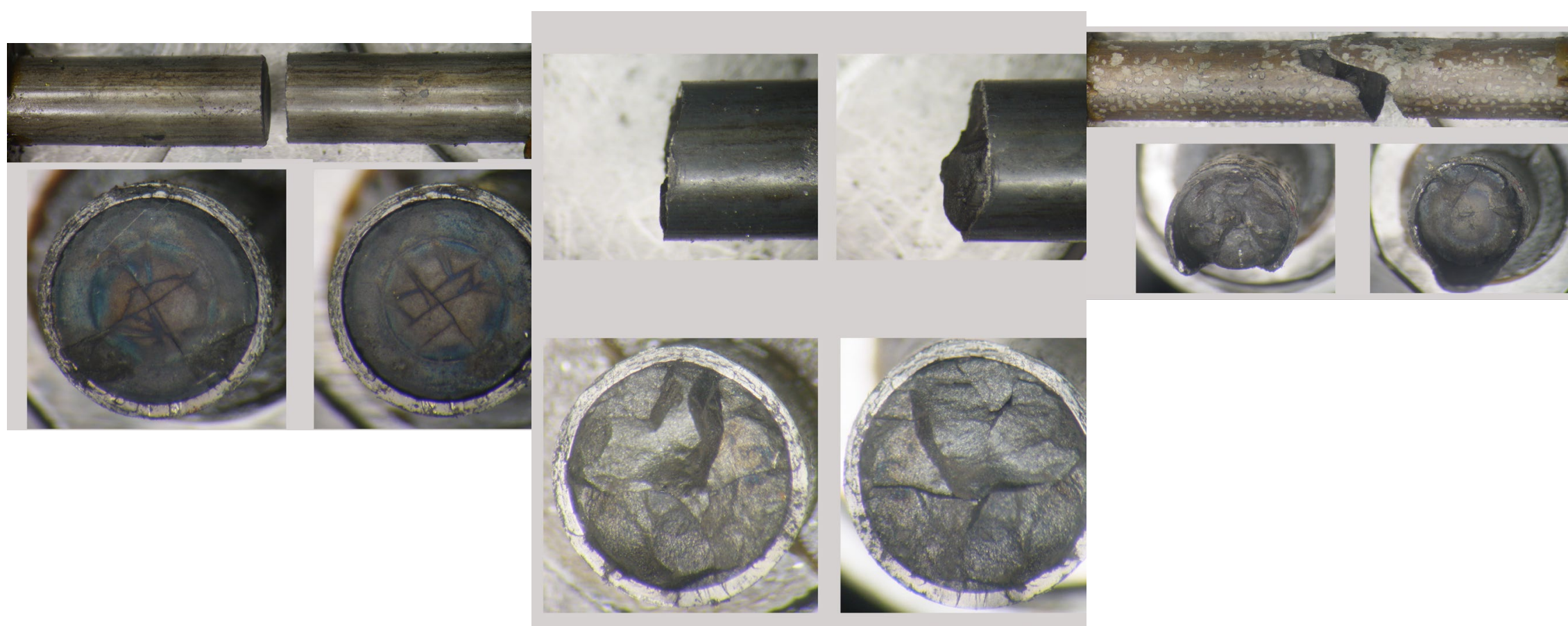

Figure 14. Typical appearance of post-fatigue test specimens. 


\section{Mechanical Testing}

To provide capability for mechanical testing, a large Instron load frame $(65 \times 31 \times 29$ in. $)$ with a $30 \mathrm{kN}$ capacity ( $\sim 1$ ton of loading force) was installed in the IFEL north hot cell. The cell location was selected based on its accessibility and its lower dose rates $(\sim 150 \mathrm{R} / \mathrm{h})$. During FY20, the load frame was modified for durability in the radiation field and to provide remote manipulation capabilities. Lead shielding was placed around the load frame's instrumentation string to provide more protection from radiation damage. The load frame was successfully installed in-cell in June 2020.

\subsection{Four-Point Bend Tests}

The 4PB test provides values for the elastic modulus in bending and the flexural stress and flexural strain response. It is the test traditionally used to study brittle materials in which the number and severity of flaws exposed to the maximum stress is directly related to the flexural strength and crack initiation. The load frame with its test fixturing (described in Appendix E) applies a constant bending moment over the inner $42.42 \mathrm{~mm}$ (1.67 in.) of the $152.4 \mathrm{~mm}$ (6 in.) test specimen. The upper fixture is advanced at $0.050 \mathrm{~mm} / \mathrm{s}$ in the downward direction, whereas the lower fixture is fixed and does not move.

All Phase 1 4PB (DE.07) tests, except for those planned for aerosol collection, are complete. Both RT and $200^{\circ} \mathrm{C}$ tests were completed. Video and audio records of the tests were acquired along with the displacement and load. Each test segment was weighed before testing. A tray was placed below the specimen to catch debris, and the broken segments and debris were weighed after each test.

Table 12 summarizes the evaluated results of the tests completed to date. Stress, strain, $0.2 \%$ offset yield strength, flexural modulus, and flexural strength were calculated. Figure 15 provides the stress vs. strain plot for the RT tests, and Figure 16 plots the stress vs. strain for the $200^{\circ} \mathrm{C}$ tests. The FHT M5 and ZIRLOclad specimens generally have higher ductility than the baseline specimens, but it is difficult to come to any firm conclusions about whether the heat treatments affected specimen performance with the limited data available. Given the limited number of tests, it is possible that the difference between the FHT and baseline specimens is within the normal variation and/or could be a trend related to burnup. The M5-clad rods are more ductile than specimens that have ZIRLO, Zirc-4, or LT Zirc-4-clad specimens. Data assessment will continue in FY21.

The amount of fuel released during fracture was monitored by weighing each specimen before and after the test and weighing the debris collected. The largest difference from pretest to posttest weight was $1.7 \pm 0.1 \mathrm{~g}$ for F35P17-1472-1625 (RT test). There is not a trend of mass loss with test temperature or burnup. There is a tendency for the RT tests to have more mass loss, likely because the cladding fracture is more energetic at RT than at $200^{\circ} \mathrm{C}$. The maximum mass lost represents about one-quarter of a pellet, whereas the more typical mass loss is less than one-tenth of a full pellet. Often, the released material was composed of small particulate, as shown in Figure 17. Several 4PB tests will be completed with the aerosol collection system to better quantify the size distribution and quantity of aerosol particles released during fracture. The aerosol tests have not yet been completed (see Section 13).

Appendix E provides more details about the $4 \mathrm{~PB}$ tests completed and the data reduction methods used. 
Table 12. Measured and calculated 4PB data.

\begin{tabular}{|c|c|c|c|c|c|c|c|c|c|c|c|}
\hline Test specimen & $\begin{array}{c}\text { Cladding } \\
\text { alloy }\end{array}$ & $\begin{array}{c}\text { Heat- } \\
\text { treatment }\end{array}$ & $\begin{array}{c}\text { Estimated } \\
\text { Burnup } \\
\text { (GWd/ MTU) }\end{array}$ & $\begin{array}{l}\text { Test } \\
\text { temp. } \\
\left({ }^{\circ} \mathrm{C}\right)\end{array}$ & $\begin{array}{c}\text { Average } \\
\text { Specimen } \\
\text { OD }\end{array}$ & $\begin{array}{l}\text { Deflection } \\
\text { at failure } \\
(\mathrm{mm})\end{array}$ & $\begin{array}{l}\text { 0.2\% Yield } \\
\text { strength } \\
\text { (MPa) }\end{array}$ & $\begin{array}{c}\text { Flexural } \\
\text { Strength } \\
\text { (MPa) }\end{array}$ & $\begin{array}{c}\text { Failure } \\
\text { strain (\%) }\end{array}$ & $\begin{array}{c}\text { Flexural } \\
\text { Modulus } \\
\text { (MPa) }\end{array}$ & $\begin{array}{l}\text { Flexural } \\
\text { rigidity } \\
\left(\mathbf{N}-\mathbf{m}^{2}\right)\end{array}$ \\
\hline 30AD05-1299-1452 & M5 & --- & 60 & 25.7 & 9.423 & 8.3 & 508 & 737 & 7.5 & $2.35 \mathrm{E}+04$ & 9.1 \\
\hline 30AE14-0978-1131 & M5 & FHT & 59 & 26.6 & 9.459 & 11.7 & 473 & 700 & 10.6 & $2.27 \mathrm{E}+04$ & 8.9 \\
\hline 3D8E14-1025-1178 & ZIRLO & --- & 64 & 25.3 & 9.500 & 7.4 & 570 & 880 & 6.7 & $2.39 \mathrm{E}+04$ & 9.6 \\
\hline 3F9N05-2063-2216 & ZIRLO & FHT & 59 & 24.7 & 9.471 & 10.6 & 509 & 823 & 9.6 & $2.20 \mathrm{E}+04$ & 8.7 \\
\hline 3A1F05-1279-1432 & LT Zirc-4 & --- & 57 & 26.4 & 9.465 & 5.8 & 580 & 830 & 5.2 & $2.39 \mathrm{E}+04$ & 9.4 \\
\hline F35P17-1319-1472 & Zirc-4 & FHT & 52 & 24.9 & 9.503 & 5.4 & 535 & 735 & 4.8 & $2.18 \mathrm{E}+04$ & 8.7 \\
\hline F35P17-1472-1625 & Zirc-4 & FHT & 53 & 27.2 & 9.531 & 6.5 & 533 & 795 & 5.9 & $2.25 \mathrm{E}+04$ & 9.1 \\
\hline 30AD05-0850-1003 & M5 & --- & 60 & 200.0 & 9.429 & 5.8 & 389 & 529 & 5.2 & $2.17 \mathrm{E}+04$ & 8.4 \\
\hline 30AD05-1800-1953 & M5 & --- & 59 & 200.0 & 9.423 & 6.1 & 420 & 577 & 5.5 & $2.31 \mathrm{E}+04$ & 8.9 \\
\hline 30AE14-0825-0978 & M5 & FHT & 58 & 200.0 & 9.457 & 11.8 & 397 & 584 & 10.7 & $2.26 \mathrm{E}+04$ & 8.9 \\
\hline 30AE14-2050-2203 & M5 & FHT & 60 & 200.0 & 9.454 & 12.3 & 380 & 584 & 11.1 & $2.16 \mathrm{E}+04$ & 8.5 \\
\hline 3D8E14-0872-1025 & ZIRLO & --- & 64 & 200.0 & 9.497 & 7.1 & 471 & 748 & 6.4 & $2.23 \mathrm{E}+04$ & 8.9 \\
\hline 3D8E14-1907-2060 & ZIRLO & --- & 64 & 200.0 & 9.492 & 7.2 & 464 & 730 & 6.5 & $2.17 \mathrm{E}+04$ & 8.6 \\
\hline 3F9N05-0872-1025 & ZIRLO & FHT & 59 & 200.0 & 9.465 & 7.9 & 440 & 669 & 7.1 & $2.11 \mathrm{E}+04$ & 8.3 \\
\hline 3F9N05-1910-2063 & ZIRLO & FHT & 59 & 200.0 & 9.469 & 9.1 & 424 & 676 & 8.3 & $2.10 \mathrm{E}+04$ & 8.3 \\
\hline 3A1F05-1432-1585 & LT Zirc-4 & --- & 56 & 200.0 & 9.459 & 5.2 & 485 & 681 & 4.7 & $2.21 \mathrm{E}+04$ & 8.7 \\
\hline 3A1F05-2230-2383 & LT Zirc-4 & --- & 54 & 200.0 & 9.480 & 5.1 & 464 & 644 & 4.6 & $2.07 \mathrm{E}+04$ & 8.2 \\
\hline F35P17-2230-2383 & Zirc-4 & FHT & 51 & 200.0 & 9.514 & 7.5 & 429 & 675 & 6.8 & $2.01 \mathrm{E}+04$ & 8.1 \\
\hline \multicolumn{6}{|c|}{ Average at RT: } & 8.0 & 530 & 786 & 7.2 & $2.29 \mathrm{E}+04$ & 9.1 \\
\hline & & & & \multicolumn{2}{|c|}{ Average at $200^{\circ} \mathrm{C}:$} & 7.7 & 433 & 645 & 7.0 & $2.16 \mathrm{E}+04$ & 8.5 \\
\hline
\end{tabular}




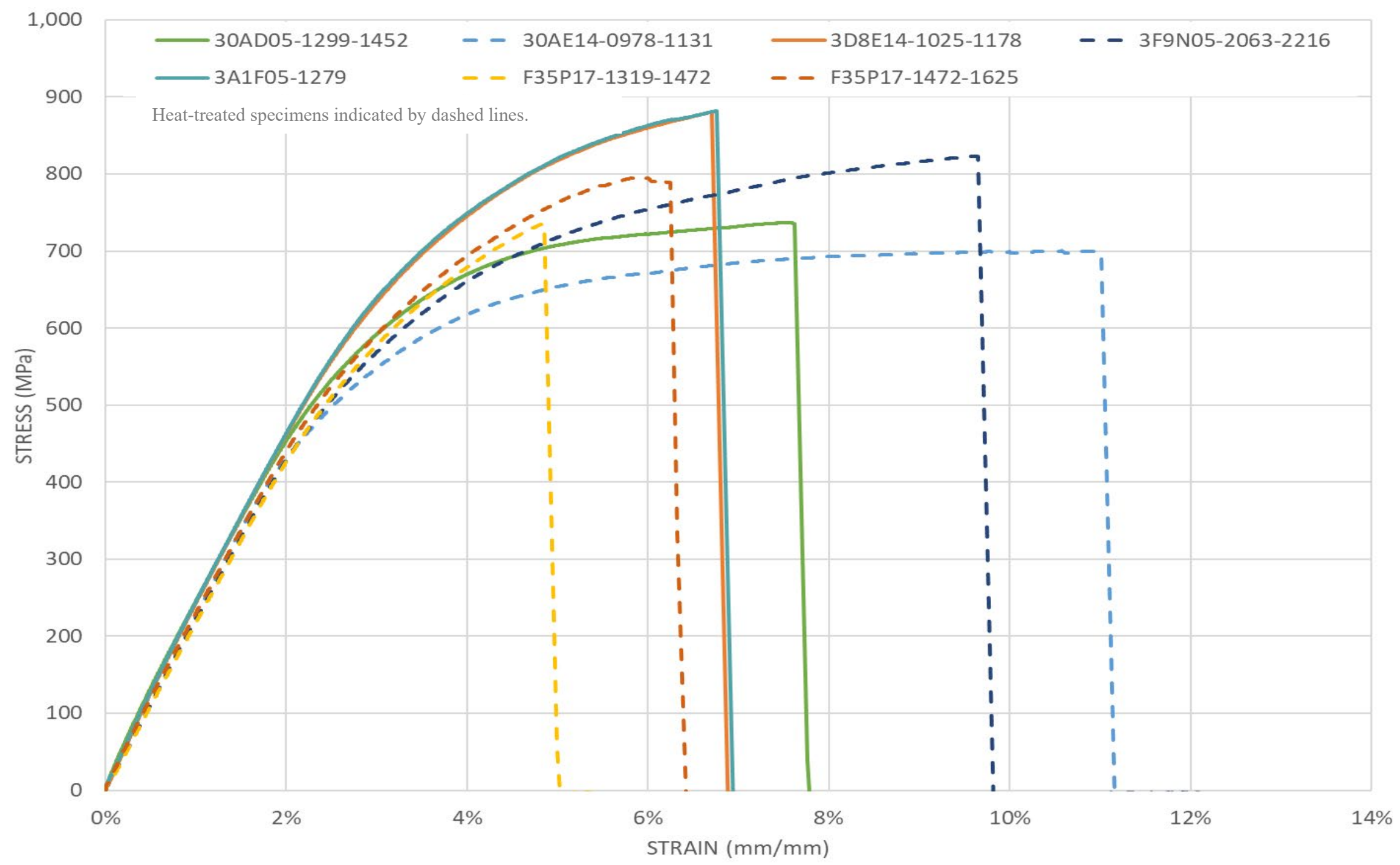

Figure 15. Stress vs. strain plot for RT data. 


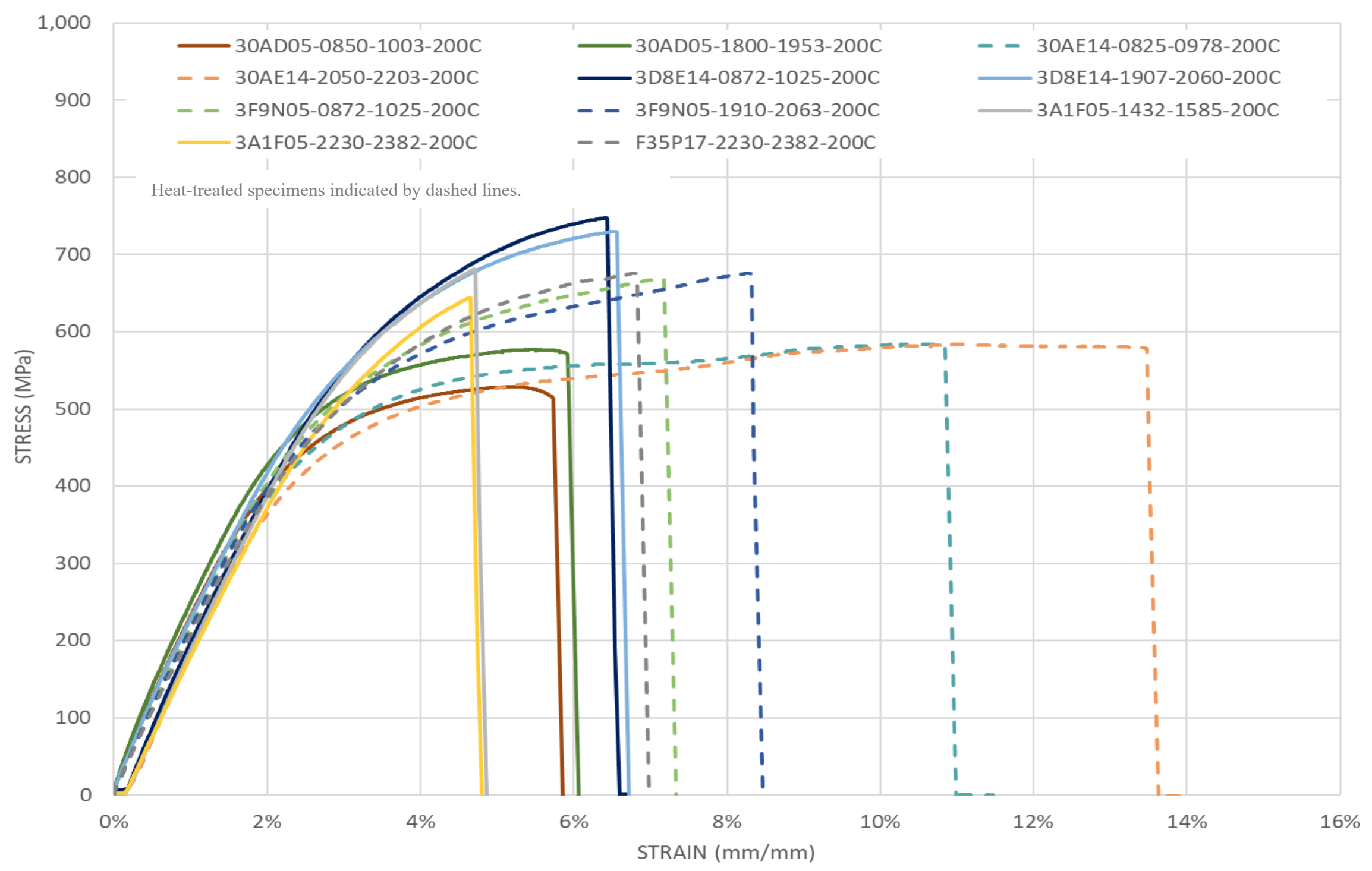

Figure 16. Stress vs. strain plot for $200^{\circ} \mathrm{C}$ data. 

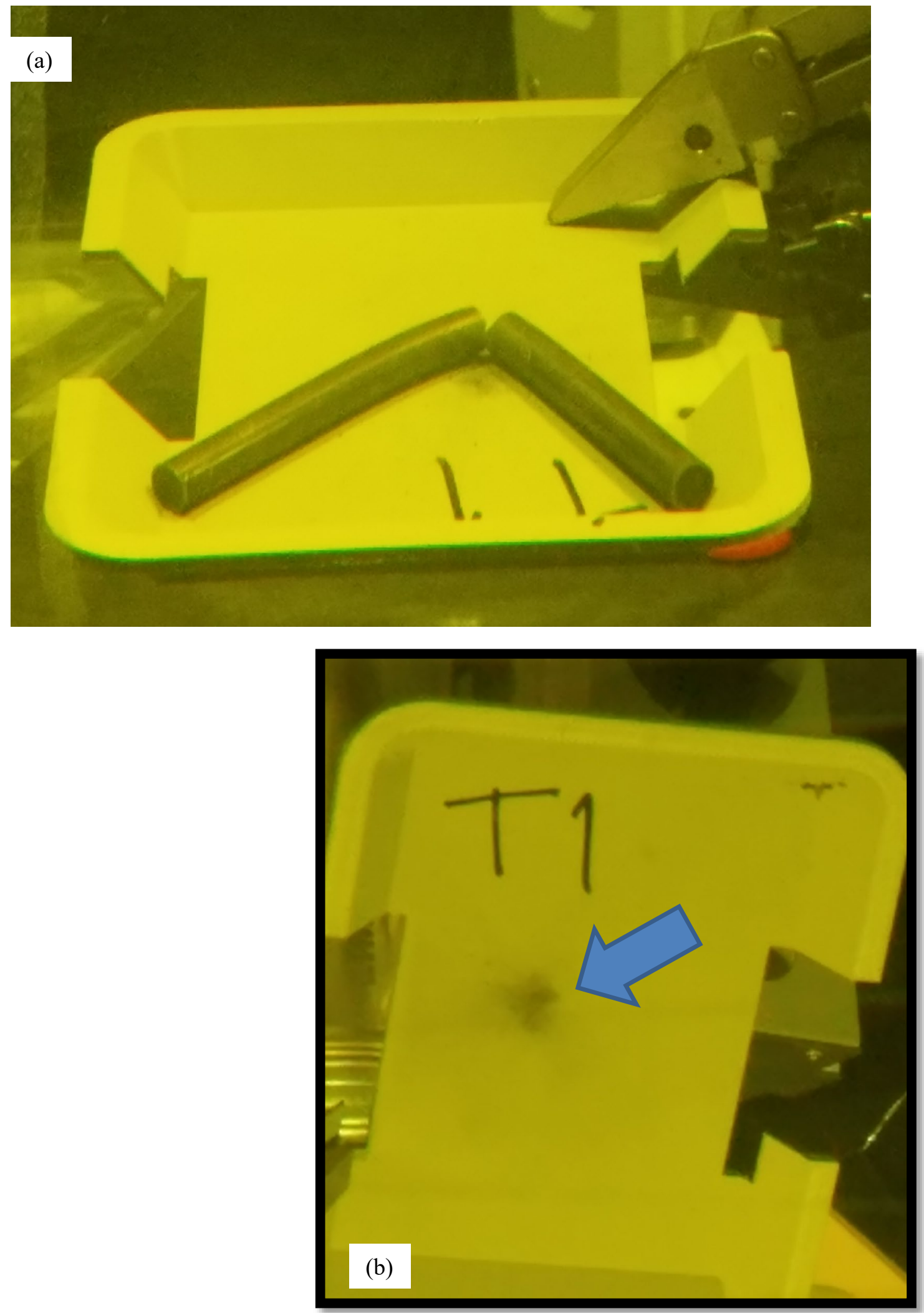

Figure 17. (a) Posttest debris was captured by a catch tray located below the specimen with (b) the typical RT debris field composed of small particles. 


\subsection{Axial Tension Testing}

To perform axial tension testing (DE.08), a small amount of fuel must be dissolved from each end to allow for the insertion of a grip. The grip is used to prevent specimen crushing at the load point. Therefore, although the rough-cut segments are available, they must be further processed to prepare them for the test. $\mathrm{RT}$ and $200^{\circ} \mathrm{C}$ tests are planned.

\subsection{Fueled Ring Compression Testing}

ANL has developed a significant body of data on cladding hydride reorientation and the associated effects on cladding ductility using RCTs over the last decade, and Billone documented the most recent summary of results in 2019 [17]. Several baseline and FHT sister rod specimens were shipped to ANL for RCTs.

ORNL's RCT (DE.10) data provide supplementary information on the load-bearing capability of intact fuel rods (cladding and pellets). Similar to RCT of cladding specimens, the fueled rod segment is loaded across its diameter, and the load to specimen failure is measured.

The RCT specimens are $\sim 25 \mathrm{~mm}$ long for RCTs, as shown in Figure 19, and each specimen should contain two full pellets. Five tests were completed at $200^{\circ} \mathrm{C}$ and 12 tests were completed at RT, and the results, which have not been corrected for machine compliance, are summarized in Table 13. The specimens typically carried load until at least one cladding fracture developed. Frequently, as shown in Figure 18, the specimen broke into two equal halves.

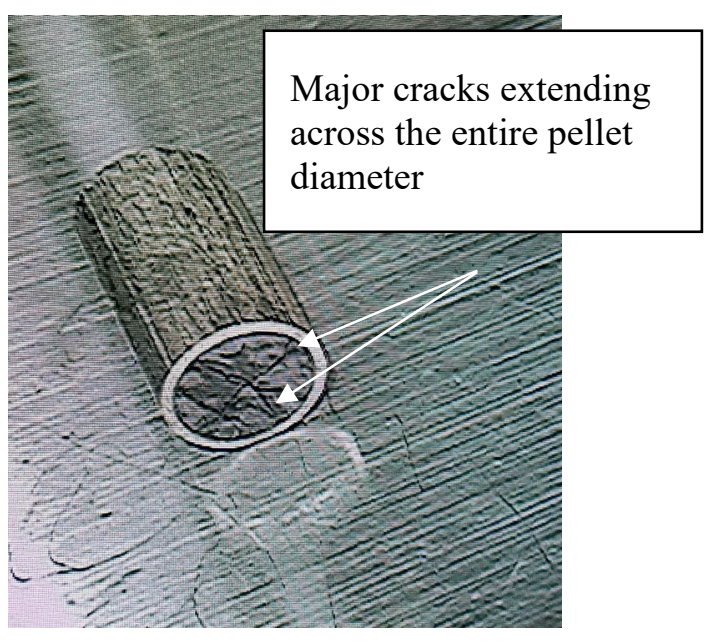

Figure 19. Typical test specimen.

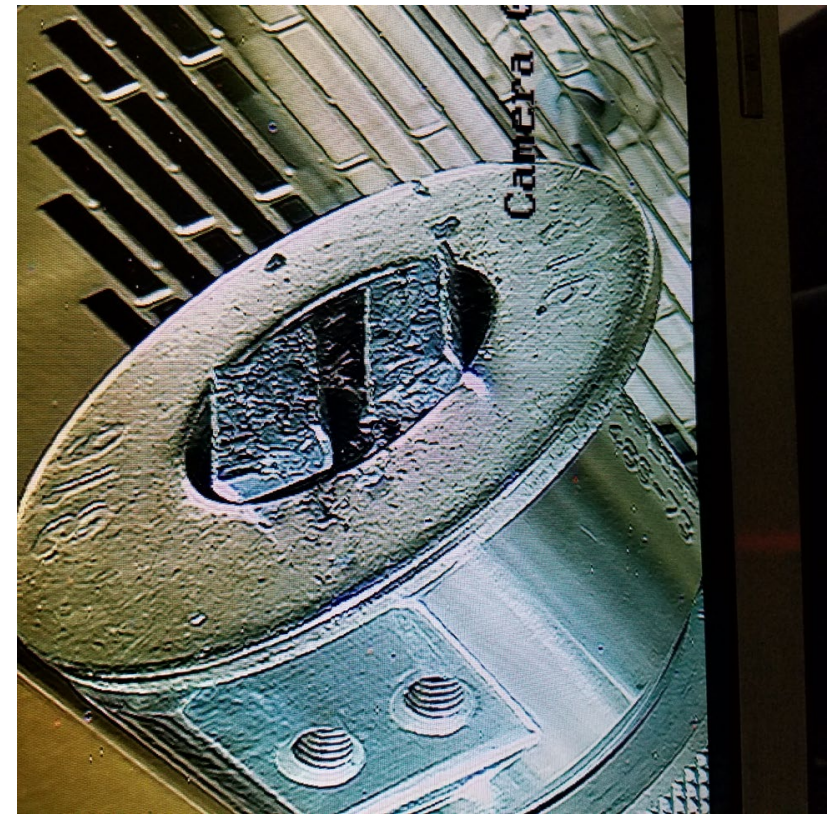

Figure 18. Typical post-RCT appearance.

The average load-bearing capability of the segments in transverse compression is $16,415 \mathrm{~N}\left(3,690 \mathrm{lb}_{\mathrm{f}}\right)$. The load-bearing capability does not trend with specimen average burnup, and there is not an appreciable difference in the maximum load from RT to $200^{\circ} \mathrm{C}$. Cladding type also does not largely influence the loadbearing capability, and there is no difference related to the heat treatment applied to some of the rods. The load-bearing capability of the fueled specimen is about eight times higher than that of a defueled cladding specimen (Appendix E, Figure E-21). 
As the tests progressed, it became clear that fracture typically occurred at the location of one of the major diametrical pellet cracks, as illustrated in Figure 20. Usually there were two major cracks, defined as fulldiameter cracks, visible at the end of the specimen. Two specimens from F35P17 were tested with the major crack aligned along the loading path and perpendicular to the loading path. There is a difference in the results for those two samples, but unfortunately the data were not recorded within the software for one of the tests, and only the notation on peak load in the laboratory notebook is available, which is not exact. If possible, further tests or finite element analyses should investigate load capacity with pellet crack orientation.

Table 13. RCT peak load data.

\begin{tabular}{l|c|c|c|c|c|c|c}
\hline \multicolumn{1}{c|}{ Sample ID } & $\begin{array}{c}\text { Test } \\
\text { temperature } \\
\left({ }^{\circ} \mathbf{C}\right)\end{array}$ & $\begin{array}{c}\text { Cell } \\
\text { temperature } \\
\left({ }^{\circ} \mathbf{C}\right)\end{array}$ & $\begin{array}{c}\text { Cladding } \\
\text { alloy }\end{array}$ & $\begin{array}{c}\text { Heat } \\
\text { treatment }\end{array}$ & $\begin{array}{c}\text { Estimated } \\
\text { specimen } \\
\text { burnup } \\
(\mathbf{G W d / M T U})\end{array}$ & $\begin{array}{c}\text { Peak load } \\
(\mathbf{N})\end{array}$ & $\begin{array}{c}\text { Peak load } \\
(\mathbf{l b f})\end{array}$ \\
\hline 30AD05-2320-2345 & 25.2 & 25.2 & M5 & --- & 59 & 17,985 & 4,043 \\
\hline 30AD05 -3150-3175 & 25.3 & 25.3 & M5 & --- & 56 & $17,000^{*}$ & $3,822^{*}$ \\
\hline 30AE14-2585-2610 & 25.9 & 25.9 & M5 & FHT & 60 & 17,632 & 3,964 \\
\hline 30AE14-3418-3443 & 25.9 & 25.9 & M5 & FHT & 47 & 19,510 & 4,386 \\
\hline 3D8E14-2322-2347 & 25.1 & 25.1 & ZIRLO & --- & 64 & 15,788 & 3,549 \\
\hline 3D8E14-3116-3141 & 25.1 & 25.1 & ZIRLO & --- & 60 & 17,210 & 3,869 \\
\hline 3D8E14-2347-2372 & 200 & 26.2 & ZIRLO & --- & 64 & 17,752 & 3,991 \\
\hline 3F9N05-2482-2507 & 25.6 & 25.6 & ZIRLO & FHT & 59 & 17,444 & 3,921 \\
\hline 3F9N05-3350-3375 & 25.6 & 25.6 & ZIRLO & FHT & 50 & 17,049 & 3,833 \\
\hline 3A1F05-3375-3400 & 200 & 25.8 & ZIRLO & FHT & 50 & 18,683 & 4,200 \\
\hline 3A1F05-2645-2670 & 24.8 & 24.8 & LT Zirc-4 & --- & 52 & 12,303 & 2,766 \\
\hline 3A1F05-2670-2695 & 24.9 & 24.9 & LT Zirc-4 & --- & 55 & 16,232 & 3,649 \\
\hline F35P17-2645-2670 & 200 & 25.8 & LT Zirc-4 & --- & 55 & 12,384 & 2,784 \\
\hline F35P17-2960-2985 & 25.7 & 25.7 & Zirc-4 & FHT & 51 & 12,476 & 2,805 \\
\hline F35P17-2670-2695 & 25.7 & 25.7 & Zirc-4 & FHT & 50 & 12,961 & 2,914 \\
\hline F35P17-2985-3010** & 200 & 25 & Zirc-4 & FHT & 51 & 15,915 & 3,578 \\
\hline & & 25.3 & Zirc-4 & FHT & 50 & $12,500^{*}$ & $2,810^{*}$ \\
\hline
\end{tabular}

* The data file was not saved for this test. The value is from the estimate recorded in the laboratory notebook.

** A major pellet crack as aligned with the loading direction.

*** A major pellet crack as aligned perpendicular to the loading direction.

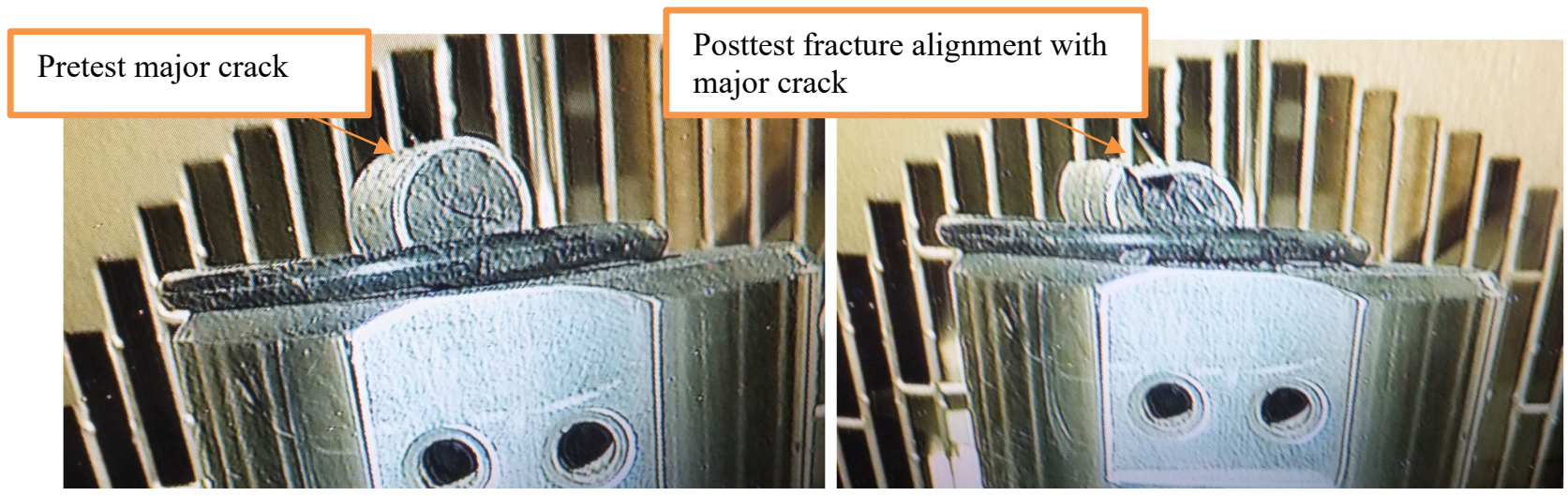

Figure 20. RCT fracture path along major pellet crack. 


\subsection{Microhardness Tests}

Microhardness testing (DE.09) will be completed in a glove box, and the equipment needed for the work was installed in the glove box. Specimens must be prepared for testing, which will commence once the priority METs are completed because the microhardness preparation uses the same equipment and personnel. RT and $200^{\circ} \mathrm{C}$ tests are planned.

\subsection{Burst Tests}

No progress has been made on configuring the available equipment for burst tests. 


\section{Aerosol Collection Apparatus and Approach}

To investigate the release of aerosolized radioactive material from a HBU fuel rod during fracture $(10 \mu \mathrm{m}$ or less is generally considered to be the upper limit of human respirability [18]), an aerosol collection capability (AERO) is being developed for deployment on the CIRFT equipment (DE.05) and Instron load frame, which is used for DE.07, DE.08, and DE.10. Two different collection configurations - one for CIRFT and one for the load frame-will be developed, but the aerosol collection media and approach are expected to be the same.

The initial AERO design was configured for the Instron load frame. The initial collection enclosure was a relatively large aluminum box that provided a large amount of vertical travel for the load frame and fixturing with the sampling devices mounted on the interior of the box. Several experiments using surrogate materials were completed in FY20, and the enclosure was downsized to a more compact box with the sampling media mounted externally. The smaller enclosure is 3D printed polyvinyl chloride that can be rinsed, dissolved, or imaged. Sampling tubing fixed in the bottom of the enclosure allows direct access to the location in which the material is expected to be expelled from the specimen during 4PB testing. An illustration of the collection enclosure is shown in Figure 21 and 21.

The initial AERO design included two versions of the aerosol collection cards; the first had a four-filter cascade impactor with particle collection cut points of $2.5,1.0,0.50$, and $0.25 \mu \mathrm{m}$, and the second had a cyclone with a $4 \mu \mathrm{m}$ cut point. Performance testing with the cyclone indicates that it is not well-suited to this collection task, and its use was discontinued. The cascade impactor works well and will be expanded to include higher cut point stages to encompass the range of respirable particles.

After experimenting with silver filters, the collected particles were easily dislodged. To avoid loss of the collected material, scanning electron microscopy carbon tabs will be used as the collection substrate. Testing concluded that the use of the carbon tabs does not change the collection cut point or capacity. Each impactor has its own dedicated vacuum pump to maintain the appropriate sampling flow rate.

Inertial impaction is the method used to collect particulates released from the sister rod specimen as it is fractured during testing. Impactors are devices that separate the particulates based on size. In the four-stage impactor, air containing the particulates to be sampled is accelerated through an orifice toward a collection filter placed at a fixed distance below an orifice. The collection filter forces the air stream to change direction abruptly, and particles that are large enough have enough inertia to escape the air stream and are collected on the filter. Particles that are smaller follow the air stream and remain suspended, moving on to the next stage of the impactor.

The cut point is the aerodynamic size of particles that are collected by the sampler with $50 \%$ efficiency. Ideally, all particles greater than a certain size are collected on the filter, and all particles that are smaller pass through. However, because impactors act on aerodynamic variables and do not perform like a mechanical barrier, such as a sieve, the collection efficiency is not $100 \%$. Based on the orifice diameter and flow rate used, collection efficiency increases for particles larger than the cut point and decreases for smaller particles. For a $4 \mu \mathrm{m}$ cut point, $100 \%$ of $10 \mu \mathrm{m}$ particles and $50 \%$ of $4 \mu \mathrm{m}$ particles are removed from the air stream and deposited on the filter.

A prototype of the collection enclosure used with the Instron load frame was 3D printed, and the fit-up of the enclosure with the 4PB fixture was evaluated. The specification of the equipment to be used for particle collection is complete, and initial verification testing of the system's basic functionality is complete. Three verification tests were completed. With each test, refinements to the cascade and sampling system were made. Final verification testing is pending the acquisition of the modified cascade. 


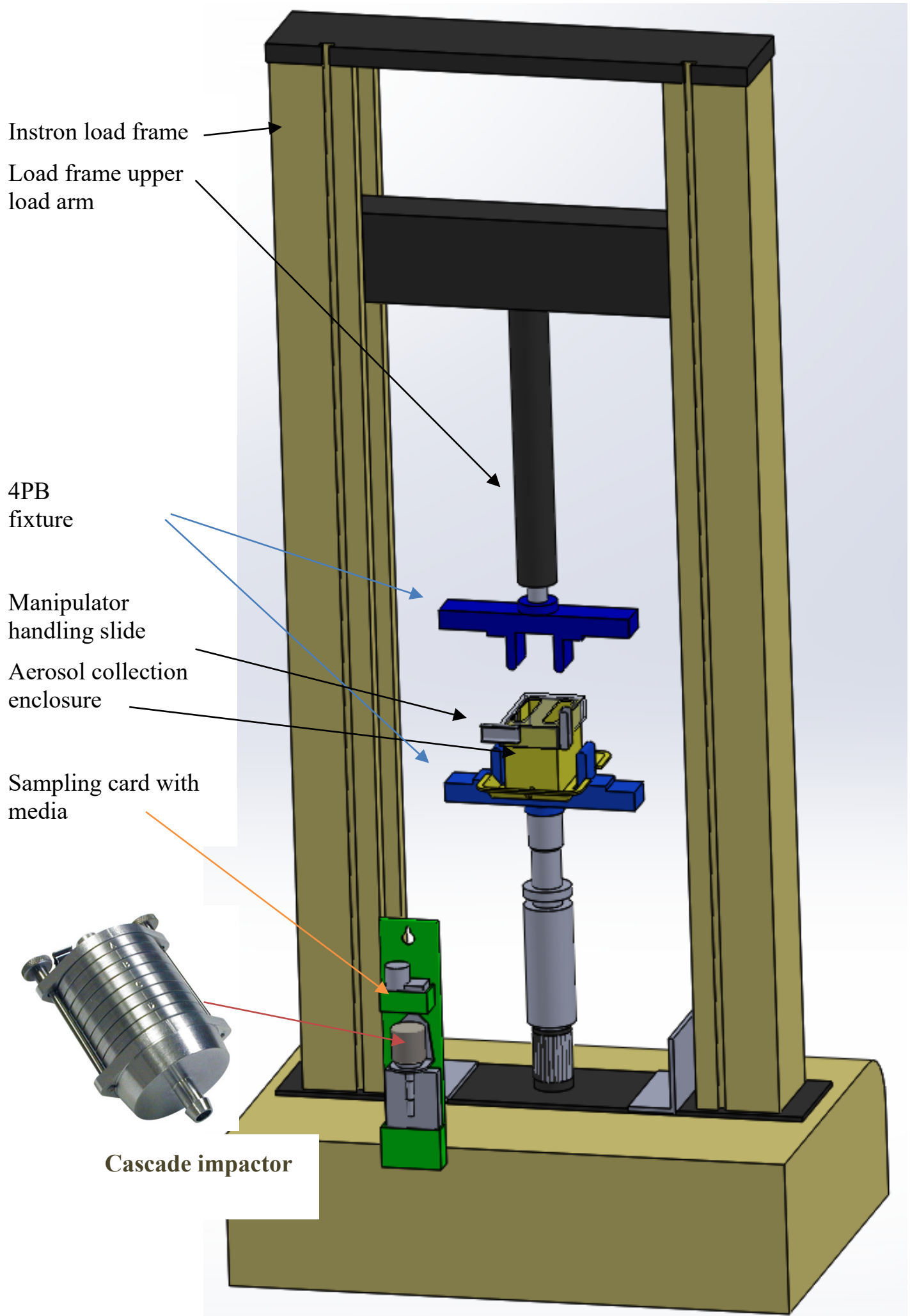

Figure 21. Illustration of the load frame aerosol collection enclosure with one sampling card shown. 


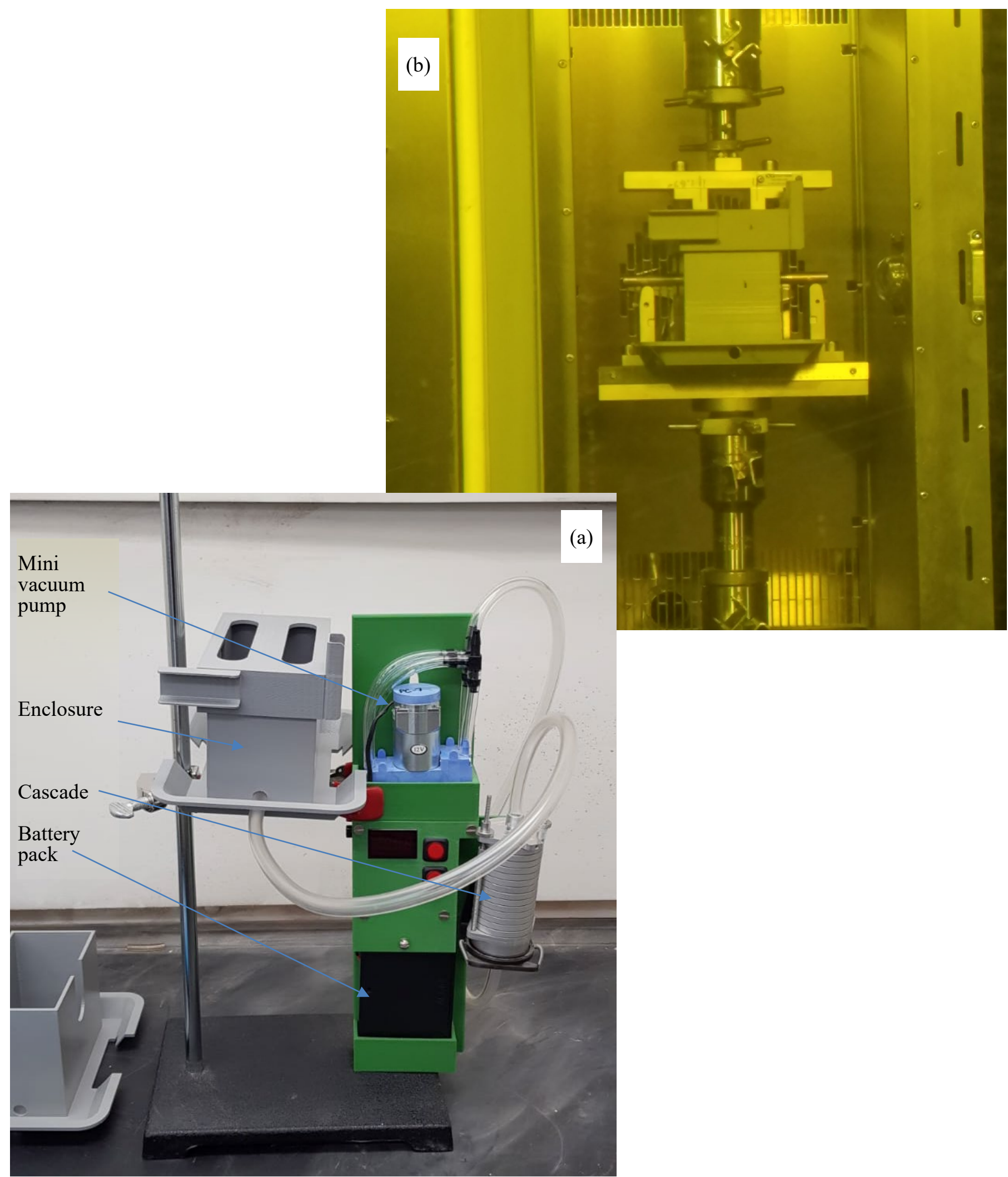

Figure 22. Sampling card with multistage cascade impactor and dedicated pump (a) set up for verification testing and (b) fit up on the load frame in the hot cell. 


\section{Summary of Results}

Table S-1 in the summary details the testing completed to date and statuses of the tests still to be completed.

To date, three fuel rods have been heat-treated: one Zirc-4-clad (F35P17), one ZIRLO-clad (3F9N05), and one M5-clad (30AE14) rod. Following FHT, the three rods were segmented along with four baseline rods, and all are being examined in detail.

Rod internal pressure and void volume measurements are as expected, although it seems that the FHT has resulted in a larger void volume for the ZIRLO-clad rod. Pellet stack gas transmissibility at room temperature was measured and, in all cases, gas was transmissible through the pellet stack at room temperature, requiring between $30 \mathrm{~min}$ and $24 \mathrm{~h}$ to reach equilibrium conditions, depending upon the pressure differential applied. The data correlates well using porous media prediction models. Comparisons of rod internal pressure and void volume measurements with predictions from fuel rod performance codes FAST and BISON indicate a tendency for FAST to overpredict void volume and BISON to underpredict void volume.

Fission gas sampling and analysis yielded the expected ratio of gases; fission gas release ratios have not yet been calculated. Burnup analysis results are available for three specimens and the isotopic content of eight other samples are being analyzed.

Fueled and defueled specimen METs are available for each of the Phase 1 rods. Additional views are in progress. Section views were inspected for hydride orientation and radial hydrides are visible in the heattreated M5-clad specimen and the ZIRLO-clad heat-treated specimen. There is a high hydride density in the heat-treated Zirc-4 specimen. The few radial hydrides are short. The baseline ZIRLO-clad specimen includes short radial hydrides. The other baseline specimens did not have radial hydrides. An axial MET was created at a pellet-pellet gap and METs through the gap do not show a change in the hydride precipitation density. A section of the cladding will be analyzed for total hydrogen content to determine whether the total cladding hydrogen content varies between the pelleted region and the pellet-pellet gap

Specimens were defueled and the oxygen-nitrogen-hydrogen analyzer was set up in preparation for total cladding hydrogen measurements. Out of cell verification testing of the oxygen nitrogen hydrogen analyzer is underway and cladding measurements are expected to follow in early FY21.

31 tests using the Cyclic Integrated Reversible-Bending Fatigue Tester (CIRFT) were completed on 25 specimens. The preliminary results indicate that the baseline sister rod's fatigue lifetime is consistent with other rods of the same type that were tested in the past. The heat-treated M5- and ZIRLO-clad rods resulted in a shorter fatigue lifetime as a consequence of a reduced flexural rigidity related to the FHT. The Zirc-4clad heat-treated specimens from F35P17 did not yield consistent results and it is recommended that at least 2 more confirmatory tests be completed. A test on a specimen with a grid-to-rod-fretting (GTRF) mark in the maximum strain location did not result in a reduced fatigue lifetime. Simulation of flexural rigidity, pellet-pellet, pellet-clad bonding to better understand test results and provide prediction capability is underway.

The CIRFT cumulative effects test fixture is being evaluated out of cell. Modeling of the cumulative impact test to determine appropriate fixture configuration is complete and indicates that applying an impact to a specimen mounted in a dogbone yields an impact load that is too high. If cumulative effects tests will be completed a different application must be researched.

All Phase $14 \mathrm{~PB}$ tests, except for those planned for aerosol collection, are complete. Tests were conducted at both room temperature (RT) and at $200^{\circ} \mathrm{C}$. In general, the heat-treated M5 and ZIRLO-clad specimens have higher ductility and lower flexural rigidity than the baseline specimens, but it is difficult to come to any firm conclusions about whether the heat treatments affected specimen performance with the limited data available. Additional evaluations of the data will be completed in FY21. The pellet mass lost from 4PB specimens was measured with the maximum released corresponding to a quarter of a pellet, while less than 
one tenth of a full pellet material release was more typical. There was not a trend of pellet mass loss related to test temperature, although the RT fractures seemed more energetic.

All Phase 1 fueled RCT are complete. There is not an appreciable difference in the maximum load from RT to $200^{\circ} \mathrm{C}$. Cladding type doesn't appear to have a large influence on the load-bearing capability either, and there doesn't appear to be a difference related to the heat-treatment applied to some of the rods. The main observed variant is the orientation of the major cracks in the pellet, as these appear to determine the specimen fracture plane and nucleate fracture of the adjacent cladding. Observed transverse bearing load of the specimen is $16.4 \mathrm{kN}(3,690 \mathrm{lb})$ on average with a minimum load-bearing capability of $12.3 \mathrm{kN}(2,766$ $\mathrm{lb}_{\mathrm{f}}$ ) for the segments tested. The load-bearing capability of the fueled RCT specimen is about eight times higher than that of a defueled cladding specimen.

An aerosol collection system with fixturing and sampling devices was designed to characterize and quantify the respirable fraction of $\mathrm{UO}_{2}$ particles released during rod fracture. The fixture is used in conjunction with four-point bend tests. The aerosol collection system is currently being tested and validated out of cell.

Preparations for microhardness tests, axial tension, and burst tests are underway. 


\section{REFERENCES}

1. Electric Power Research Institute, High Burnup Dry Storage Cask Research and Development Project: Final Test Plan, contract no. DE-NE-0000593, Palo Alto, California, 2014.

2. S. Saltzstein et al., Visualization of the High Burnup Spent Fuel Rod Phase 1 Test Plan, SAND2018-8042-O, 2018.

3. R. A. Montgomery et al., Post-Irradiation Examination Plan for High Burnup Demonstration Project Sister Rods, SFWD-SFWST-2017-000090 ORNL/SR-2016/708, Oak Ridge National Laboratory, 2016.

4. R. A. Montgomery et al., Sister Rod Nondestructive Examination Final Report, SFWD-SFWST2017-000003 Rev. 1 (M2SF-17OR010201021) / ORNL/SPR-2017/484 Rev. 1 (ORNL/SPR2018/801), Oak Ridge National Laboratory, 2019.

5. B. Bourdiliau et al., "Impact of Irradiation Damage Recovery During Transportation on the Subsequent Room Temperature Tensile Behavior of Irradiated Zirconium Alloys," J. ASTM Int., 7, no. 9 (2010). Paper ID JAI103006.

6. $\quad$ Electric Power Research Institute, End-of-Life Rod Internal Pressures in Spent Pressurized Water Reactor Fuel, 3002001949, Palo Alto, California, 2013.

7. R. W. Shimskey et al., PNNL Phase 1 Update on Sister Rod Destructive Examination Results, SFD-SFWST-M2SF-19PN010201037, Pacific Northwest National Laboratory, September 2019 [pending release].

8. G. Pan et. al., "Performance Characteristics of High Burnup ZIRLO Cladding Fuel Rods," Proceedings of TopFuel/Global Fuel Performance Meeting, Seattle, Washington, 2019.

9. K. Geelhood, Sister Rod Thermomechanical Modeling with FAST, PNNL-28224, 2018.

10. S. Stimpson, Sister Rod Predictions of End-of-Life Rod Internal Pressure and Void Volume, ORNL/SPR-2019/1173 M4SF-19OR0102010210, Oak Ridge National Laboratory, 2019.

11. V. V. Rondinella et al., "Measurement of Gas Permeability Along the Axis of a Spent Fuel Rod," Top Fuel 2015, Zurich, Switzerland, 2015.

12. J.-A. Wang and H. Wang, FY 2017 Status Report: CIRFT Data Update and Data Analyses for Spent Nuclear Fuel Vibration Reliability Study, Revision 1, ORNL/SPR-2017/521, SFWDSFWST-2017-000030/R1, 2017.

13. J.-A. Wang and H. Wang, Mechanical Fatigue Testing of High Burnup Fuel for Transportation Applications, NUREG/CR-7198/R1, 2017.

14. W. J. O’Donnell and B. F. Langer, "Fatigue Design Basis for Zircaloy Components," Nuclear Science and Engineering 20 (1964): 1-12.

15. K. Geelhood et. al., "Modeling Structural Loading of Used Nuclear Fuel under Conditions of Normal Transportation," Ceramic Materials for Energy Application IV, The American Ceramic Society, 2015.

16. P. McConnell et al., Normal Conditions of Transport Truck Test of a Surrogate Fuel Assembly, SAND2014-20495/FCRD-UFD-2014-000066, Revision 0.1, Sandia National Laboratories, December 2014.

17. M.C. Billone, Ductility of High-Burnup-Fuel ZIRLO ${ }^{\text {TM }}$ following Drying and Storage, ANL19/14, M2SF-19AN010201011 Rev. 3, Argonne National Laboratory, June 2019.

18. NUREG-2125, Spent Fuel Transportation Risk Assessment, Final Report, 2014, pp. E21-22. 